\title{
OXYGEN ENRICHED COMBUSTION SYSTEM PERFORMANCE STUDY
}

\author{
Phase II Final Report \\ 100 Percent Oxygen Enriched Combustion \\ in Regenerative Glass Melters
}

by

Geoffrey B. Tuson

Hisashi Kobayashi

M. J. Campbell

August, 1994

Work Performed Under Contract No. DE-FCO7-88ID12833

Prepared for

U.S Department of Energy

Idaho Operations Office, Idaho Falls, Idaho

Sponsored by the Office of the Assistant Secretary for

Energy Efficiency and Renewable Energy

Office of Industrial Technology

Washington, DC

Prepared by

Praxair Incorporated

Old Saw Mill River Road

Tarrytown, NY 10591 


\section{DISCLAIMER}

This report was prepared as an account of work sponsored by an agency of the United States Government. Neither the United States Government nor any agency thereof, nor any of their employees, make any warranty, express or implied, or assumes any legal liability or responsibility for the accuracy, completeness, or usefulness of any information, apparatus, product, or process disclosed, or represents that its use would not infringe privately owned rights. Reference herein to any specific commercial product, process, or service by trade name, trademark, manufacturer, or otherwise does not necessarily constitute or imply its endorsement, recommendation, or favoring by the United States Government or any agency thereof. The views and opinions of authors expressed herein do not necessarily state or reflect those of the United. States Government or any agency thereof. 


\section{DISCLAIMER}

Portions of this document may be illegible in electronic image products. Images are produced from the best available original document. 


\section{TABLE OF CONTENTS}

List of Tables

List of Figures

1.0 EXECUTIVE SUMMARY

$\begin{array}{lll}2.0 & \text { INTRODUCTION } & 7\end{array}$

3.0 HOST MELTER CHARACTERISTICS 10

3.1 End-Port Melter 10

3.2 Side-Port Melter 14

4.0 END-PORT MELTER CONVERSION AT CARR-LOWREY GLASS COMPANY 15

4.1 Measurement and Data Collection Methods 15

4.2 Installation and Start Up of Oxy-Fuel Combustion System 18

4.3 Comparative Performance - Air-Fuel and Oxy-Fuel Melting 23

4.3.1 General Observations 23

4.3.2 Glass Quality 25

$\begin{array}{ll}\text { 4.3.3 Energy Performance } & 27\end{array}$

$\begin{array}{ll}\text { 4.3.3.1 Method of Energy Performance Comparison } & 27\end{array}$

4.3.3.2 Baseline Energy Performance 29

4.3.3.3 100\% OEC Energy Performance and Energy Savings 30

4.3.4 Stack Emissions $\quad 36$

$\begin{array}{lll}\text { 4.3.4.1 } \mathrm{NO}_{\mathrm{x}} \text { Emissions } & 37\end{array}$

4.3.4.2 Particulate Emissions $\quad 39$

4.3.4.3 Carbon Monoxide Emissions $\quad 42$

4.4 Burner Performance $\quad 42$

5.0 SIDE-PORT MELTER CONVERSION AT GALLO GLASS COMPANY 44

5.1 Measurement and Data Collection Methods 44

5.2 Installation and Start Up of Oxy-Fuel Combustion System 45

5.3 Comparative Performance - Air-Fuel and Oxy-Fuel Melting 46

5.3.1 Energy Performance 46

5.3.2 Stack Emissions $\quad 51$

5.3.2.1 $\mathrm{NO}_{\mathrm{x}}$ Emissions $\quad 52$

5.3.2.2 Particulate Emissions $\quad 54$

5.3.2.3 Carbon Monoxide and $\mathrm{SO}_{2}$ Emissions $\quad 55$

5.4 Burner Performance $\quad 57$ 

$\begin{array}{ll}5.5 \text { VPSA Oxygen Supply System } & 57\end{array}$

5.5.1 Process Description and Plant Design 57

5.5.2 Installation and Start-up 62

$\begin{array}{ll}\text { 5.5.3 VPSA Plant Performance } & 64\end{array}$

6.0 ENERGY IMPLICATIONS AND ECONOMICS OF REGENERATIVE MELTER CONVERSION TO $100 \%$ O.E.C.

$\begin{array}{ll}6.1 \text { Energy Implications } & 70\end{array}$

6.2 Economics of Melter Conversion $\quad 73$

$\begin{array}{lll}7.0 & \text { COMBUSTION SPACE MODELLING } & 82\end{array}$

$\begin{array}{llr}8.0 & \text { REFERENCES } & 84\end{array}$ 


\subsection{EXECUTIVE SUMMARY}

Glass melting with $100 \%$ Oxygen Enriched Combustion (100\% OEC) is gaining acceptance within the U.S. glass industry as an economical way of reducing melter energy consumption and stack emissions, and reducing the capital costs of melter construction or rebuild. The two successful glass melter conversions described in this report, conducted with supporting funds provided by the U.S. Department of Energy, have reinforced this growing industry interest in and acceptance of $100 \%$ OEC melting. The melter conversions constituted the second phase of a cooperative project between the Department of Energy and Praxair, Inc. Phase I of the project involved market and technical feasibility assessments of oxygen enriched combustion for a range of high temperature industrial heating applications, along with performance evaluation of a pilot scale Pressure Swing Adsorption (PSA) oxygen plant. The results of the Phase I studies were previously published by the Department of Energy $(1,2,3)$.

Goals of the Phase II evaluation project were to:

1. Demonstrate that energy savings are achievable with $100 \%$ OEC compared to regenerative preheated air combustion.

2. Verify that an advanced Pressure Swing Adsorption oxygen production system can reliably supply oxygen for industrial heating applications at an energy consumption rate of less than $350 \mathrm{kWh} /$ ton of equivalent pure oxygen produced.

3. Demonstrate reduction in $\mathrm{NO}_{\mathrm{x}}$ emissions by $90 \%$ compared with regenerative combustion systems. 
4. Achieve reductions in emissions of particulates and other pollutants.

Two regenerative container glass melters were converted to $100 \%$ OEC operation for the Phase II study. The first was a 75 tpd end-fired melter at Carr-Lowrey Glass Company in Baltimore, Maryland. This was a temporary conversion conducted for purposes of the evaluation project. The melter operated for five weeks with $100 \% \mathrm{OEC}$, with oxygen delivered to the plant as a liquid.

The second melter conversion took place in a 350 tpd container glass melter owned by Gallo Glass Company in Modesto, California. This was a permanent conversion to $100 \%$ OEC operation, and its success has since led Gallo to convert additional melters to $100 \%$ OEC. An on-site Pressure Swing Adsorption oxygen supply system was installed at Gallo to supply oxygen for $100 \%$ OEC melting. PSA oxygen plants were identified during Phase I as offering the most economical combination of capital and energy costs for the range of oxygen demands typical at many glass melting, as well as many other industrial heating facilities (4).

Major conclusions derived from the glass melter conversions conducted at CarrLowrey and Gallo are summarized as follows:

- Glass melter energy consumption is reduced by conversion to $100 \% \mathrm{OEC}$, even when baseline operation involves regenerators that are highly efficient at transferring heat from furnace exhaust gases to combustion air. Natural gas savings of 10 to 20 percent, along with similar percentage reductions in electric boost, are achievable. These savings are attributable to the high combustion energy availability achieved with $100 \%$ OEC, and to reduced radiative heat 
losses from the furnace due to greatly reduced exhaust port area.

- It was verified that a commercial scale advanced PSA oxygen plant can reliably supply oxygen at an energy consumption rate well below $350 \mathrm{kWh}$ per ton of equivalent pure oxygen. The particular PSA plant design used at Gallo achieves maximum efficiency by cycling the adsorbent beds between pressurized and evacuated states, and is referred to as a Vacuum/Pressure Swing Adsorption (VPSA) plant. The plant at Gallo supplied 90 to $91 \%$ purity oxygen at 20 to 25 psig to Gallo's header at an electrical demand of 320 to $325 \mathrm{kWh}$ per ton of oxygen. Without plant silencers, which were required at this location, power consumption would have been $310 \mathrm{kWh}$ per ton. VPSA plants delivering oxygen at lower pressure, and using the latest technology advances, can produce oxygen at $250 \mathrm{kWh}$ per ton. Even with the high oxygen production efficiency of VPSA technology, a "back to the power plant" analysis indicates that the overall energy impact of $100 \%$ OEC conversion of regenerative melters is roughly a break even proposition in cases where electric boost energy input is unchanged. A net energy savings results in cases where electric boost energy input is significantly reduced and replaced with oxy-fuel input. Utilization of exhaust gas waste energy to preheat melter charge materials, which has not yet been demonstrated on an oxy-fuel melter, would move this technology to a clear net energy savings. Large $\mathrm{NO}_{\mathrm{x}}$ emissions reduction are achieved by conversion to $100 \%$ OEC operation. Both conversions resulted in $\mathrm{NO}_{\mathrm{x}}$ emissions reductions of about 
$90 \%$. In the case of the Gallo melter, where no batch nitrates were used, $\mathrm{NO}_{\mathrm{x}}$ emissions below $1.0 \mathrm{lb}$ per ton of glass were achieved, both with a high purity oxygen supply, and when the oxidant stream had a nitrogen concentration of 3 percent.

o Where direct comparison between baseline and $100 \%$ OEC operation at equal pull was possible, particulate emissions were reduced by 25 percent following $100 \%$ OEC conversion. Carbon monoxide emissions were also reduced, while $\mathrm{SO}_{2}$ emissions increased slightly over baseline levels.

o Economic analysis of various melting options shows the net present value (NPV) of the combined capital and operating costs of $100 \%$ OEC melting is higher than that of conventional regenerative operation with no flue gas treatment. However, $100 \%$ OEC is the most economical means of achieving $\mathrm{NO}_{\mathrm{x}}$ emissions well below the best levels achievable with conventional regenerative firing.

\subsection{INTRODUCTION}

The field test project described in this report was conducted to evaluate the energy and environmental performance of $100 \%$ oxygen enriched combustion $(100 \%$ OEC) in regenerative glass melters. Additional objectives were to determine other impacts of $100 \%$ OEC on melter operation and glass quality, and to verify on a commercial scale that an onsite Pressure Swing Adsorption oxygen plant can reliably supply oxygen for glass melting with low electrical power consumption. The tests constituted Phase II of a cooperative project between the United States Department of Energy, and Praxair, Inc. Phase I of the project 
involved market and technical feasibility assessments of oxygen enriched combustion for a range of high temperature industrial heating applications. An assessment of oxygen supply options for these applications was also performed during Phase I, which included performance evaluation of a pilot scale 1 ton per day PSA oxygen plant (4).

Two regenerative container glass melters were converted to $100 \%$ OEC operation and served as host sites for Phase II. A 75 ton per day end-fired melter at Carr-Lowrey Glass Company in Baltimore, Maryland, was temporarily converted to $100 \%$ OEC in mid1990. A 350 tpd cross-fired melter at Gallo Glass Company in Modesto, California was rebuilt for permanent commercial operation with $100 \%$ OEC in mid-1991. Initially, both of these melters were supplied with oxygen from liquid storage. Subsequently, in late 1992, a Pressure Swing Adsorption oxygen plant was installed at Gallo to supply oxygen for $100 \%$ OEC glass melting. The particular PSA plant design used at Gallo achieves maximum efficiency by cycling the adsorbent beds between pressurized and evacuated states, and is therefore referred to as a Vacuum/Pressure Swing Adsorption (VPSA) plant.

Low level oxygen enrichment, oxygen lancing, and auxiliary oxy-fuel burners have been used in glass melting since the 1940's, primarily to increase glass melter production rates. Beginning in the mid 1980 's, some glass manufacturers began conversion of numerous day tanks and unit melters to $100 \%$ OEC using specially designed oxy-fuel burners $(5,6)$. Pre-conversion operation of these smaller melters typically involved little or no heat recovery, making it possible in many cases to justify $100 \%$ OEC by energy savings alone. Other reported advantages of $100 \%$ OEC in these conversions included reduced $\mathrm{NO}_{\mathrm{x}}$ and particulate emissions, and improved glass quality. 
While smaller melters with limited heat recovery have proven to be economical candidates for $100 \%$ OEC, about 90 percent of glass tonnage is produced in large melters equipped with regenerators to transfer heat from exhaust gases to combustion air. In these

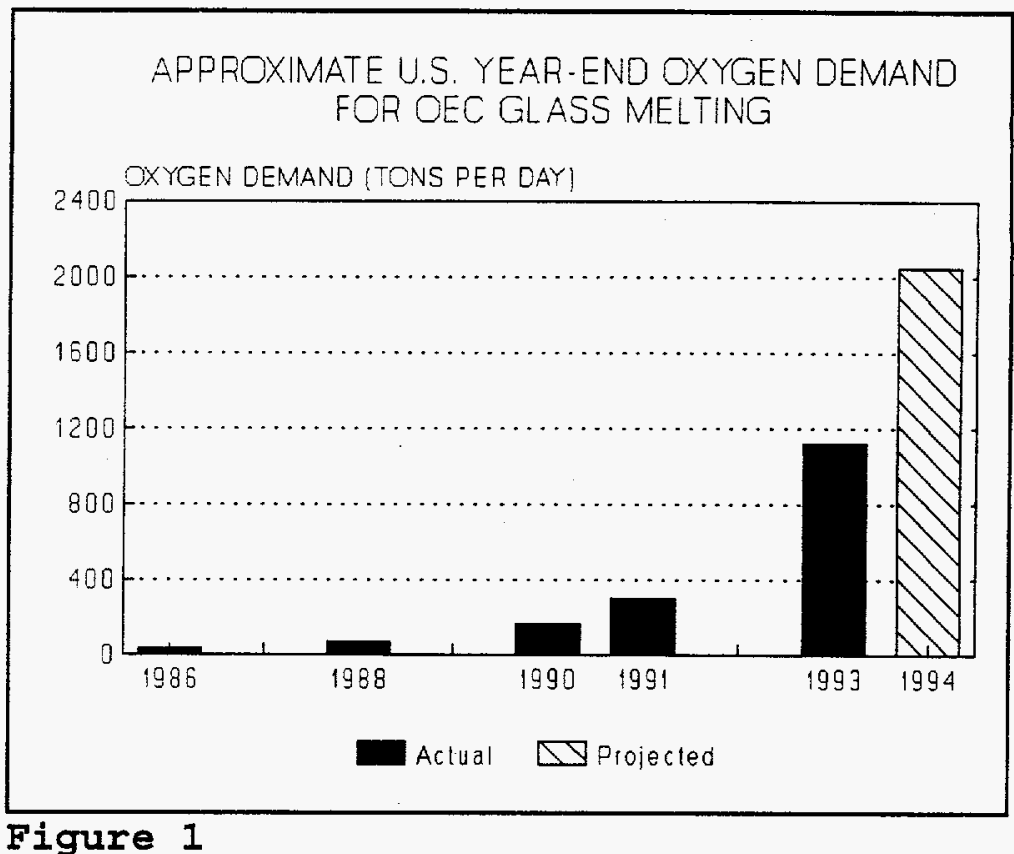
melters, the energy savings in percentage terms achievable with $100 \%$ OEC is not as great as in melters with little or no heat recovery. However, Phase I analysis indicated significant energy savings could still be expected following conversion to $100 \%$ OEC, due to reduction in energy carried away by stack gases, and to reduced furnace radiation heat losses because of greatly reduced exhaust port area (2). This energy savings potential, combined with reduced capital requirements for furnace rebuild, and with the potential for reduced stack emissions without resorting to flue gas treatment, has resulted in great interest in $100 \%$ OEC by a glass industry facing increasing regulatory pressure to reduce emissions. This is evidenced by Figure 1 which estimates, based on data compiled from a variety of sources, the volume of oxygen consumed for OEC glass melting in the U.S. in recent years. 


\subsection{HOST MELTER CHARACTERISTICS}

Evaluation project field work was carried out at two locations: Carr-Lowrey Glass Company, in Baltimore, Maryland, and Gallo Glass Company in Modesto, California. Descriptive features of the host melters at these location are summarized in Table I. Gallo Glass originally agreed to serve as host site for the entire project, and plans were made to convert a melter to $100 \%$ OEC just prior to the end of its regenerative campaign. However, because of a change in Gallo's furnace rebuild schedule, an alternate location was sought in order to get the project under way. Carr-Lowrey Glass Company agreed to host an initial evaluation of $100 \%$ OEC, which was conducted during a temporary melter conversion during the summer and fall of 1990 .

As test work at Carr-Lowrey was being completed, Gallo's rebuild schedule, along with their decision to evaluate oxy-fuel firing, became firmer. Gallo agreed to be the host for continued $100 \%$ OEC testing work, beginning in the summer of 1992 . In particular, the greater pull and oxygen demand of Gallo's melter made Gallo a good location for evaluating performance issues related to on-site VPSA oxygen supply.

\subsection{End-Port Melter}

Melter \#7 at Carr-Lowrey Glass Company, is a 75 ton per day, end-fired melter producing flint glass for cosmetics bottle manufacture. Carr-Lowrey's primary interest was to test the use of auxiliary oxy-fuel burners to reduce particulate emissions. Carr-Lowrey agreed to a temporary test of $100 \%$ OEC prior to this more limited use of oxygen. A melter rebuild was scheduled for December, 1989, which presented an opportunity to install burner blocks and make other preparations. Tests of $100 \%$ OEC were conducted at Carr-Lowrey 
TABLE I. HOST MELTER FEATURES AND BASELINE OPERATION

TYPE

GLASS TYPE

HEARTH AREA

PRESSURE CONTROL SYSTEM

MELTER EXHAUST

TEMPERATURE

AIR PREHEAT

TEMPERATURE

FUEL CONSUMPTION

(MMBTU/TON)

EARLY CAMPAIGN

LATE CAMPAIGN

ELECTRIC BOOST

(MMBTU/TON)

TOTAL ENERGY CONS.

(MMBTU/TON)

EARLY CAMPAIGN

LATE CAMPAIGN
CARR-LOWREY

MELTER \#7

END-FIRED

CONTAINER

$300 \mathrm{SQ} \cdot \mathrm{FT}$.

NATURAL DRAFT

STACK W/DAMPER

$2650 \mathrm{~F}$

$2130 \mathrm{~F}$

4.73
GALLO GLASS MELTER \#1

CROSS-FIRED

CONTAINER

1248 SQ.FT.

MORGAN ISELY

EJECTOR

2800 F. (est)

$2300 \mathrm{~F}$
0.68

0.55

4.1

5.4

4.65 
for three weeks in July, and two weeks during October, 1990, with combustion equipment supplied by Praxair. Auxiliary oxy-fuel burners were then operated for an additional six months, to collect data on burner maintenance requirements and durability.

A cross-sectional view of Carr-Lowrey's melter \#7 is shown in Figure 2. The melter is 25 feet long by 12 feet wide ( 300 square foot hearth area). Normally, it is fired with natural gas through injectors located beneath the combustion air ports. Fuel oil is used as a back up fuel during natural gas curtailments. The combustion system is supplemented by five pairs of boosting electrodes spaced along the length of the melter.

Combustion products leave the charge end of the melter through inclined ports into a two pass regenerator, and then exhaust through a natural draft stack. Melter pressure is controlled by stack damper adjustment. Combustion air is drawn into a blower from the melt shop floor, and forced through the regenerators into the melter. Reversal of exhaust and combustion air flow through the regenerators occurs every twenty minutes.

Glass exits the melter through a submerged throat into an attached refiner, from which glass is distributed to four forehearths. The refiner is fired with natural gas burners with no air preheat. Refiner combustion products are usually exhausted over the top of a shadow wall into the melter, although they can be exhausted separately through ports in the refiner crown.

Melter \#7 supplies glass to a manufacturing operation producing bottles for an assortment of specialized orders. Consequently, pull from the melter, and melter operating conditions, change frequently in response to job changes on the production floor. Figure 3 plots daily pull during 2 months covering part of the baseline data collection period and the 


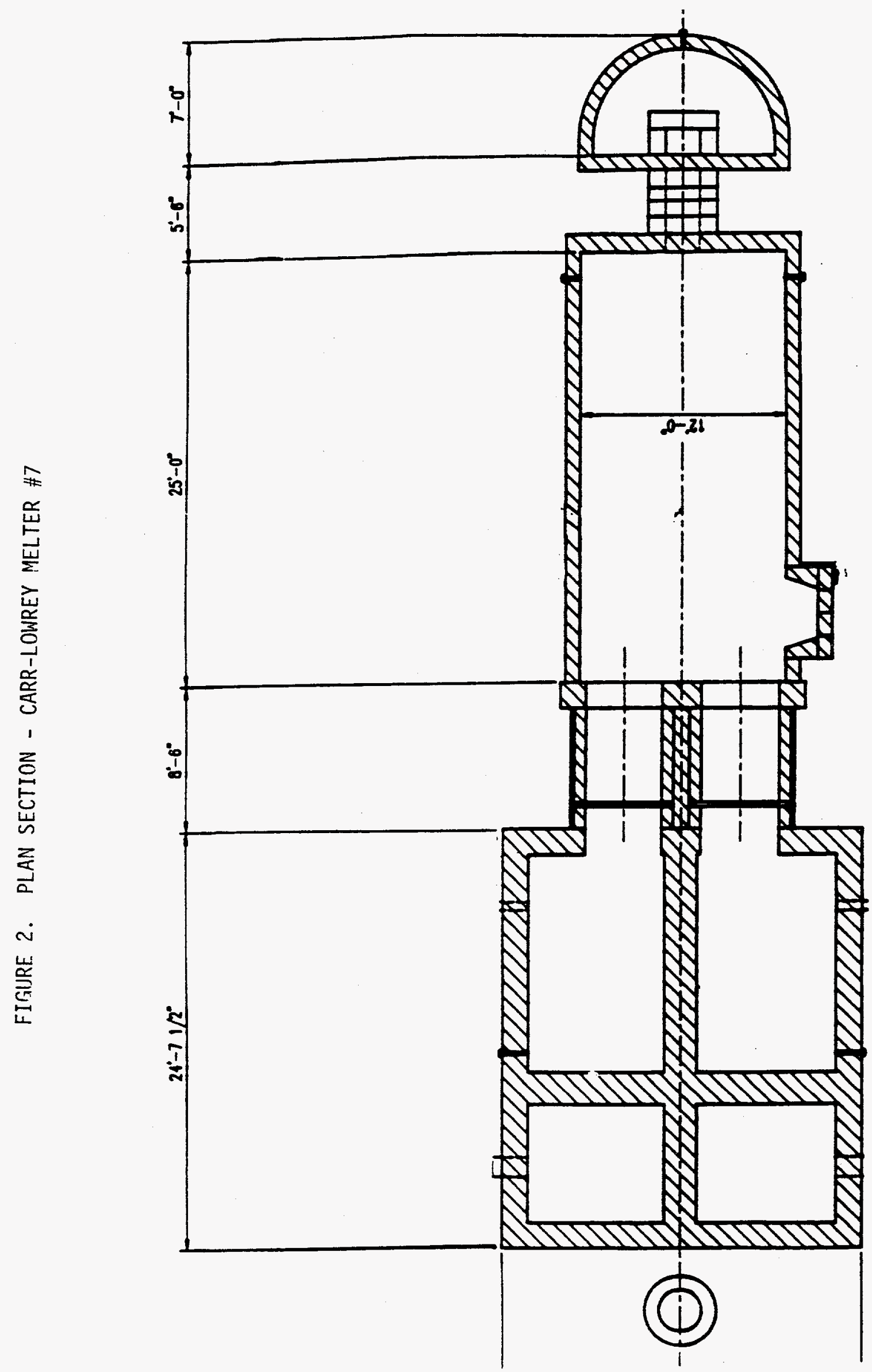


first period of $100 \%$ OEC testing. As indicated, pull from melter \#7 ranged from 37 to 78 tons per day during this period.

As glass pull fluctuates, the melter operators monitor batch line position and the temperature of glass approaching the throat of the melter. Firing rate and electric boost are

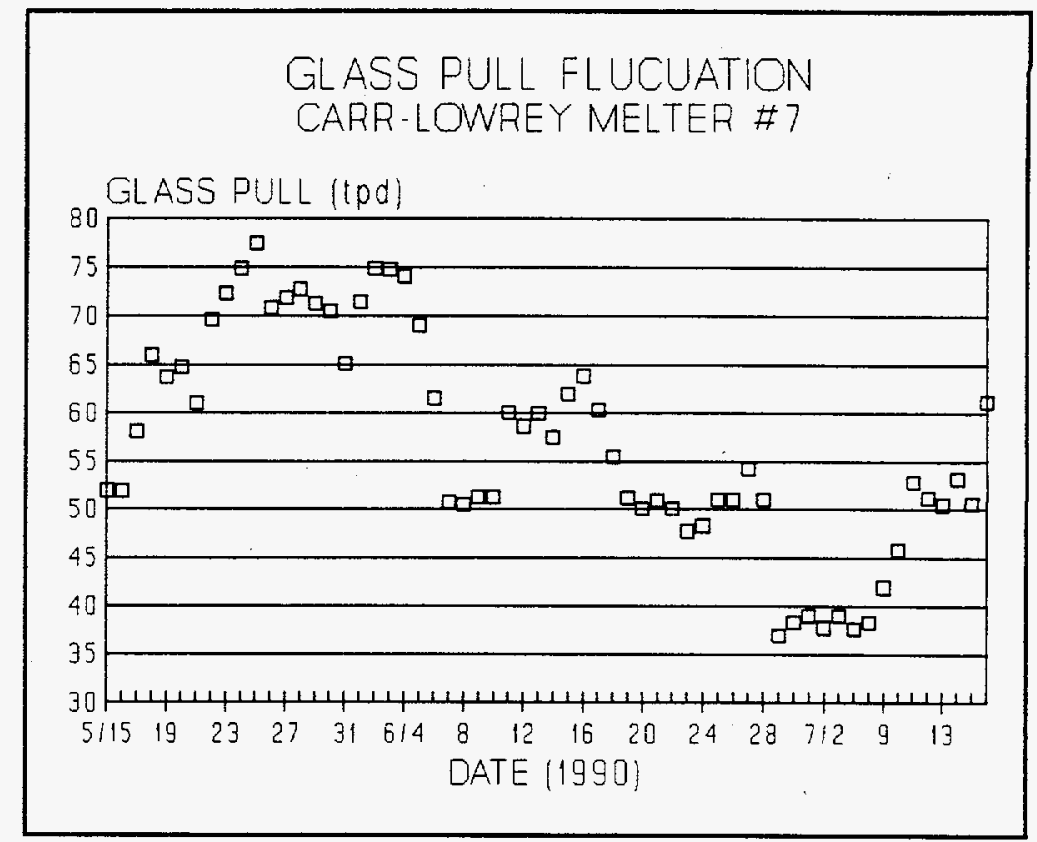

\section{FIGURE 3}

adjusted in order to keep unmelted batch from advancing beyond the hot spot near the midpoint of the melter, and to keep the temperature of glass approaching the throat within a desired range. In making these adjustments, the operators maintain a preset ratio between the use of top firing and electric boost.

\subsection{Side-port Melter}

Gallo Glass Company's melter \#1 produces flint soda-lime glass for wine bottle manufacture. Melter hearth area is 1248 square feet, and typical glass pull is 330 to 350 tpd. Large pull fluctuations like those at Carr-Lowrey occur rarely at Gallo, making this a more typical container operation. Prior to conversion to $100 \%$ OEC the melter was fired from five natural gas combustion ports in each melter breastwall. The melter is equipped with boost electrodes to supplement combustion heat input.

Gallo's primary objective in converting melter $\# 1$ to $100 \%$ OEC was to reduce $\mathrm{NO}_{x}$ 
emissions (7). The melter was rebuilt in the spring of 1991, and the regenerators were removed. An oxy-fuel combustion system designed and built by Corning, Incorporated was installed for permanent commercial operation. Start up of the melter with $100 \%$ OEC occurred in late July, 1991. The melter operated for over a year supplied by liquid oxygen delivered by truck to the plant. Late in 1992, Praxair started up an on-site VPSA oxygen plant at Gallo to supply oxygen for glass melting.

\subsection{END-PORT MELTER CONVERSION AT CARR-LOWREYGLASS COMPANY}

A total of five weeks of $100 \%$ OEC testing was conducted at Carr-Lowrey, broken into two periods separated by about 3 months. Following these tests, two oxy-fuel burners were operated in the melter for six months in an auxiliary firing mode to evaluate longer term burner maintenance and reliability issues.

\subsection{Measurement and Data Collection Methods}

Carr-Lowrey's melter \#7 was operated with air-gas firing for the first six months following its rebuild during early winter, 1989. The baseline melter operating conditions listed in Table I were measured during this period. The same parameters, with some additions, were also measured during $100 \%$ OEC operation. The data collection methods used, summarized in Table II, included the following:

1. Fuel and power consumption, glass and refractory temperatures, furnace pressure, and refiner firing rate were recorded on hourly log sheets. In addition, during $100 \%$ OEC operation, oxygen and fuel consumption data from the oxygen combustion system control panel was recorded. During oxy-fuel operations, the natural gas meter used for baseline measurements operated in series with the calibrated meter on the fuel skid of the oxygen 
TABLE II. DATA COLLECTION METHODS

TYPE OF DATA

COLLECTION METHOD

- - - - - - - -

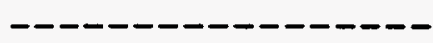

BASELINE FUEL CONSUMPTION

TURBINE METER

FUEL/OXYGEN CONSUMPTION

VORTEX FLOW METERS

REFINER FUEL CONSUMPTION

ORIFICE METERS

EXHAUST \& AIR PREHEAT

TEMPERATURES

SUCTION PYROMETER

MELTER AND REGENERATOR

REFRACTORY TEMPERATURES

OPTICAL PYROMETER

AND THERMOCOUPLES

MELTER GAS COMPOSITION

ELECTROCHEMICAL NOX

INFRARED $\mathrm{CO} 2$

ELECTROCHEMICAL O2

STACK EMISSIONS

STANDARD EPA METHODS

BY MONARCH LABS

GLASS QUALITY

SEED COUNT 
combustion system. This made possible a direct comparison of meter readings, and indicated that the baseline fuel measurements understated actual fuel usage. As a result, a correction factor was determined and applied to the baseline data. Oxygen and fuel flow across orifice runs at the individual oxy-fuel burners were recorded periodically during $100 \%$ OEC operation. This provided data on firing rate distribution, and served as a check on the flow control skid meters.

2. A water cooled sample probe and portable gas analyzers were used to determine $\mathrm{CO}_{2}, \mathrm{O}_{2}$, and $\mathrm{NO}$ concentrations in the exhaust ports and at various locations in the melter. This information was used to estimate air infiltration rates, and to determine the effect of operating adjustments on $\mathrm{NO}_{\mathrm{x}}$ emissions.

3. A suction pyrometer was used to measure exhaust and air preheat temperatures at varying pulls and firing rates.

4. Thermocouples were inserted between the rider tiles several inches above the rider arches on both sides of the regenerator. This was done in response to concerns raised about possible rider arch overheating during $100 \%$ OEC operation.

5. Gauges were installed at orifice runs for air-gas burners firing the attached refiner. This was necessary for closing the melter energy balance, and to detect any shift of load between the melter and refiner.

6. Carr-Lowrey personnel conducted seed counts on a daily basis, and otherwise monitored glass quality.

In addition to the above, Monarch Analytical Laboratories, Inc. was contracted to conduct stack emissions tests during the baseline and $100 \%$ OEC operation. $\mathrm{NO}_{x}, \mathrm{SO}_{2}, \mathrm{CO}$, and particulate emissions were measured using standard E.P.A. methods. 


\subsection{Installation and Start Up of Oxy-Fuel Combustion System}

Preparations for $100 \%$ OEC operation were made during the melter rebuild at CarrLowrey, with assistance from KTG Glassworks Technology, Inc. Burner blocks for five oxyfuel burners were installed in the melter breastwalls, at the locations shown in Figure 4. The blocks were arranged so the burners would be installed horizontally, with centerlines about 20 inches above the glass surface. KTG also prepared slots in the port necks for insertion of baffles during $100 \%$ OEC operation to reduce radiation from the melter to the regenerator.

The oxygen supply and combustion system installed in melter \#7 consisted of the following major components:

1) A liquid oxygen supply tank located outside the melt shop building. Oxygen from the tank passed through atmospheric vaporizers, a main pressure regulator, and the main oxygen supply shutoff valve before entering the building piping.

2) Main fuel and oxygen flow control skids, for measuring and controlling the flow of natural gas and oxygen to the melter.

3) Auxiliary orifice assemblies for fuel and oxygen at each burner to measure and control the flow of natural gas and oxygen to each burner.

4) A main control console housing programmable controllers and hard-wired interlocks for safe, automatic control of the combustion system.

5) Five water-cooled Praxair "A" burners installed in burner blocks in the melter breast walls. Two of these burners were replaced with non-water cooled burners during the second period of $100 \%$ OEC testing. 
Figure 4

OXY-FUEL BURNER LOCATIONS END-FIRED MELTER

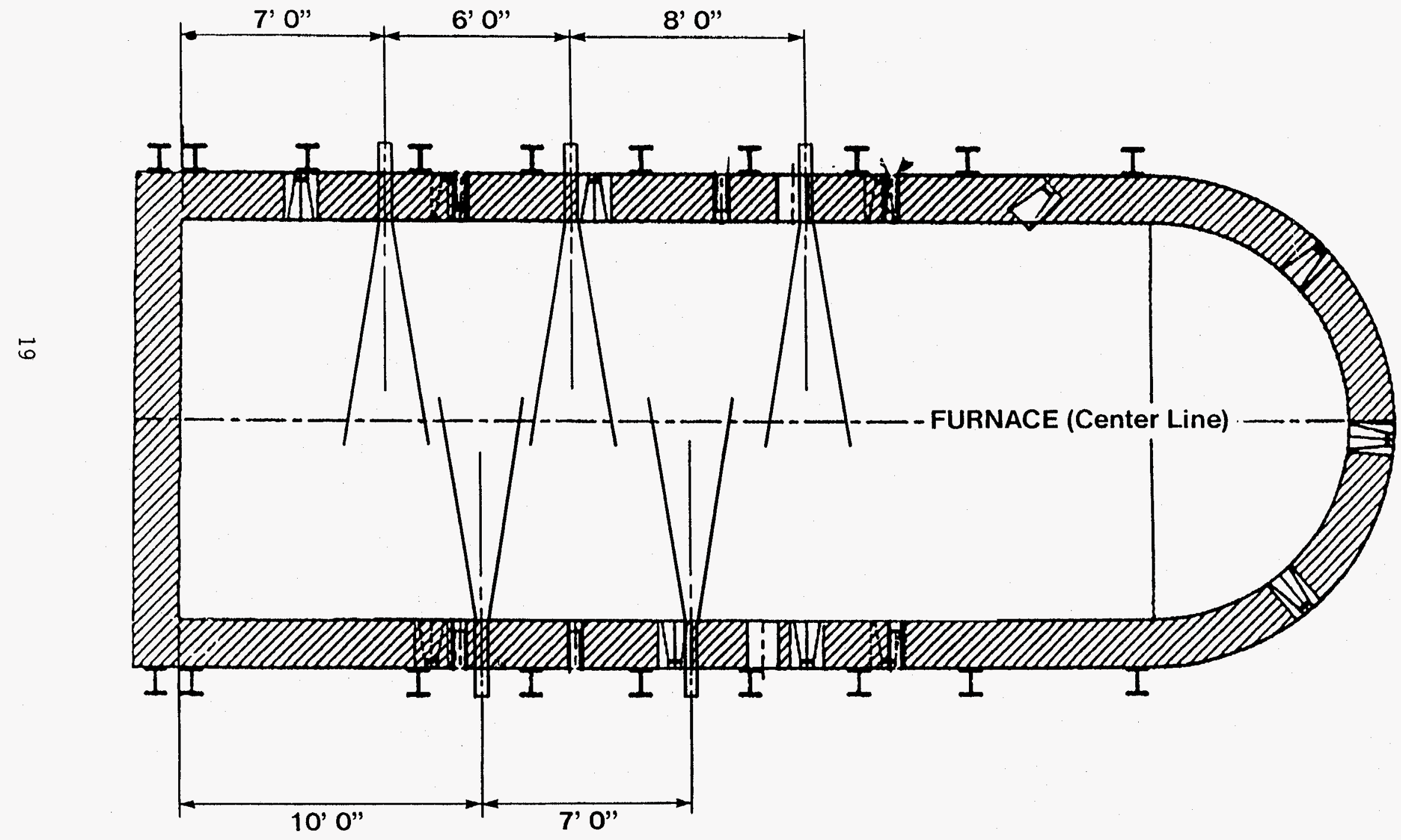


Praxair "A" burners were selected for the test because of their low $\mathrm{NO}_{\mathrm{x}}$ emissions characteristics. "A" burners are characterized by a central fuel tube surrounded by a ring of oxygen nozzles. Oxygen from these nozzles is injected into the furnace at sufficiently high velocity to entrain a large volume of furnace gases prior to mixing with the fuel. The result is low concentration mixing of oxygen and fuel, relatively low flame temperature, and a reduced rate of $\mathrm{NO}_{\mathrm{x}}$ formation. A detailed discussion of "A" burner $\mathrm{NO}_{\mathrm{x}}$ emissions measured under laboratory conditions, and a comparison to emissions achieved with other burners, was reported as part of the earlier DOE funded Phase I study (3). Figure 5 plots $\mathrm{NO}_{\mathrm{x}}$ emissions measured during that study from various burners operated at different levels of oxygen enrichment.

Installation of oxygen and gas piping to and around the melter, and site preparation for the liquid oxygen supply system, commenced during the second half of May, 1990. All mechanical and electrical installation work other than burner mounting was complete by June 22nd. The burners were installed, and final control system checks were made, on June 25th. Start up of the oxygen combustion system took place on June 26th.

Once installation and final checks were complete, changeover from air-fuel operation to $100 \%$ OEC took less than an hour. The "A"burners were started up at low fire with the air-fuel system still operating. After determining that ignition was established and the oxygen combustion system was operating normally, the firing rate of the " $\mathrm{A}$ " burners was gradually increased to a level sufficient to meet the furnace heat load. Simultaneously, the air-fuel system was turned down and then shut off, and the reversing damper was locked at mid-position. Adjustments were made at the auxiliary orifice assemblies to distribute fuel 


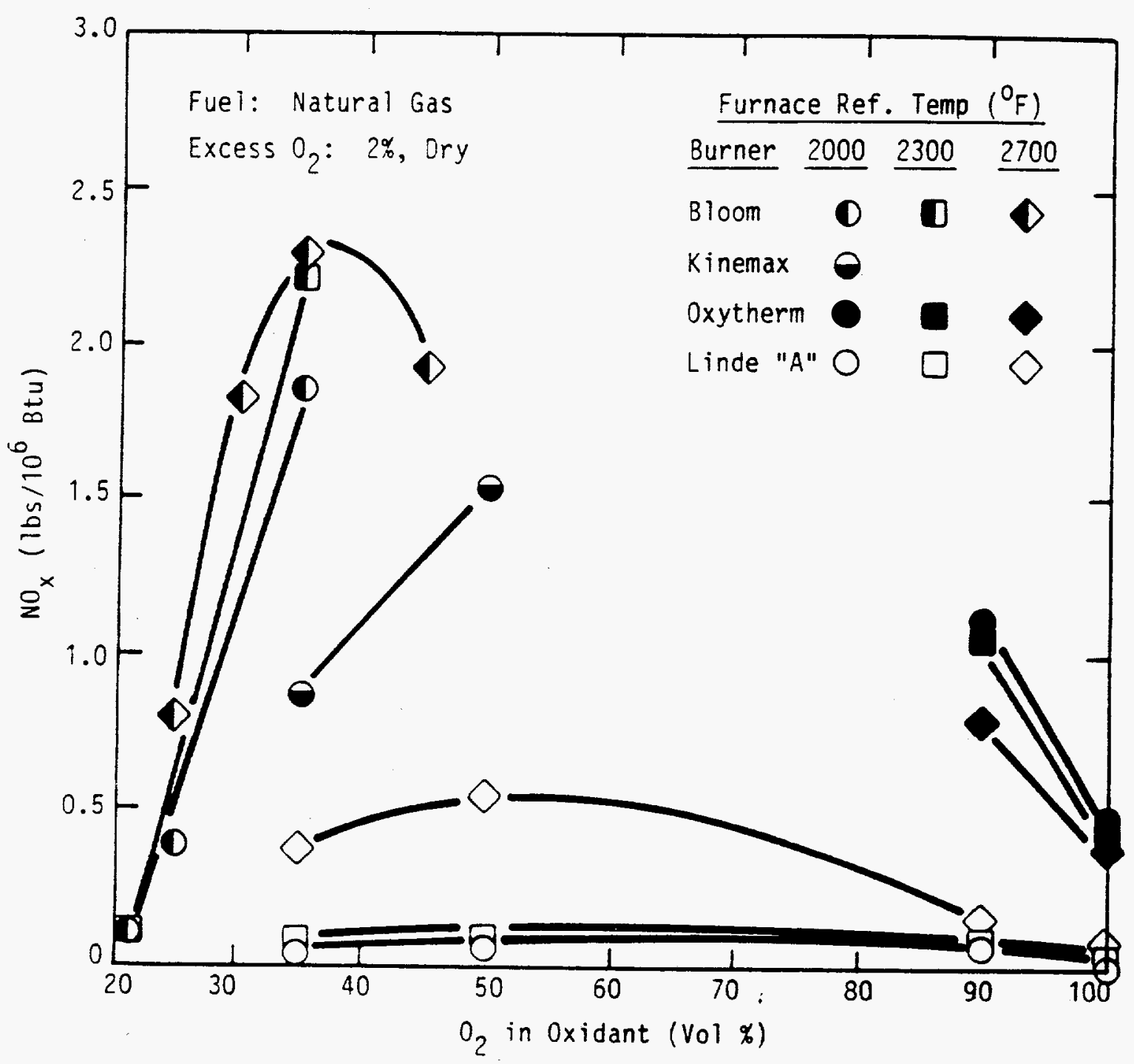

Figure 5 . Sumary of NO emissions for pilot scale burners fired with natural ğas. 
and oxygen flows through the individual burners, while overall oxygen to fuel ratio was held constant by the automatic control system. Finally, bricks were removed from the port neck slots prepared earlier by KTG, and baffles constructed of ceramic fiber boards were inserted to reduce radiation losses from the melter. Inserting these baffles as deeply as planned proved difficult, and only about a 60 percent port area reduction was achieved. In a permanent conversion, port area can be reduced by about 90 percent, based on the exhaust gas volume reduction achieved with $100 \%$ OEC.

During the period of the start up when both combustion systems were operating, fuel supply valves were set so the oxygen combustion system's fuel flow control skid was piped in parallel with fuel piping supplying the air-fuel system. Once the air-fuel system was turned off, valves were reset so the fuel skid operated in series with melter \#7's natural gas meter. This was done to allow Carr-Lowrey's fuel meter readings to be compared directly to those of the calibrated meter on the oxygen combustion system fuel skid.

One additional step taken prior to the first period of $100 \%$ OEC operation was the installation of temporary blowers and ductwork so cooling air could be introduced at the top of the regenerators in the event of rider arch overheating. Readings from thermocouples installed between the rider tiles indicated this was unnecessary, and blowers were not installed during the second period of $100 \%$ OEC testing. 


\subsection{Comparative Performance - Air-Fuel and Oxy-Fuel Melting}

\subsubsection{General Observations}

Several observations were made by Carr-Lowrey and Praxair personnel comparing melter operation with air-fuel and oxy-fuel firing. These observations related to issues such as ease of melter control, glass surface appearance, and air infiltration rate.

Carr-Lowrey's melter operators stated that the cross firing arrangement of the oxyfuel burners, and the ability to redistribute fuel input among burners, allowed improved melter control relative to end-port regenerative firing. They observed that batch line location responded more quickly to firing rate changes, and that melter temperature profile was more easily adjusted.

At the initial start up of the oxygen combustion system, fuel input was distributed about evenly among the five burners in the melter breastwalls, with some bias toward higher firing rates in burners 3 and 4 . As the test period progressed, heat input was gradually transferred from the burners closest to the melter end walls (burners 1 and 5), to burners 2, 3 and 4. This arrangement provided a steeper temperature profile and a more clearly defined hot spot at about midway up the melter. Carr-Lowrey's operators felt this contributed to the improved control of the batch line.

Refractory temperatures from side to side of melter were relatively uniform during oxy-fuel operation. No refractory hot spots were observed during the $100 \%$ OEC tests, either on the crown, the burner blocks, or on the breastwalls opposite the burners. There was no increase in stones that would evidence any localized refractory overheating.

Melter operators adjusted total firing rate in order to maintain a preset relationship 
between bridgewall temperature to pull. When adherence to this relationship caused bottom temperatures to deviate from target levels, electric boost adjustments were made. Electric boost and fuel energy consumption for air-fuel and oxy-fuel operation are compared and discussed in detail in section 4.3 .3

There was a large amount of air infiltration into the melter, despite maintenance of positive furnace pressure. The extent to which excess air came from the combustion system, as opposed to infiltration, was difficult to determine during baseline operation due to uncertainty about combustion air metering accuracy. However, at similar operating pressures during $100 \%$ OEC operation, the air infiltration rate was determined to be about $25,000 \mathrm{scfh}$, based on measurements of $\mathrm{CO}_{2}$ and $\mathrm{O}_{2}$ concentrations in the combustion space atmosphere.

A major source of air infiltration was the side wall cooling system, which directs air at the flux line blocks and other areas requiring cooling. Temporarily shutting off this system while monitoring oxygen and $\mathrm{CO}_{2}$ concentrations in the melter indicated that it was responsible for about 50 percent on total air infiltration. Air-fuel combustion products also likely passed over the shadow wall between the refiner and melter, even when the refiner exhaust ports were open. After packing around the burners and sealing obvious openings, the overall oxygen to fuel ratio to the burners was reduced to compensate for remaining infiltration. The ratio was eventually reduced to about $1.65: 1$, in order to hold exhaust oxygen concentration below 2 percent (dry basis).

Foaming behavior of the glass melt was affected by conversion to oxy-fuel firing. During air-fuel operation at Carr-Lowrey, a thin layer of foam sometimes covered portions of the glass surface between the batch line and the front wall. The amount of foam is 
influenced in part by the condition of the combustion atmosphere, as evidenced by the fact that foam at times disappears and reappears along with changes in the direction of melter firing. The thickness of the foam layer, and the extent of the glass area covered, increased noticeably during the first period of $100 \%$ OEC operation. The foam presented a barrier to heat transfer from the combustion space to the glass, and as detailed later, electric boost levels had to be raised during the first period of testing to compensate for this.

Opinions of consultant glass chemistry experts were solicited on how foam formation could be reduced during a planned second round of $100 \%$ OEC testing. There was general agreement that the likely source of the foam was $\mathrm{SO}_{2}$ bubbles released from the melt. A more oxidizing atmosphere lowers glass surface tension, which can allow these bubbles to form a stable foam (8). The increased oxidizing potential of the melter atmosphere, due to high water vapor concentration during $100 \%$ OEC operation, was therefore a likely cause of the increased foaming. Remedies suggested were to more closely control the oxygen to fuel ratio to lower oxygen concentration in the combustion space, and to adjust the batch formulation to slightly reduce the oxidation state of the glass. These solutions were tried in combination during the second round of $100 \%$ OEC testing. The dry basis oxygen concentration in the meiter was maintained at 1 to 2 percent, and the carbocite content of the batch was increased. The result of these adjustments was that the area of glass surface covered with foam was greatly reduced. This permitted electric boost usage to be reduced levels below normal baseline usage.

\subsubsection{Glass Quality}

There was no disruption of the forming operation during any of the changeovers to 
or from $100 \%$ OEC. Glass quality, as measured by seed count, workability, and stones, was generally unaffected by the conversions. One exception to this was the development of a thermal cord in one of four forehearths supplied by the melter during part of the first period of $100 \%$ OEC operation. Temperature gradients caused by increased foam on the glass surface during this period may have been the cause. There was no recurrence of the cord problem during the second test period, when the surface foam problem was largely corrected. 


\subsubsection{Energy Performance}

\subsubsection{Method of Energy Performance Comparison}

The approach used to collect and compare data on melter energy consumption during baseline and $100 \%$ O.E.C. operation at Carr-Lowrey is outlined as follows, with details in the sections that follow:

1. To determine baseline energy consumption, the change in Carr-Lowrey's natural gas flow totalizer was recorded for each 24 hour period, and six electric boost power readings per 24 hour period were averaged. Average pull for each 24 hours was determined from hourly pull records on melter log sheets.

2. A correction factor was applied to baseline fuel consumption to adjust for metering inaccuracy. This inaccuracy was detected during $100 \%$ OEC operation, when Carr-Lowrey's fuel meter was piped in series with the fuel meter on the oxygen combustion system fuel skid. The accuracy of the oxygen combustion system fuel meter was checked prior to shipment to Carr-Lowrey, and its readings agreed well with flow totals from orifice meters serving the individual burners, and with a $\mathrm{CO}_{2}$ mass balance using data collected during stack emissions tests.

3. Energy consumption and glass pull data during oxy-fuel firing was collected in the same manner as baseline data, with the exception that the totalized fuel consumption values were taken from the oxygen combustion system fuel flow meter. 
4. A linear regression was performed to determine the relationship between electric boost power consumption and pull during baseline operation. Fuel and electric boost data from the $100 \%$ OEC test period were then adjusted to allow fuel consumption for $100 \%$ OEC and baseline operation to be compared at equal levels of electric boost.

Additionally, the firing

rate of the attached refiner was

routinely recorded so that any

shift of heating load from the

melter to the refiner could be

detected. As indicated by Figure

6 , the relationship between

refiner firing rate and pull was

essentially the same for baseline

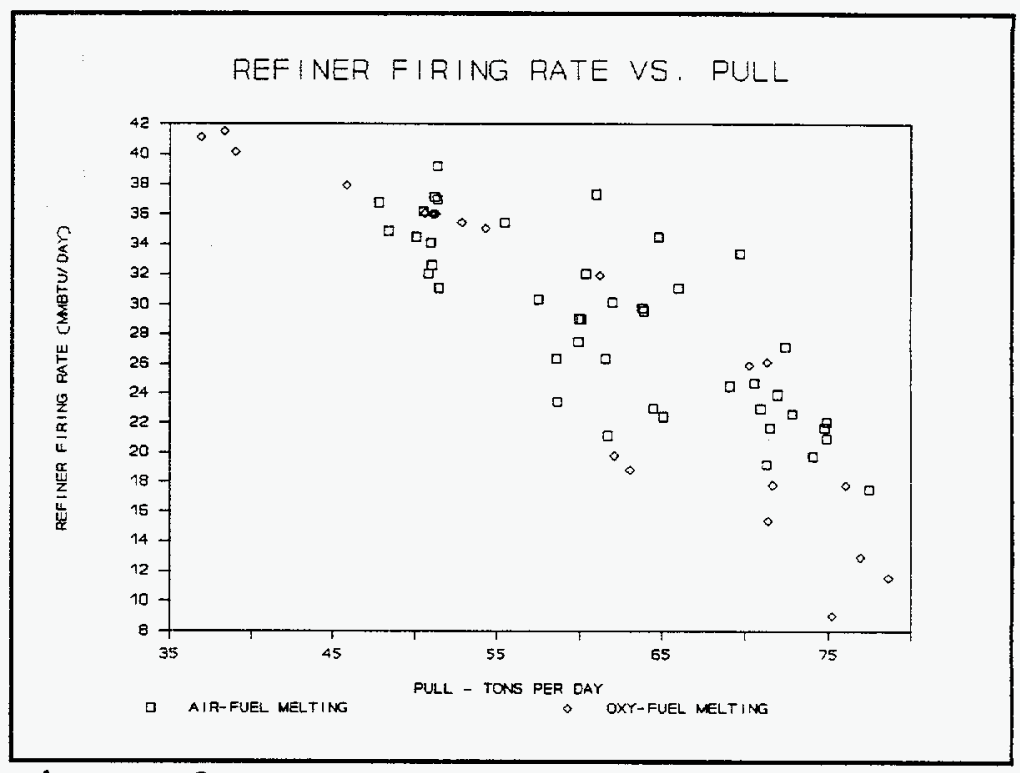

Figure 6

and $100 \%$ OEC operation. This was consistent with the fact that the melter operators kept the temperature of glass approaching the throat in a narrow range throughout the tests. Recording refiner firing rate data also allowed the heating of refiner combustion products as they passed through the melter to be factored into the melter energy. Finally, cullet ratio was monitored throughout the baseline and $100 \%$ OEC operating periods. Cullet ratio was constant at $35 \%$ throughout the entire test, and therefore did not affect the energy performance comparison. 


\subsubsection{Baseline Energy Performance}

Figure 7 plots fuel and electric boost energy consumption against glass pull during the baseline operating period. Electric boost supplied an almost constant 12 percent of total energy input during the baseline period. (Stated differently, electrical energy input

\section{FIGURE 7}

equalled between 13 to 14 percent of fuel energy input).

The nearly constant fuel to electric boost ratio, along with the linearity of the energy consumption versus pull data in Figure 7 , suggests that the available energy from combustion (fuel energy input, less energy content of combustion products exiting the

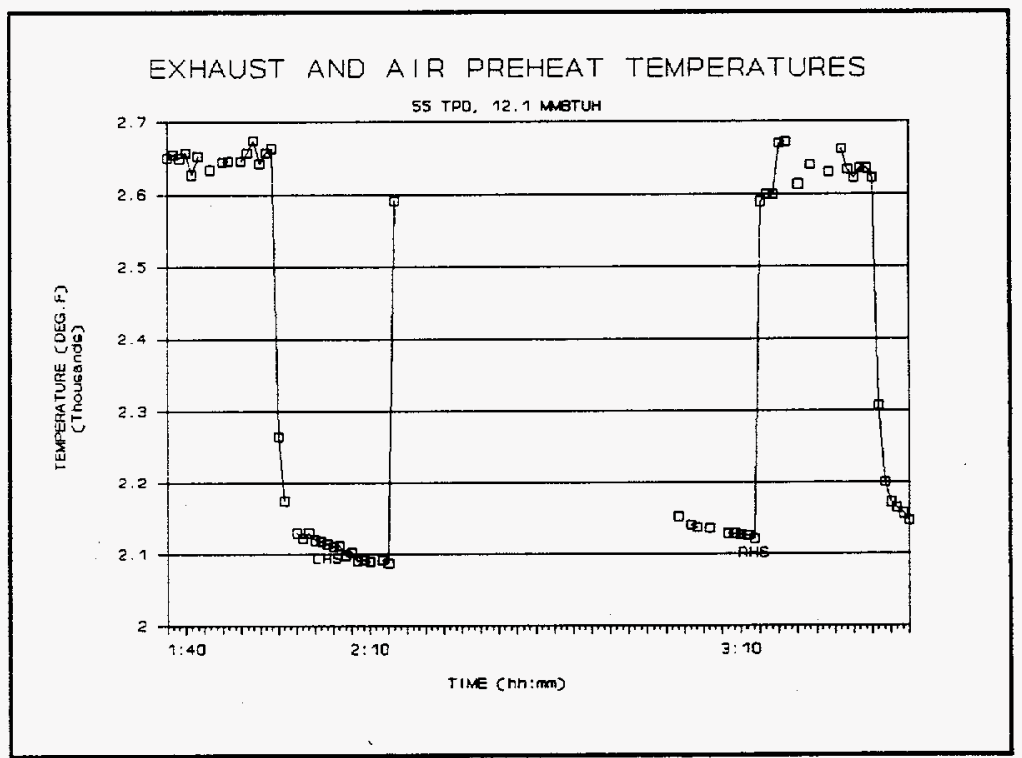

Figure 8
ENERGY CONSUMPTION VS. PULL

CARR LOWREY BASELINE OPERATION

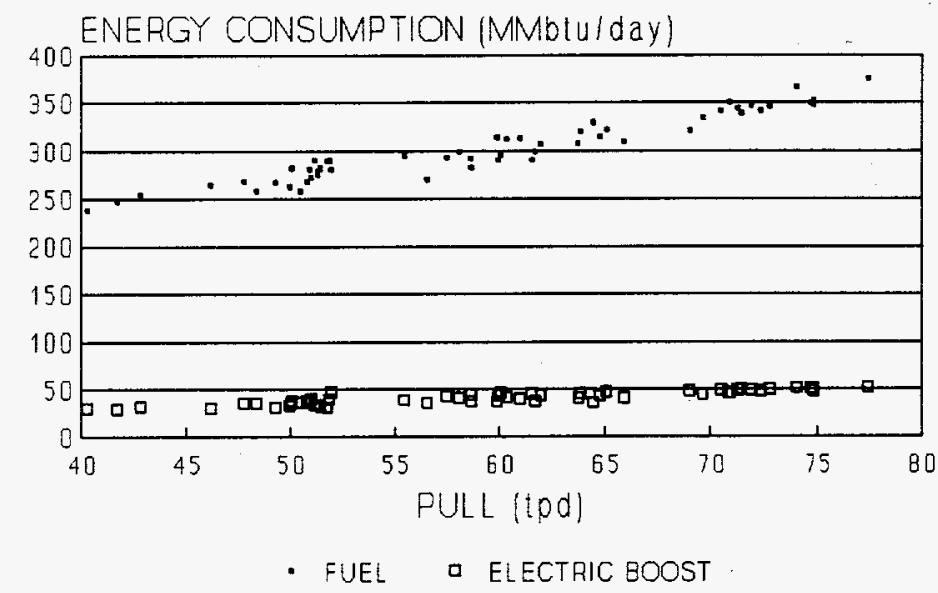

14


consistent with the fact that the difference between exhaust gas temperature and air preheat temperature was relatively constant, as illustrated by Figures 8 and 9. These figures plot baseline exhaust and air preheat temperatures in the port necks at 55 tpd pull/12.1 MMbtuh firing

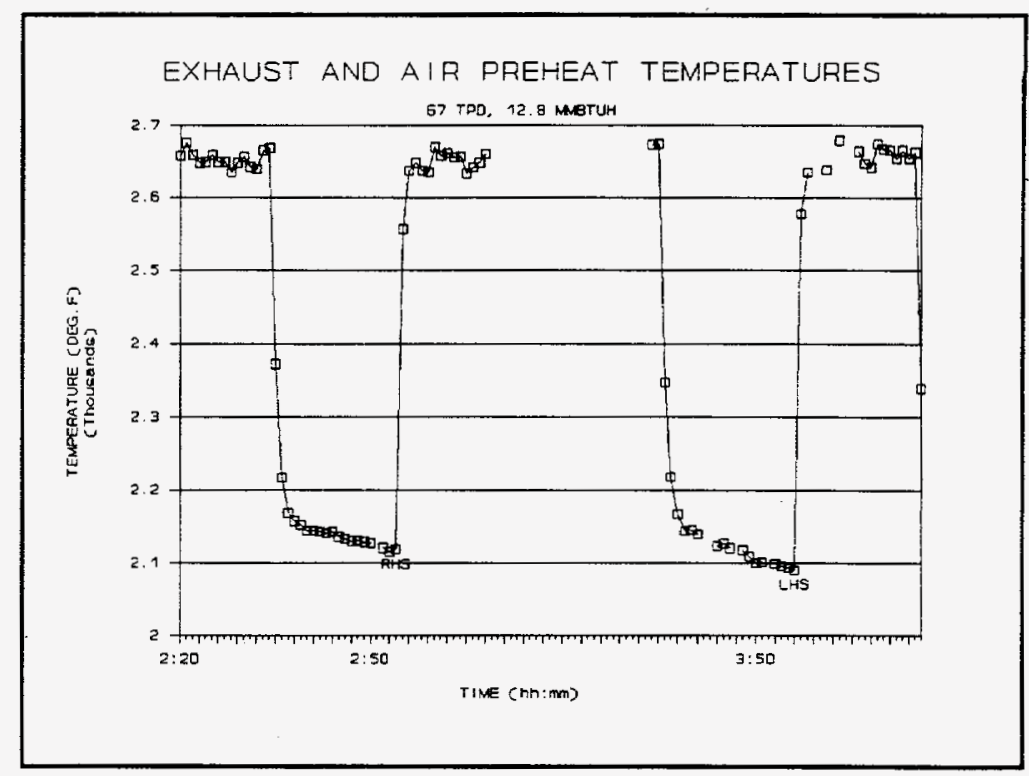

FIGURE 9

rate, and 67 tpd pull/12.8 MMbtuh firing rate, respectively. Comparison of the two figures indicates that baseline exhaust temperature varied little with changing pull, and that to the extent it did, air preheat temperature varied similarly.

The insensitivity of baseline exhaust temperature to pull can be explained by the relative locations of the batch charger and exhaust ports. Exhaust gases approaching the exhaust port pass over relatively cool unmelted batch which absorbs heat and cools the charge end refractories and exhaust gases by radiation. As the firing rate increases with increasing pull, the mass flow of cold batch into the melter also increases, helping to hold temperatures relatively constant.

\subsubsection{100\% OEC Energy Performance and Energy Savings}

The first step in comparing melter energy performance during oxy-fuel and baseline operation was a comparison of electric boost power consumption. Figure 10 replots the baseline electric boost data from Figure 7 on a different scale, along with a least squares 
linear fit to the data. Figure 11 plots electric boost usage during $100 \%$ OEC testing, and shows that it differed from the "standard" level of boost defined by the linearization of the baseline data. The higher use of electric boost at low pull during $100 \%$ OEC operation than during baseline operation is attributed to increased glass surface foam during the first oxyfuel test period, when most of the low pull data was collected. This foam inhibited heat transfer to the glass from combustion space gases and refractory, requiring that more electric boost be used to maintain targeted temperature in glass

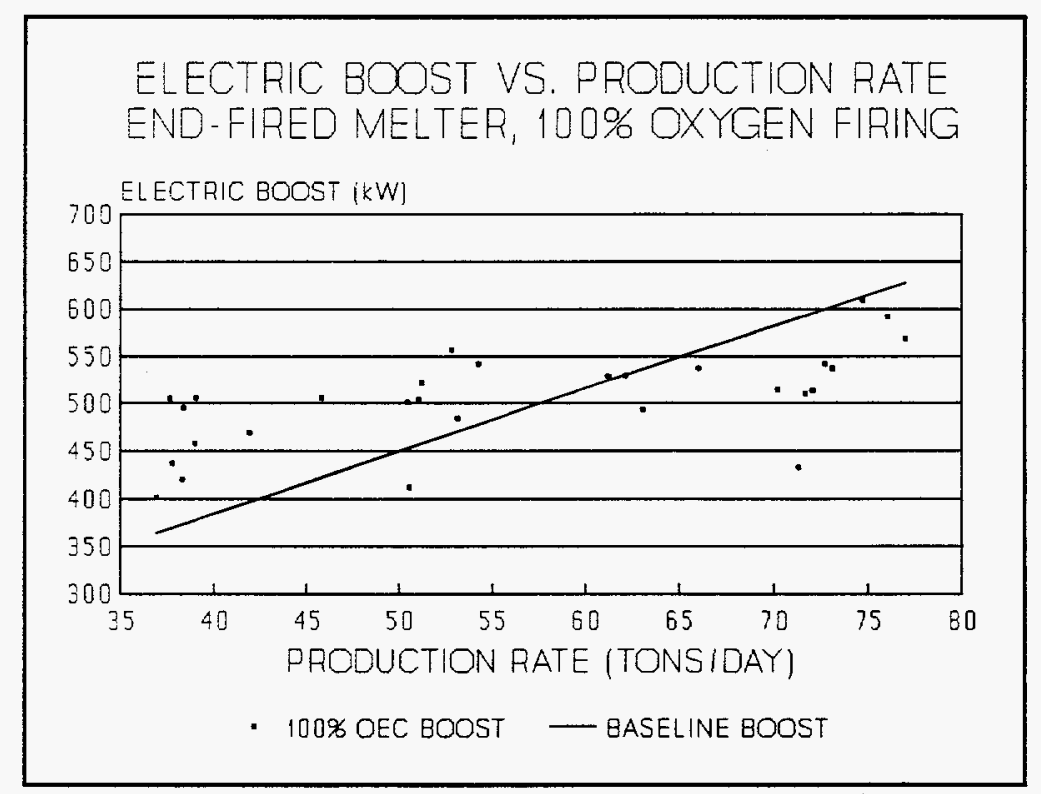

\section{FIGURE 11}

approaching the throat of the melter. The $100 \%$ OEC data at higher pulls was collected after the problem of increased surface foam was largely corrected by batch and firing 
adjustments. These data indicate electric boost usage averaged about 10 percent less than baseline usage.

Baseline and $100 \%$ OEC energy performance are most easily compared by adjusting fuel consumption data for differences in electric boost. This was done

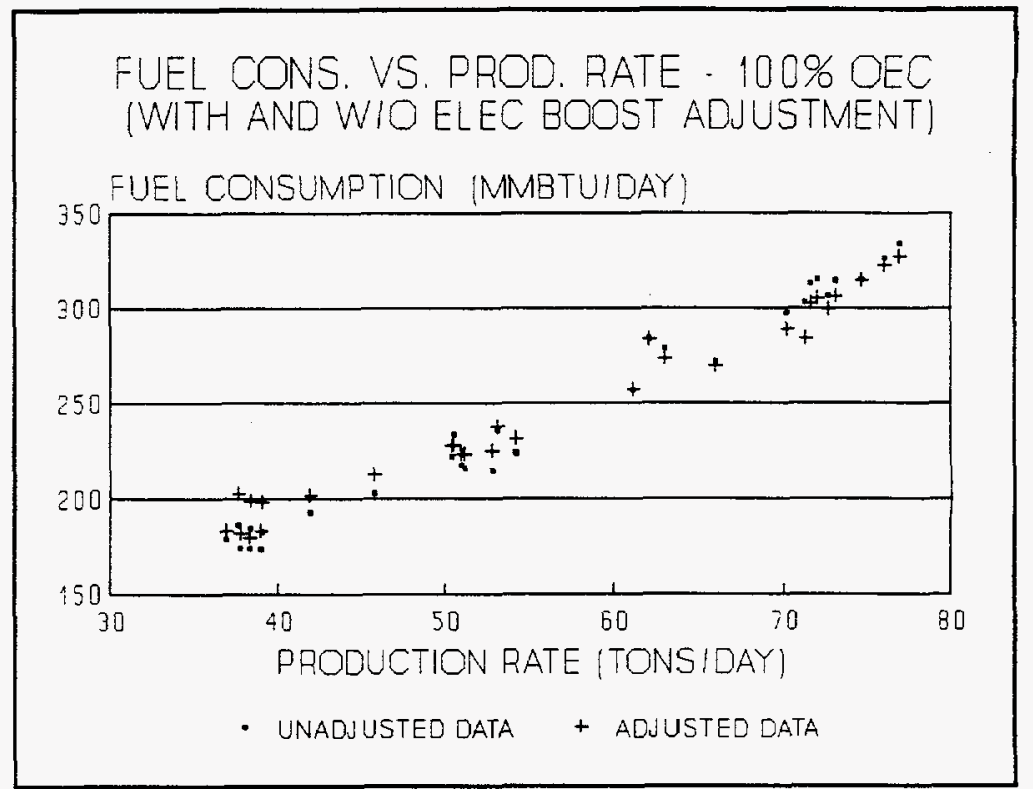

FIGURE 12

for each 24 hour period of $100 \%$ OEC operation, by calculating the expected change in fuel consumption that would have resulted if a "standard" amount of electric boost, defined by the linearization shown on Figure 10, had been used. At the exhaust conditions measured during $100 \%$ OEC operation, $1.47 \mathrm{btu}$ of natural gas input would be needed to replace $1 \mathrm{btu}$ of electrical input. This corresponds to an increase (decrease) of $0.12 \mathrm{MMbtu}$ per day of fuel input per $1.0 \mathrm{~kW}$ decrease (increase) required to adjust electric boost to the "standard" level. The impact of this correction on the $100 \%$ OEC fuel consumption data was small, as shown in Figure 12.

The adjusted fuel consumption data from Figure 12 is replotted on Figure 13, along with baseline fuel data from Figure 7. Linear regressions of the two sets of data are also plotted. Comparison of these linearizations indicates that natural gas savings achieved at Carr-Lowrey, after adjustment for electric boost differences, averaged about 15 percent. Savings ranged from about 20 percent at 40 tpd pull to 12 percent at 75 tpd pull. Specific 
fuel consumption and total specific energy consumption at 75 tpd pull decreased from 4.7 to 4.1 MMbtu per ton, and from 5.35 to $4.75 \mathrm{MMbtu}$ per ton, respectively.

The fuel savings achieved with $100 \%$ OEC can be attributed to two main factors:

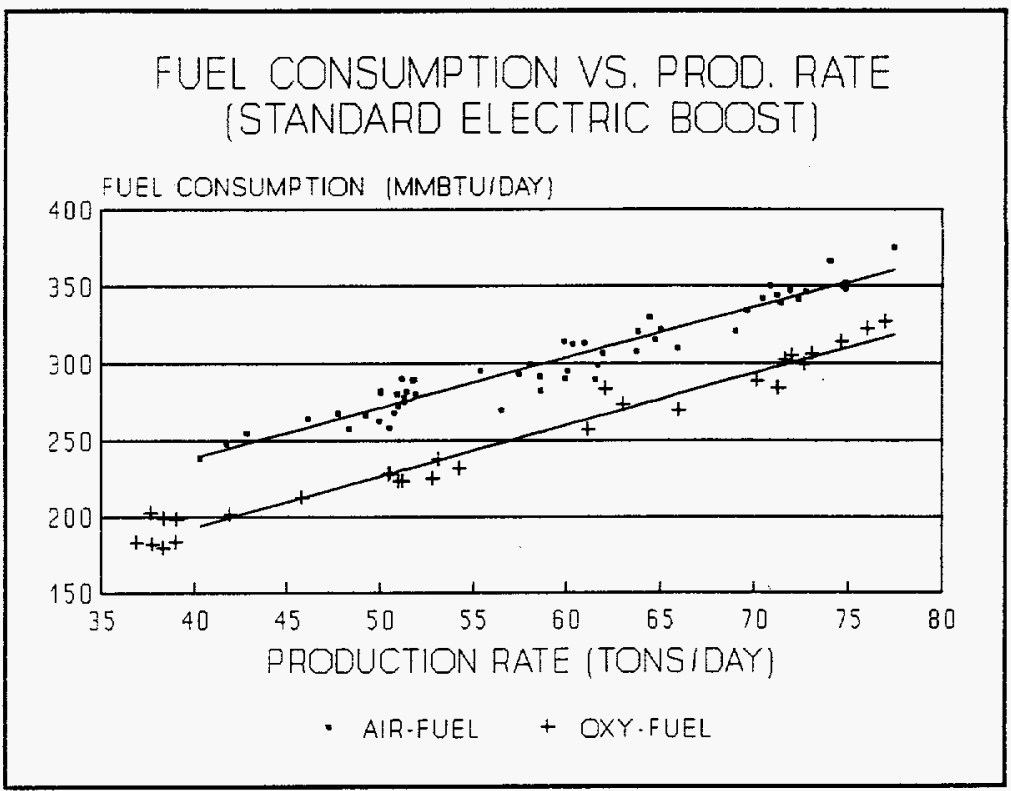

Figure 13

higher fuel energy availability with $100 \%$ OEC than with preheated air-fuel combustion, and reduced net radiative heat flux from the melter to the regenerator ports. The first of these factors is illustrated by Figure 14, which plots the energy input needed to deliver $1 \mathrm{btu}$ of useful energy for $100 \%$ OEC and air-fuel firing with methane, at a

ENERGY INPUT REQUIRED TO SUPPLY 1 BTU OF USEFUL HEAT (3\% EXHAUST O2)

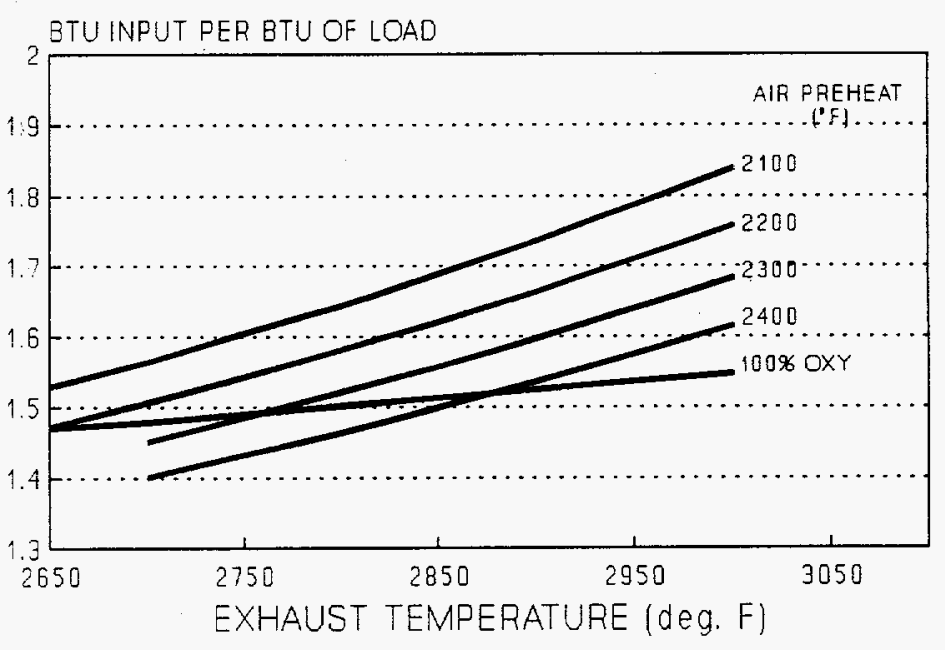

\section{Figure 14}

dry basis exhaust oxygen concentration of 3 percent. The figure indicates that, for a given temperature of furnace gases entering the exhaust ports, regenerators must preheat 
combustion air to within about $450^{\circ} \mathrm{F}$ of that temperature in order to achieve the same energy availability as with $100 \%$ OEC.

As indicated earlier by Figures 8 and 9, typical baseline exhaust and air preheat temperatures measured at Carr-Lowrey, averaged over a reversal cycle, were $2650^{\circ} \mathrm{F}$ and $2130^{\circ} \mathrm{F}$, respectively, and the estimated air:fuel ratio at the burner would have resulted in a dry basis exhaust oxygen concentration of $3.5 \%$ in the absence of air infiltration. Exhaust temperatures measured during $100 \%$ OEC operation also averaged about $2650^{\circ} \mathrm{F}$. Under these conditions, about $3.5 \%$ percent less fuel energy was needed to satisfy a given load with $100 \%$ OEC than with air-fuel firing.

The second major contributor to fuel savings at Carr-Lowrey was reduced radiation from the melter to the regenerator. As indicated by the melter energy balances presented in Table III, this load was reduced by about two-thirds, based on a thermal radiation model using as inputs the port areas, view factors, and temperatures involved. The control boundary for the energy balance passes vertically through the charge end wall, and through the shadow wall separating the melter from the refiner. Therefore, net radiation from the melter to the regenerator ports is treated as an output, and the heat content of gases entering the melter from the refiner is treated as an input.

A permanent melter conversion to $100 \%$ OEC at Carr-Lowrey would have allowed a greater reduction in exhaust/combustion port area than achieved during the test project. Modelling indicates that a 90 percent reduction in port area would have reduced total specific energy consumption to $4.65 \mathrm{MMbtu} / \mathrm{ton}$, and increased fuel savings at 75 tpd to about 15 percent. It should also be noted that this and other specific energy numbers 
TABLE III. ENERGY BALANCE COMPARISON: END-FIRED MELTER

OPERATING CONDITIONS

OXYGENADD'L PORT - - - - - - - - - - - - - - -

GLASS PRODUCTION (TPD) AIR OXYGEN

REDUCTION

\begin{tabular}{|c|c|c|c|}
\hline NATURAL GAS CONSUMPTION (MMBTUH) & 14.7 & 12.9 & $12 \cdot 5$ \\
\hline ELECTRICITY CONSUMPTION ( $\mathrm{kW})$ & 590 & 590 & 590 \\
\hline TOTAL SPECIFIC ENERGY CONS. (MMBTU/TON) & 5.35 & 4.77 & 4.64 \\
\hline A/F OR O2/F RATIO AT BURNERS & 11.2 & 1.65 & 1.65 \\
\hline OXYGEN CONSUMPTION (TPD) & & 21.5 & 20.9 \\
\hline COLD AIR INFILTRATION (SCFH) & 25000 & 25000 & 25000 \\
\hline MELTER EXHAUST TEMP (deg.F) & 2650 & 2650 & 2650 \\
\hline PREHEAT TEMP (deg.F) & 2130 & 80 & 80 \\
\hline
\end{tabular}

ENERGY BALANCE

INPUTS (MMBTU/DAY)

FUEL

ELECTRIC POWER

REFINER COMB. PRODUCTS

AIR PREHEAT

TOTAL INPUT:

OUTPUTS (MMBTU/DAY)

TO GLASS (including batch $\mathrm{CO} 2$ )

RADIATION TO REGENERATOR

STRUCTURE HEAT LOSS

EXHAUST GAS (excluding batch $\mathrm{CO} 2$ )

TOTAL OUTPUT:

FUEL SAVINGS

\begin{tabular}{rrr}
352 & 310 & 301 \\
48 & 48 & 48 \\
13 & 13 & 0 \\
164 & 0 & 0 \\
\hline 577 & 371 & 349
\end{tabular}

\begin{tabular}{rrr}
184 & 184 & 184 \\
21 & 7 & 2 \\
42 & 42 & 42 \\
331 & 138 & 121 \\
\hline 577 & 371 & 349
\end{tabular}

MMBTU / DAY

PERCENT

MMBTU/TON 02

$\begin{array}{rr}42 & 51 \\ 11.9 & 14.5 \\ 1.95 & 2.44\end{array}$


presented so far were achieved with a high rate of air infiltration. Specific energy consumption with $100 \%$ OEC would have been reduced additionally, to about 4.3 $\mathrm{MMbtu} / \mathrm{ton}$, if the estimated air infiltration rate had been reduced by 80 percent, assuming compensating adjustments were made to fuel input rather than electric boost.

The energy savings analysis presented above compares $100 \%$ OEC energy performance to energy performance early in a baseline campaign. Data from the end of the previous baseline campaign showed specific fuel, electric, and total energy consumptions of $4.8,1.58$, and $6.38 \mathrm{MMbtu} / \mathrm{ton}$, respectively, at 65 tpd pull. A precise comparison of $100 \%$ OEC data to this late baseline campaign data is difficult due to much heavier use of electric boost during the previous campaign, and to uncertainty about fuel metering accuracy prior to the rebuild. However, taken at face value, the data indicates a reduction in total specific energy consumption with $100 \%$ OEC of about 25 percent compared to late baseline campaign operation, despite heavier use of electric boost at that time. Some deterioration in energy performance is also to be expected during a campaign with $100 \%$ OEC, due to refractory wear resulting in increasing wall heat loss. However the performance deterioration should be less than during baseline operation, where increased energy use is related primarily to regenerator fouling, with wall heat loss increases playing a secondary role (9).

\subsubsection{Stack Emissions}

Stack emissions tests at Carr-Lowrey were conducted by Monarch Analytical Laboratories, Inc. Baseline tests were conducted on two consecutive days in June, 1991, with three one-hour sampling runs conducted each day. One cay of stack tests was conducted 
during each of the two $100 \%$ OEC test periods in July and October, 1991. Standard EPA methods were followed to determine flue gas volume and composition, and the rate of emissions of nitrogen oxides, particulates, and carbon monoxide.

\subsubsection{1 $\mathrm{NO}_{\mathrm{x}}$ Emissions}

Table IV summarizes $\mathrm{NO}_{\mathrm{x}}$ emissions data collected during baseline and oxy-fuel operation at Carr-Lowrey, including approximate composition of the combustion space atmosphere at the time of the measurements. Baseline $\mathrm{NO}_{x}$ emissions averaged over $20 \mathrm{lbs}$ per ton of glass; near the high end of the range generally reported for regenerative container melters. Most of this baseline $\mathrm{NO}_{\mathrm{x}}$ emission can be assumed to be thermal $\mathrm{NO}_{\mathrm{x}}$ resulting from the combustion process. A small portion (roughly 2 pounds per ton of glass) probably came from the breakdown of niter contained in the batch. The batch used in melter \#7

\begin{tabular}{|c|c|c|c|}
\hline \multicolumn{4}{|c|}{ NOX EMISSIONS - CARR-LOWREY MELTER \#7 } \\
\hline & AIR & OXYGEN & OXYGEN \\
\hline PULL (TPD) & 62.7 & 46.8 & 76.8 \\
\hline BRDGWALL TEMP (F) & 2676 & 2672 & 2766 \\
\hline $\begin{array}{l}\text { FUEL (MMBTU/HR) } \\
\text { FLUE GAS (SCFH) }\end{array}$ & $\begin{array}{r}13.6 \\
200,000\end{array}$ & $\begin{array}{r}8.9 \\
53,000\end{array}$ & $\begin{array}{r}13.7 \\
66,000\end{array}$ \\
\hline $\begin{array}{ll}\text { FURNACE } & \text { ATMOSPHERE } \\
\mathrm{N}_{2} & (\text { (\%WET) } \\
\mathrm{H}_{2} \mathrm{O} & \text { (\%WET) } \\
\mathrm{CO}_{2} & \text { (\%WET) } \\
\mathrm{O}_{2} & \text { (\%WET) }\end{array}$ & $\begin{array}{r}72 \\
14 \\
9 \\
5\end{array}$ & $\begin{array}{r}38 \\
36 \\
22 \\
4\end{array}$ & $\begin{array}{r}30 \\
43 \\
26 \\
1\end{array}$ \\
\hline $\begin{array}{ll}\text { NOx } & \text { (LB/HR) } \\
& \text { (LB/MMBTU) } \\
& \text { (LB/TON) }\end{array}$ & $\begin{array}{l}66.4 \\
4.28 \\
21.6\end{array}$ & $\begin{array}{r}5.75 \\
0.68 \\
2.9\end{array}$ & $\begin{array}{l}6.6 \\
0.6 \\
2.1\end{array}$ \\
\hline \multicolumn{4}{|c|}{ NOX FROM NITER ( $100 \%$ CONVERSION) } \\
\hline $\begin{array}{l}\text { (LB/HR) } \\
\text { (LB/TON) }\end{array}$ & $\begin{array}{l}7.0 \\
2.7\end{array}$ & $\begin{array}{l}6.2 \\
2.7\end{array}$ & $\begin{array}{l}8.6 \\
2.7\end{array}$ \\
\hline
\end{tabular}

TABLE IV 
contains about 5.0 pounds of niter (NaNO3) per ton on glass produced. Complete conversion of the nitrogen content of this niter to $\mathrm{NO}_{2}$ would yield 2.7 pounds of $\mathrm{NO}_{2}$ per ton of glass.

An 85 to 90 percent reduction in $\mathrm{NO}_{\mathrm{x}}$ emissions on a pounds per ton of glass basis was achieved by conversion to $100 \%$ OEC, despite nitrogen concentrations of over 30 percent in the combustion space due to the high rate of air infiltration discussed earlier. $\mathrm{NO}_{\mathrm{x}}$ emissions averaged 2.9 and $2.1 \mathrm{lbs}$. per ton of glass during the first and second periods of $100 \%$ OEC operation, respectively. On a pounds per MMbtu basis, the corresponding numbers are 0.68 and 0.5 pounds per $\mathrm{MMBtu}$, respectively. The lower $\mathrm{NO}_{\mathrm{x}}$ emissions during the second round of $100 \%$ OEC testing than the first, despite higher pull and combustion space temperatures, is probably attributable to the lower oxygen and nitrogen concentrations maintained in the melter during the second period.

While $\mathrm{NO}_{x}$ emissions were greatly reduced by conversion to $100 \%$ OEC, they were significantly higher than the level predicted for thermal $\mathrm{NO}_{\mathrm{x}}$ emissions alone based on laboratory tests. In tests conducted as part of Phase $\mathrm{I}, \mathrm{NO}_{\mathrm{x}}$ emissions of 0.03 pounds per MMbtu were measured during $100 \%$ OEC operation of a Praxair "A" burner fired into a $2700^{\circ} \mathrm{F} \mathrm{lab}$ furnace with low nitrogen concentration (3). Results consistent with these have been found in " $\mathrm{A}$ " burner tests in a $2800^{\circ} \mathrm{F}$ furnace with varying nitrogen concentrations at Praxair's Tarrytown, NY Technical Center. In these tests $\mathrm{NO}_{\mathrm{x}}$ emissions have varied in proportion to furnace nitrogen concentration, and were below 0.5 pounds per MMbtu even during simulation of auxiliary firing into an air-fuel fired furnace with a nitrogen concentration of $70 \%$. 
Figure 15 compares typical $\mathrm{NO}_{\mathrm{x}}$ data from a $2800^{\circ} \mathrm{F}$ lab furnace fired with an "A" burner to actual $\mathrm{NO}_{\mathrm{x}}$ emissions measured during $100 \%$ OEC operation at Carr-Lowrey. As indicated by the figure, the actual $\mathrm{NO}_{x}$ emissions measured were two to three times higher

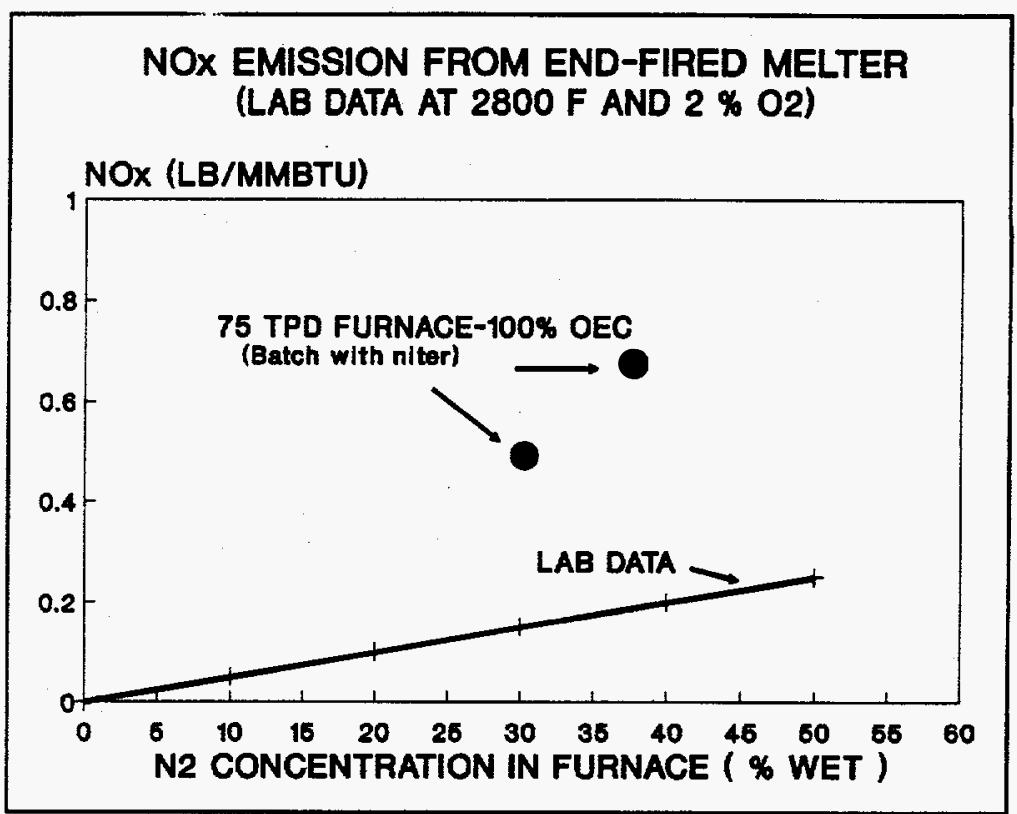

FIGURE 15 than predicted by the lab data.

The most likely explanation for this difference is the presence of niter in Carr-Lowrey's batch. As stated earlier, complete conversion of the nitrogen contained in Carr-Lowrey's batch niter to $\mathrm{NO}_{2}$ would yield 2.7 pounds of $\mathrm{NO}_{x}\left(\mathrm{as} \mathrm{NO}_{2}\right)$ per ton of glass. Assuming that a majority of this nitrogen was converted to $\mathrm{NO}_{x}$, as predicted by thermochemical data, the $\mathrm{NO}_{\mathrm{x}}$ remaining to attribute to combustion agrees more closely with the laboratory data.

\subsubsection{Particulate Emissions}

Particulate emissions from soda-lime glass melters are predominantly the result of volatilization of $\mathrm{NaOH}$ from the glass melt, which subsequently reacts with $\mathrm{SO}_{2}$ in the flue system to form submicron sized $\mathrm{Na}_{2} \mathrm{SO}_{4}$ particulate (10). Modelling studies conducted for Praxair predict reduced volatilization of $\mathrm{NaOH}$ for a given glass surface temperature following conversion from regenerative to oxy-fuel firing (11). The extent of reduction depends in part on the degree to which gas velocity at the glass surface is reduced by 
converting to $100 \%$ OEC. The model predicts that a particulate emissions reduction of approximately $50 \%$ should be typical.

Particle size analysis of the particulate captured during both baseline and $100 \%$ OEC operation at Carr-Lowrey confirmed the expectation that emissions resulted primarily from the condensation of volatiles, as opposed to physical entrainment of batch materials. The mass median diameter of the particulate captured was 0.4 microns during baseline operation, and 0.2 microns during $100 \%$ OEC operation. In contrast, batch particle fines typically range in size up to about 20 microns (12).

Figures 16 and 17 plot baseline and $100 \%$ OEC particulate emissions data from Carr-Lowrey against pull and bridgewall temperature, respectively. The baseline data shown at the lowest pulls (47 and 54 tpd, 2710 bridgewall temperature) is probably not

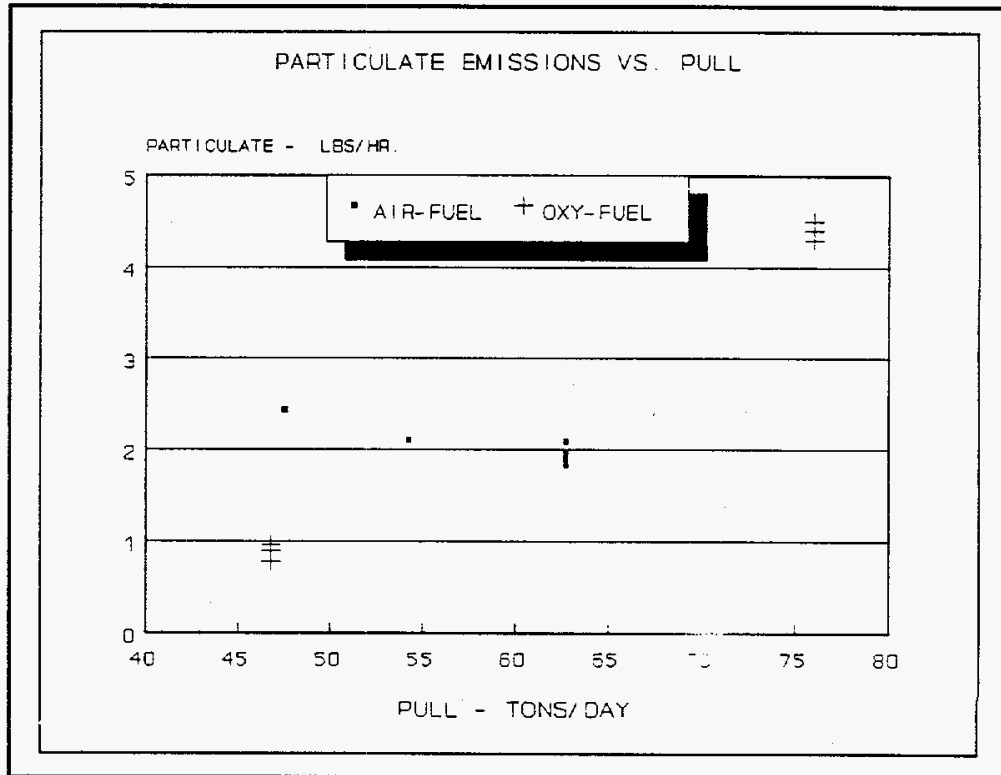

Figure 16

representative, because pull was reduced just prior to these measurements, and the melter operation was not at a steady state.

Changes in pull from measurement to measurement make drawing conclusions about the impact of conversion to $100 \%$ OEC on particulate emissions difficult. However, the changing emissions levels measured can be compared to behavior reported elsewhere. An 
empirical equation developed by Ryder et al. for particulate emissions from container melters predicts a $19 \%$ increase in particulate emissions with each $25^{\circ} \mathrm{F}$ increase in bridgewall temperature. The equation also predicts that particulate emissions will vary directly with

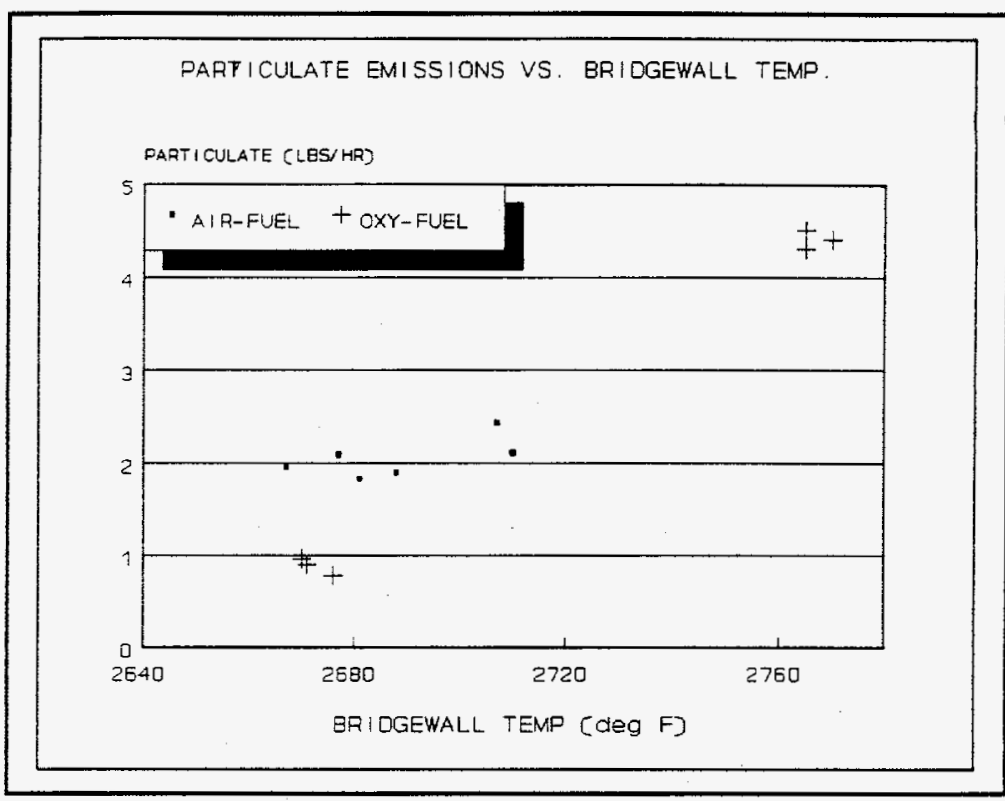

Figure 17

pull, if all other variables are held constant (10). Taking these factors into consideration, and using baseline particulate data at 63 tpd as a starting point, the approximate doubling of particulate emissions during $100 \%$ OEC operation at 76 tpd and $90^{\circ} \mathrm{F}$ higher temperature is in line with predicted behavior for regenerative firing, which suggests no reduction from expected levels was caused by conversion to oxy-fuel firing. In contrast, the reduction in particulate emissions relative to baseline operation that occurred with $100 \%$ OEC at 47 tpd, is greater than predicted for changes in pull and bridgewall temperature alone.

A possible explanation for this discrepancy in results is presented in Figure 18, which shows the temperatures measured between the rider tiles prior to and during the stack emissions test with $100 \%$ OEC at 76 tpd. As the stack tests were being conducted, the temperature of the right hand side of the regenerator was leveling off at a level well above the usual temperature at the end of a baseline exhaust cycle. This excursion to higher than normal temperatures likely caused release of previously condensed $\mathrm{Na}_{2} \mathrm{SO}_{4}$ from the regenerator during the stack test period. 
Stack opacity during high pull operation at Carr-Lowrey increased from baseline readings in the high teens, to readings in the low 20 's after conversion to $100 \%$ OEC. Reduced gas volume at the stack exit was the likely cause of this increase. Measured stack gas volume flow

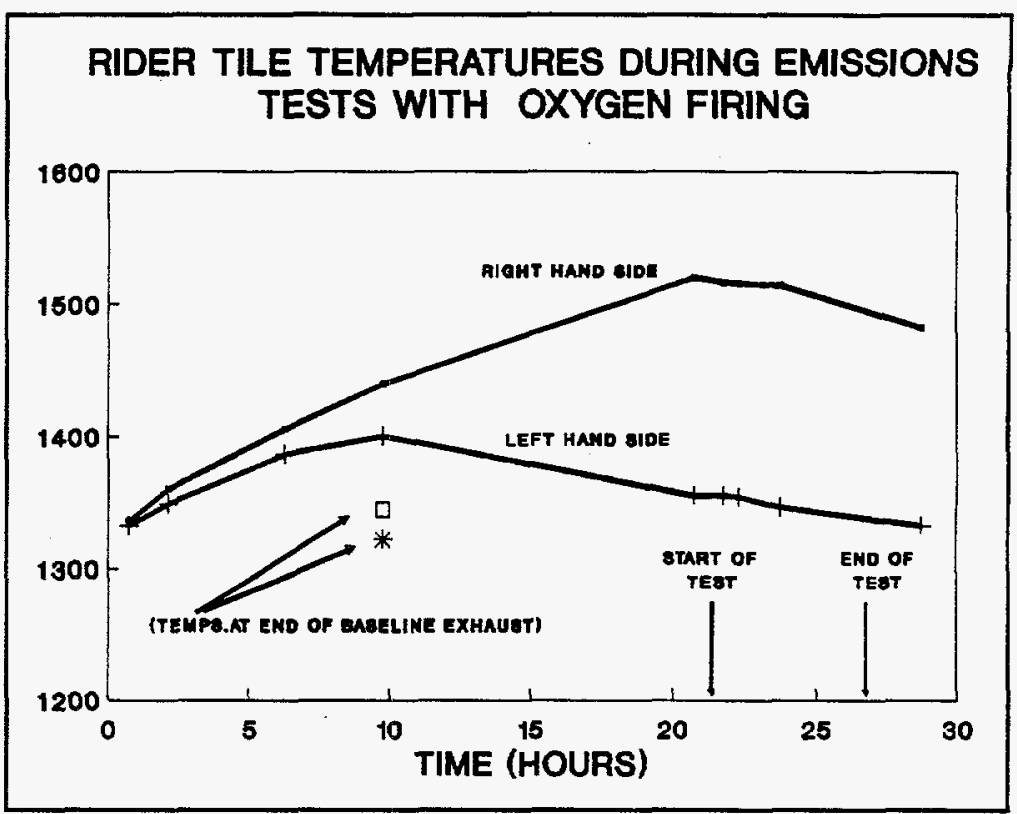

Figure 18 at the sampling point during $100 \%$ OEC operation at 76 tpd was only 75 percent of the volume measured during baseline operation at $63 \mathrm{tpd}$.

\subsubsection{Carbon Monoxide Emissions}

Carbon monoxide emissions measured during the baseline and $100 \%$ OEC test periods at Carr-Lowrey are summarized in Table V. Carbon monoxide emissions were negligible during the first $100 \%$ OEC test period, with concentrations at the sampling point consistently below $1 \mathrm{ppm}$. During the second 100\% OEC test period, when excess oxygen in the melter was more tightly controlled, $\mathrm{CO}$ emissions ranged from 1 to $6 \mathrm{ppm}$, which was similar to the baseline emissions range.

\subsection{Burner Performance}

The water cooled "A" burners used during the first round of tests frequently became fouled by condensibles from the furnace atmosphere. These burners had to be retracted 


\section{Table V}

CARBON MONOXIDE EMISSIONS - CARR-IOWREY MELTER \#7

AIR-FUEL

OXY FUEL

PERIOD 1 PERIOD 2

CARBON MONOXIDE

$\begin{array}{rrcr}\text { ppm } & 1.8-4.5 & 0.4-0.7 & 1.0-5.7 \\ \text { LB/HR } & 0.04-0.11 & <.01 & 0.02-0.10 \\ \text { LB/TON } & 0.02-0.04 & <.01 & 0.01-0.03\end{array}$

from the melter and cleaned every 36 to 48 hours in order to prevent plugging of the oxygen nozzles. Non-water cooled burners were used to replace two of the "A"burners during the second $100 \%$ OEC test period. These burners operated the two weeks of the second test period without requiring any cleaning. This led to a decision to use non-water cooled burners for previously planned extended burner testing.

The "extended burner test" commenced in January, 1991. The purpose was to evaluate long term oxy-gas burner performance in a glass melting environment. For this purpose, one auxiliary oxy-gas burner was installed in each melter breastwall, to supplement the heat input of the regenerative air-fuel system. These burners alternately cycled on and off as the air-fuel system reversed, so that only the burner on the exhausting side of the melter was firing. The firing rates of the auxiliary burners ranged from two to three MMbtuh. As was the case during second period of $100 \%$ OEC testing, no significant fouling of the non-water cooled burners occurred during the extended burner test. A cursory 
cleaning of the burners was done every four to six weeks when they were pulled out for inspection.

\subsection{SIDE-PORT MELTER CONVERSION AT GALLO GLASS COMPANY}

The main objectives of continuing the $100 \%$ OEC Evaluation Project at Gallo Glass were to demonstrate the compatibility of VPSA oxygen supply with good glass melting performance and low stack emissions, and to evaluate VPSA plant energy performance. Gallo also agreed to collection of melter energy performance data with $100 \%$ OEC, and comparison of this data to historical energy performance data.

Testing at Gallo was conducted in a series of steps over a two year period. Baseline emissions data on Gallo's melter \#1 was collected in January, 1991 as the melter neared the end of its regenerative melting campaign. The melter was rebuilt during the following spring, with modifications for $100 \%$ OEC operation. Oxy-fuel melting of glass commenced in August, 1991. Energy performance and stack emissions data were collected during the first two months of $100 \%$ OEC operation. A final set of emissions measurements, and energy performance measurements of the melter and VPSA oxygen plant, were conducted in February 1993.

\subsection{Measurement and Data Collection Methods}

Annubar meters on the oxygen combustion system flow control skids supplied by Corning were used to measure fuel and oxygen consumption during $100 \%$ OEC operation at Gallo. This data, along with electric boost power consumption and other continuously measured operating parameters, was recorded automatically by Gallo's control room computers. The fuel and electric boost data, in combination with Gallo's pull and cullet 
ratio records, were used to determine the energy performance of the melter with $100 \%$ OEC. This was compared to historical baseline energy performance data based on fuel and combustion air measurements from orifice flow meters.

Portable $\mathrm{CO}_{2}, \mathrm{O}_{2}$ and $\mathrm{NO}_{\mathrm{x}}$ analyzers like those used at Carr-Lowrey were used to gather data on gas composition in the melter and melter exhaust during $100 \%$ OEC operation. This data was collected prior to and during each of the $100 \%$ OEC stack emissions tests, and provided a basis for estimating air infiltration rates and nitrogen concentration in the melter. It supplied useful feedback on the effectiveness of steps taken to seal the melter, and the impact of various firing adjustments on $\mathrm{NO}_{\mathrm{x}}$ emissions.

Stack emissions tests using standard EPA methods were conducted by Monarch Analytical Laboratories at Gallo prior to the melter rebuild, seven weeks following start up of the melter with $100 \%$ OEC, and a third time after start up of the on-site VPSA oxygen plant.

The measurement methods used to evaluate VPSA plant performance are covered in section 5.4.3.

\subsection{Installation and Start Up of Oxy-Fuel Combustion System}

Gallo Glass Company and Corning Incorporated worked together in preparing melter \#1 for oxy-fuel firing. During the melter rebuild, all but one port on each side of the 1248 square foot furnace was removed. The two remaining ports served as exhaust outlets to direct furnace gases to a Morgan-Isley ejector system (7). Corning designed and supplied the oxy-fuel burners and combustion control system. A total of ten non-water cooled oxyfuel burners were installed in an opposed arrangement in burner blocks in the melter 
breastwalls. While the melter was being rebuilt, Praxair installed liquid oxygen supply tanks, vaporizers, and pressure regulating equipment to meet the melter's projected oxygen demand and combustion control system pressure requirements.

Heat up and fill of the glass melter proceeded smoothly, and more quickly than typical of the regenerative air-fuel melters at Gallo. Temporary heat up burners were used to raise melter temperature sufficiently to permit auto-ignition of the oxy-fuel burners. Once oxy-fuel firing commenced, melter fill with cullet, and then batch, proceeded quickly and without interruption. The high available heat from the oxy-fuel combustion resulted in a steady rise in furnace temperature during the fill process. In contrast Gallo's experience in filling conventional melters is that filling often has to be stopped in order to allow furnace temperature to recover (7).

Within one week of fill, all forming machines supplied by the melter were operating at full production. Glass quality following conversion to oxy-fuel melting, as measured by seed and blister levels, was equivalent to pre-conversion quality (7).

\subsection{Comparative Performance - Air-Fuel and Oxy-Fuel Melting}

\subsubsection{Energy Performance}

Specific energy consumption of Gallo's melter \#1 prior to and following conversion to $100 \%$ OEC operation are presented in Table VI. The energy figures are averages from multiple 24-hour operating periods with melter pull ranging from 335 to 345 tpd, and at a cullet ratio of 25 percent. 


\section{SPECIFIC ENERGY CONSUMPTION COMPARISON GALLO GLASS MELTER \#1}

LATE

CAMPAIGN TYPICAL

AIR-FUEL AIR-FUEL OXY-FUEL

$\begin{array}{llll}\text { GLASS PULL (tpd) } & 340 & 340 & 340 \\ \text { CULLET RATIO (\%) } & 25 \% & 25 \% & 25 \% \\ \text { ENERGY (MMbtu/ton) } & & & \\ \text { Natural Gas: } & 3.95 & 3.75 & 3.35 \\ \text { Electric Boost: } & 0.58 & 0.52 & 0.43 \\ \text { Total: } & 4.53 & 4.27 & 3.78\end{array}$

Specific fuel consumption following conversion to oxy-fuel firing was reduced by $15 \%$ relative to operation late in the baseline campaign, and by about $11 \%$ relative to more typical baseline operation earlier in the campaign. Electric boost usage was reduced by $26 \%$ relative to usage late in the baseline campaign, and by about $17 \%$ relative to typical baseline operation.

Energy balances for baseline and $100 \%$ OEC operation are presented in Table VII. As at Carr-Lowrey, the energy savings achieved with $100 \%$ OEC is attributable to higher combustion energy availability following conversion to $100 \% \mathrm{OEC}$, and to reduced thermal radiation from the melter to the exhaust ports due to the large reduction in port area. This last factor was enhanced by the location of the exhaust ports near the charge end of the melter, and profiling the melter to keep temperatures relatively low in this zone. This resulted in lower exhaust gas temperature than the average exhaust temperature achieved with regenerative firing. 
TABLE VII. GLASS FURNACE ENERGY BALANCE MELTER \#1 - GALLO GLASS CO., MODESTO, CA

\begin{tabular}{|c|c|c|c|}
\hline FURNACE OPERATING CONDITIONS & $\begin{array}{r}\text { AIR } \\
\text { BASE } \\
\text { CASE }\end{array}$ & $\begin{array}{c}\text { OXY-FUEL } \\
\text { (LIQUID } \\
\text { SUPPLY) }\end{array}$ & $\begin{array}{c}\text { OXY-FUEL } \\
\text { (VPSA } \\
\text { SUPPLY) }\end{array}$ \\
\hline \multicolumn{4}{|c|}{ 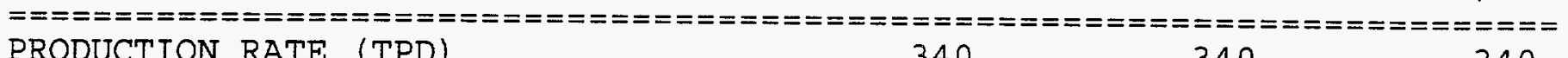 } \\
\hline PRODUCTION RATE (TPD) & 340 & 340 & 340 \\
\hline \multicolumn{4}{|l|}{ FEED CHARACTERISTICS } \\
\hline BATCH MOISTURE (\% OF WET BATCH) & 3 & 3 & 3 \\
\hline IGNITION LOSS (\% OF DRY BATCH) & 15.0 & 15.0 & 15.0 \\
\hline CULLET RATIO (\% OF WET CHARGE) & 25.0 & 25.0 & 25.0 \\
\hline CULLET MOISTURE (\% OF WET CLT) & 4 & 4 & 4 \\
\hline GROSS CHARGE RATE (TPD) & 396.10 & 396.10 & 396.10 \\
\hline WET BATCH CHARGE (TPD) & 297.07 & 297.07 & 297.07 \\
\hline WET CULLET CHARGE (TPD) & 99.02 & 99.02 & 99.02 \\
\hline H2O IN BATCH (TPD) & 8.91 & 8.91 & 8.91 \\
\hline H2O IN CULLET (TPD) & 3.96 & 3.96 & 3.96 \\
\hline ELECTRIC BOOSTING (KW) & 2,160 & 1,785 & 1,785 \\
\hline \multicolumn{4}{|l|}{ BURNER OPERATING CONDITIONS } \\
\hline $\begin{aligned} \text { NAT. GAS FLOW RATE (SCFH) } & (\mathrm{HHV} \text { MMBTU/HR) } \\
& (\mathrm{LHV} \text { MMBTU/HR) }\end{aligned}$ & $\begin{array}{r}52,400 \\
53.16 \\
47.95\end{array}$ & $\begin{array}{r}46,800 \\
47.48 \\
42.82\end{array}$ & $\begin{array}{r}47,000 \\
47.68 \\
43.00\end{array}$ \\
\hline $\begin{array}{l}\text { OXIDANT COMPOSITION } \\
\text { O2 }(\%) \\
\text { N2 }(\%) \\
\text { Ar }(\%)\end{array}$ & $\begin{array}{l}20.9 \\
79.1\end{array}$ & $\begin{array}{r}100.0 \\
0.0 \\
0.0\end{array}$ & $\begin{array}{r}90.0 \\
5.0 \\
5.0\end{array}$ \\
\hline OXIDANT PREHEAT TEMP (F) & 2300 & 77 & 77 \\
\hline COMBUSTION STOICH. RATIO (\%) & 115.0 & 100.0 & 100.0 \\
\hline $\begin{array}{ll}\text { OXIDANT CONSUMPTION } & \text { (SCFH) } \\
\text { CONTAINED OXYGEN } & \text { (SCFH) } \\
& (\mathrm{TPD})\end{array}$ & $\begin{array}{r}577,227 \\
120,641 \\
122.0\end{array}$ & $\begin{array}{r}93,694 \\
93,694 \\
94.8\end{array}$ & $\begin{array}{r}104,549 \\
94,094 \\
95.2\end{array}$ \\
\hline FLUE GAS FLOW RATE (SCFH) & 630,256 & 141,055 & 152,113 \\
\hline
\end{tabular}


TABLE VII. GLASS FURNACE ENERGY BALANCE

MELTER \#1 - GALLO GLASS CO., MODESTO, CA

\begin{tabular}{|c|c|c|c|}
\hline & $\begin{array}{l}\text { AIR } \\
\text { BASE } \\
\text { CASE }\end{array}$ & $\begin{array}{c}\text { OXY-FUEL } \\
\text { (LIQUID } \\
\text { SUPPLY) }\end{array}$ & $\begin{array}{c}\text { OXY-FUEL } \\
\text { (VPSA } \\
\text { SUPPLY) }\end{array}$ \\
\hline 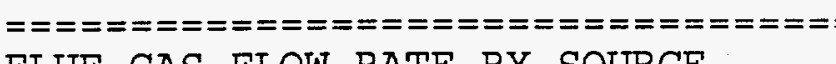 & $======$ & $:========$ & 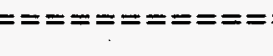 \\
\hline \multicolumn{4}{|l|}{ FLUE GAS FLOW RATE BY SOURCE } \\
\hline H2O FROM CHARGE (SCFH) & 22,623 & 22,623 & 22,623 \\
\hline CO2 FROM CHARGE (SCFH) & 31,076 & 31,076 & 31,076 \\
\hline FLUE GAS FROM COMBUSTION (SCFH) & 630,256 & 141,055 & 152,113 \\
\hline AIR INFILTRATION (SCFH) & 20,000 & 20,000 & 20,000 \\
\hline TOTAL FLUE GAS (SCFH) & 703,955 & 214,754 & 225,812 \\
\hline \multicolumn{4}{|l|}{ FLUE GAS FLOW RATE BY COMPOSITION } \\
\hline $\mathrm{CO} 2 \quad(\mathrm{SCFH})$ & 84,052 & 78,390 & 78,593 \\
\hline $\mathrm{H} 2 \mathrm{O}$ (SCFH) & 126,899 & 115,755 & 116,153 \\
\hline $\mathrm{N} 2 \quad(\mathrm{SCFH})$ & 472,888 & 16,228 & 21,458 \\
\hline $\mathrm{O} 2$ (SCFH) & 19,916 & 4,180 & 4,180 \\
\hline Ar (SCFH) & 200 & 200 & 5,427 \\
\hline TOTAL (SCFH) & 703,955 & 214,754 & 225,812 \\
\hline
\end{tabular}

FLUE GAS COMPOSITION

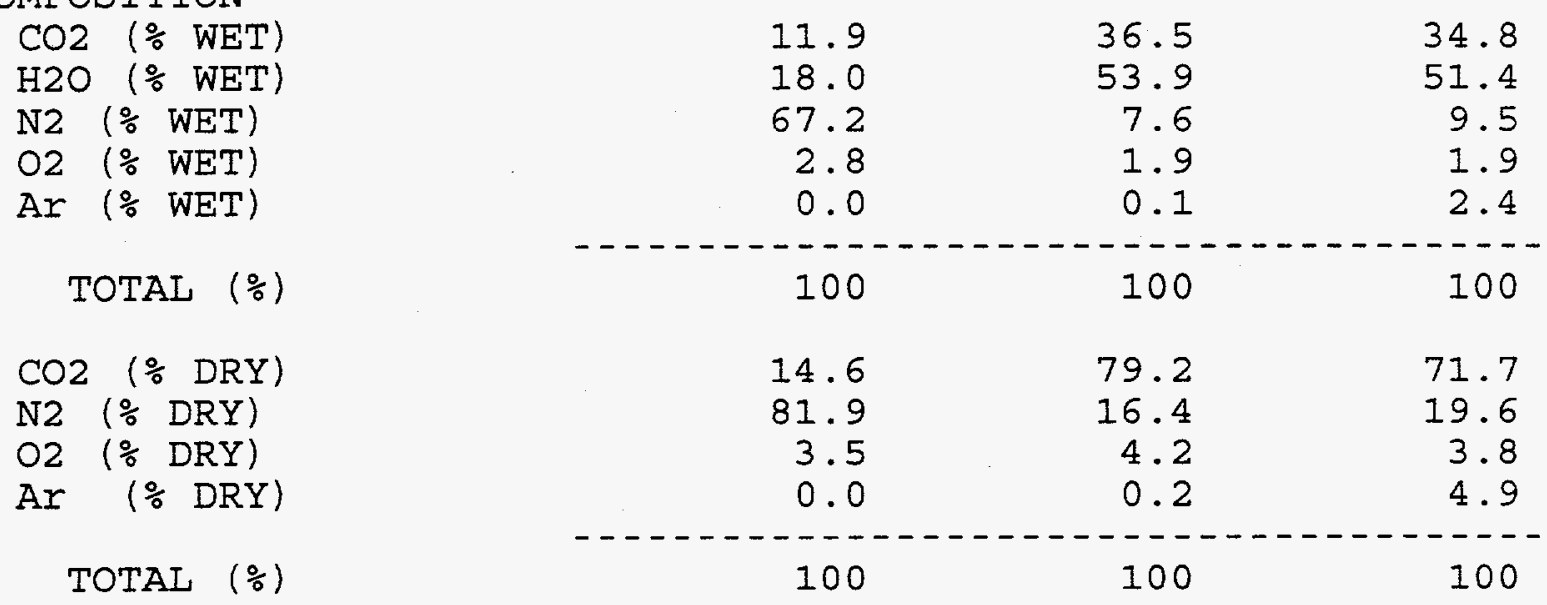

MELTER AVG CROWN TEMPERATURE (F) MELTER GAS EXIT TEMPERATURE (F) GLASS TEMPERATURE AT THROAT

REGEN TOP TEMPERATURE (F)

FLUE PORT RADIATION TEMP (F) REGEN PORT AREA (FT^2)

FLUE PORT AREA (FT^2)
2,890

2,800

2,400

2,300

86.7
2,800

2,800

(F)
2,650

2,400

2,650

2,400 
TABLE VII. GLASS FURNACE ENERGY BALANCE MELTER \#1 - GALLO GLASS CO., MODESTO, CA

\begin{tabular}{|c|c|c|c|}
\hline & $\begin{array}{r}\text { AIR } \\
\text { BASE } \\
\text { CASE }\end{array}$ & $\begin{array}{l}\text { OXY-FUEL } \\
\text { (LIQUID } \\
\text { SUPPLY) }\end{array}$ & $\begin{array}{c}\text { OXY-FUEL } \\
\text { (VPSA } \\
\text { SUPPLY) }\end{array}$ \\
\hline \multicolumn{4}{|c|}{ 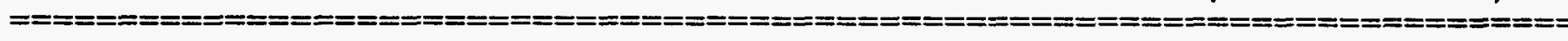 } \\
\hline \multicolumn{4}{|l|}{ MELTER ENERGY BALANCE } \\
\hline \multicolumn{4}{|l|}{ ENERGY INPUT (MMBTU/HR) (hhV) } \\
\hline FUEL & 53.16 & 47.48 & 47.68 \\
\hline ELECTRIC POWER (@3410 BTU/KWH) & 7.37 & 6.09 & 6.09 \\
\hline OXIDANT PREHEAT & 26.26 & 0.00 & 0.00 \\
\hline BATCH PREHEAT & 0.00 & 0.00 & 0.00 \\
\hline CULLET PREHEAT & 0.00 & 0.00 & 0.00 \\
\hline TOTAL INPUT & 86.79 & 53.57 & 53.77 \\
\hline \multicolumn{4}{|l|}{ ENERGY OUTPUT (MMBTU/HR) (hhV) } \\
\hline $\begin{array}{l}\text { ENERGY TO GLASS } \\
\text { FLUE LOSS }\end{array}$ & 25.55 & 25.55 & 25.55 \\
\hline WATER FROM BATCH & 1.91 & 1.84 & 1.84 \\
\hline WATER FROM CULLET & 0.85 & 0.82 & 0.82 \\
\hline CO2 FROM BATCH & 2.75 & 2.60 & 2.60 \\
\hline COMB. FLUE GAS \& INFIL. AIR & 46.29 & 16.79 & 17.13 \\
\hline FLUE LOSSES (TOTAL) & 50.95 & 21.23 & 21.57 \\
\hline \multicolumn{4}{|l|}{ WALL HEAT LOSSES } \\
\hline RADIATION TO REGEN PORTS & 4.58 & 0.00 & 0.00 \\
\hline RADIATION TO FLUE PORT & 0.00 & 1.22 & 1.22 \\
\hline WALL HEAT CONDUCTION & 4.00 & 4.00 & 4.00 \\
\hline RADIATION TO WALL OPENINGS & 1.63 & 1.46 & 1.46 \\
\hline WALL \& RAD. LOSSES (TOTAL) & 10.22 & 6.69 & 6.69 \\
\hline TOTAL OUTPUT & 86.72 & 53.47 & 53.81 \\
\hline
\end{tabular}

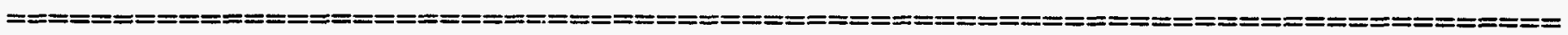
MELTER ENERGY BALANCE - SUMMARY

\begin{tabular}{|c|c|c|c|}
\hline NERGY INPUT (MMBTU/TON) (hhV) & & & \\
\hline FUEL & 3.75 & 3.35 & 3.37 \\
\hline ELECTRIC POWER (@3410 BTU/KWH) & 0.52 & 0.43 & 0.43 \\
\hline OXIDANT PREHEAT & 1.85 & 0.00 & 0.00 \\
\hline BATCH PREHEAT & 0.00 & 0.00 & 0.00 \\
\hline CULLET PREHEAT & 0.00 & 0.00 & 0.00 \\
\hline TOTAL INPUT & 612 & 370 & \\
\hline - - - - - - - - & - 2 & 海 & 3.00 \\
\hline ENERGY OUTPUT (MMBTU/TON) (hhV) & & & \\
\hline ENERGY TO GLASS & 1.80 & 1.80 & 1.80 \\
\hline FLUE LOSSES (TOTAL) & 3.60 & 1.50 & 1.52 \\
\hline WALL HEAT LOSSES (TOTAL) & 0.72 & 0.47 & 0.47 \\
\hline TOTAL OUTPUT & 6.12 & 3.77 & 3.80 \\
\hline
\end{tabular}


By the time the VPSA plants at Gallo became operational, a second melter had been converted to $100 \%$ OEC operation. The combined oxygen demand of the two melters exceeded the capacity of the VPSA plants, and piping arrangements did not allow the VPSA oxygen to be dedicated to melter $\# 1$. Consequently, the $100 \%$ OEC melters received an oxidant mixture supplied $60 \%$ by the VPSA plant oxygen, and $40 \%$ by the liquid storage tanks. The composition of this mixture was approximately $94 \%$ oxygen, $3 \%$ nitrogen, and $3 \%$ argon.

No change in the energy consumption of melter \#1 was detectable following VPSA oxygen plant start up. This was as expected based on analysis of the predicted change in overall heat load caused by nitrogen and argon impurities in the VPSA oxygen. VPSA oxygen typically contains 3 to 5 percent nitrogen by volume, and about $5 \%$ argon by volume. As indicated by the third column in Table VII, even with all oxygen to the melter supplied by a VPSA plant supplying 90\% purity oxygen, these impurities cause a less than 1 percent increase in melter heating load and firing rate relative to operation with pure oxygen. As was the case at Gallo, this impact is too small to detect within the normal variability of energy performance data.

\subsubsection{Stack Emissions}

Gaseous and particulate emissions from Gallo's melter \#1 were measured by Monarch Analytical Laboratories, Inc. several months before the end of the baseline melting campaign, and about 2 months after the start of the oxy-fuel melting campaign. Gaseous emissions were measured a third time in February 1993, when the majority of the oxygen requirement of melter \#1 was supplied by the on-site VPSA plant. 


\subsubsection{NO Emissions}

Table VIII summarizes $\mathrm{NO}_{\mathrm{x}}$ emissions data collected during stack tests at Gallo. As indicated, with all of the melter's oxygen requirement supplied by the liquid storage tanks,

\begin{tabular}{|c|c|c|c|}
\hline \multirow[t]{3}{*}{ NOX EMISSIONS } & \multirow{3}{*}{$\begin{array}{l}\text { - GALLO GI } \\
\text { BASELINE }\end{array}$} & SS MELTER & \\
\hline & & $100 \%$ OEC & \\
\hline & & LIOUID 02 & $\begin{array}{l}\text { LIQ/VPSA } \\
\text { MIXTURE }\end{array}$ \\
\hline GLASS PULL (TPD) & 335 & 342 & 339 \\
\hline \multicolumn{4}{|l|}{$\begin{array}{l}\text { COMBUSTION SPACE } \\
\text { ATMOSPHERE }\end{array}$} \\
\hline NITROGEN & $72 \%$ & $3 \%$ & $4-5 \%$ \\
\hline WATER VAPOR & $17 \%$ & $51 \%$ & $51 \%$ \\
\hline CARBON DIOXIDE & $9 \%$ & $45 \%$ & $44 \%$ \\
\hline OXYGEN & $2 \%$ & $1 \%$ & $0.5-1 \%$ \\
\hline NOX EMISSION (LB/TON) & 5.0 & 0.81 & 0.94 \\
\hline
\end{tabular}

\section{Table VIII}

$\mathrm{NO}_{\mathrm{x}}$ emissions were reduced to $0.8 \mathrm{lbs}$ per ton of glass, from a baseline level of 5.0 pounds per ton. Based on measured $\mathrm{CO}_{2}$, and $\mathrm{O}_{2}$ concentrations, air infiltration into the combustion space was very low during the first $100 \%$ OEC stack test, and resulted in a calculated nitrogen concentration of only 3 percent. The large reduction in $\mathrm{NO}_{\mathrm{x}}$ emissions from baseline levels is primarily attributable to this more than 20 -fold reduction in furnace nitrogen concentration relative to baseline concentration. 
The $\mathrm{CO}_{2}$ and $\mathrm{O}_{2}$ concentrations listed are averages of measurements made at several locations along the length of the melter near the oxy-fuel burners. Oxygen and nitrogen concentrations in the exhaust ports were significantly higher than the typical values in the combustion space, due to air infiltration through the batch charger and backwall. This air tended to "short circuit" to the exhaust ports, and therefore had little influence on nitrogen and oxygen concentrations or $\mathrm{NO}_{\mathrm{x}}$ formation in the melter combustion zone.

The importance of limiting air infiltration into the combustion space for achieving minimum $\mathrm{NO}_{\mathrm{x}}$ emissions was made clear by measurements taken in the very first days of glass production with $100 \%$ OEC, before the melter had been sealed and fully insulated. During this period, calculated (wet basis) combustion space nitrogen concentration based on $\mathrm{CO}_{2}$ and $\mathrm{O}_{2}$ measurements was as high as $12 \%$, and $\mathrm{NO}_{\mathrm{x}}$ emissions as high as 2.3 pounds per ton were measured. A careful job of melter sealing by Gallo allowed the very low nitrogen concentration and $\mathrm{NO}_{\mathrm{x}}$ emissions level indicated in Table VIII to be achieved when stack emissions tests were conducted during the second month of the melting campaign. Careful control of excess oxygen concentrations in the combustion space also contributed to the low $\mathrm{NO}_{\mathrm{x}}$ emissions achieved during both $100 \%$ OEC stack emissions tests at Gallo.

Following start up of the VPSA oxygen plants, melter \#1 was supplied with a mix of VPSA and liquid oxygen containing about $3 \%$ nitrogen and $3 \%$ argon by volume. $\mathrm{NO}_{\mathrm{x}}$ emissions measured under this condition were $0.94 \mathrm{lbs}$ per ton of glass, more than $80 \%$ below the baseline emissions level, and about 18 percent higher than the level measured with liquid oxygen supply. $\mathrm{CO}_{2}$ and oxygen concentration measurements indicated a combustion space nitrogen concentration during these tests ranging from 4 to 5 percent. This increase 
in combustion space nitrogen concentration relative to the $3 \%$ concentration determined during the initial $100 \%$ OEC stack test was consistent with the calculated expectation of about a 1.5 percentage point increase due to the $3 \%$ nitrogen concentration of the VPSA oxygen. This suggests that there was little change in air infiltration rates between the two $100 \%$ OEC stack tests. The impact of the nitrogen impurity in VPSA oxygen on the overall level of $\mathrm{NO}_{\mathrm{x}}$ emissions was small, especially relative to the variability in $\mathrm{NO}_{\mathrm{x}}$ emissions measured at different points in the melter sealing process.

\subsubsection{Particulate Emissions}

Baseline and 100\% OEC particulate emissions results from Gallo are summarized in Table IX. Three one-hour sample runs were conducted late in the baseline campaign, and again during the second month of oxy-fuel melting, using EPA method 5. Unlike at CarrLowrey, the stack tests were conducted at nearly equal pulls, which greatly facilitates comparison of the data. Also facilitating comparison was the absence of a regenerator between the melter and the sample point, which at Carr-Lowrey may have acted as a transient emissions source as checker temperatures increased during $100 \%$ OEC operation.

Particulate emissions at Gallo were reduced by about 25 percent from baseline levels, to 0.88 pounds per ton of glass, following conversion to $100 \%$ OEC. This reduction occurred despite the lower electric boost usage during $100 \%$ OEC operation than during baseline operation discussed earlier. Higher electric boost typically allows a given rate of melting to be achieved at a lower glass surface temperature, which in turn lowers the rate of $\mathrm{NaOH}$ volatilization from the glass melt. 


\section{PARTICULATE EMISSIONS - GALLO GLASS MELTER \#1}

\section{BASELINE $\quad 100 \%$ OEC}

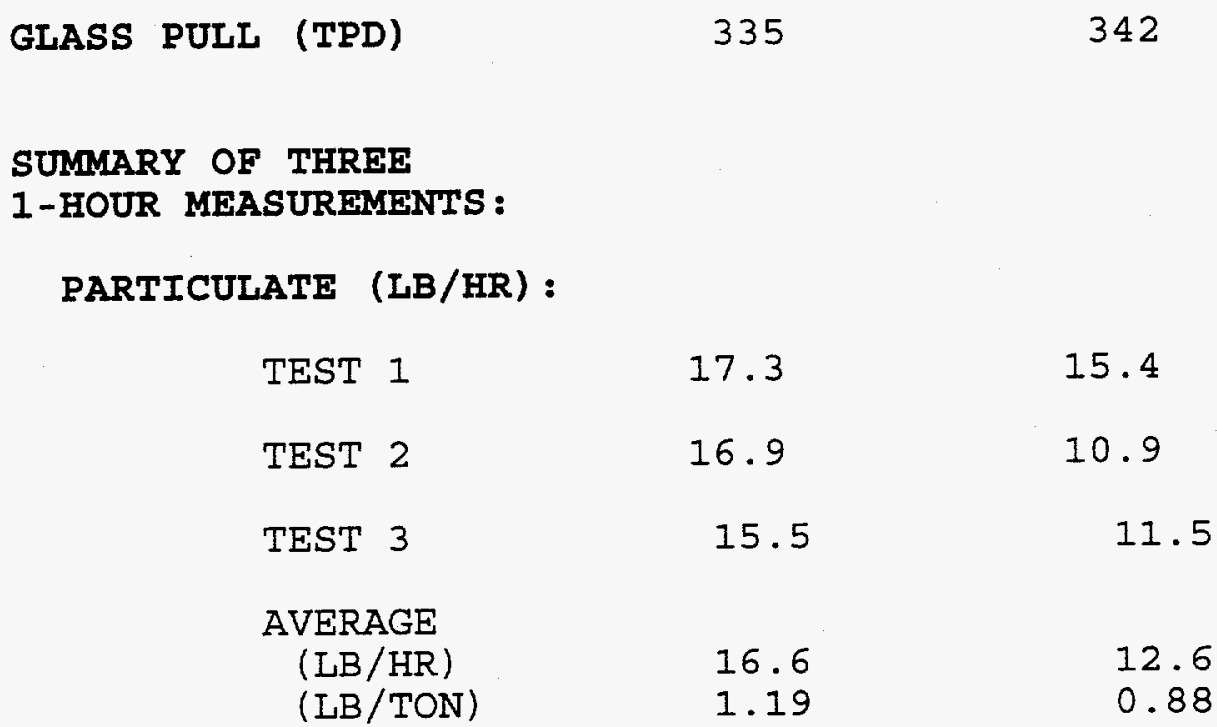

The particulate emissions reduction achieved at Gallo is in general agreement with predictions of the volatilization study referenced in section 4.3.4.2. However, the model suggests the reduction might have been greater if the burners were located further from the glass surface, lowering peak glass temperatures and gas velocities at the glass surface. However, no attempt was made to test this proposition, or to determine what tradeoffs (such as higher peak refractory temperatures) might be required to achieve still lower particulate emissions.

\subsubsection{Carbon Monoxide and $\mathrm{SO}_{2}$ Emissions}

Carbon monoxide and sulfur dioxide emissions measurements are summarized in Table X. As indicated, $\mathrm{CO}$ emissions decreased on average following conversion to $100 \%$ OEC. 
In contrast to other emissions, $\mathrm{SO}_{2}$ emissions from Gallo melter \#1 increased an average of 10 percent from baseline levels following conversion to $100 \%$ OEC. This increase may be related to the observed reduction in particulate emissions. (Particulate and $\mathrm{SO}_{2}$ emissions were measured on consecutive days). Sodium hydroxide present in the flue gases reacts with a portion of the available $\mathrm{SO}_{2}$ to form sodium sulphate particulate. The reduction in particulate emissions following $100 \%$ OEC conversion indicates less sodium hydroxide was present, which would result in a lower consumption of $\mathrm{SO}_{2}$ by this reaction. More specifically, particulate emissions were reduced by about 4 pounds per hour following conversion to $100 \%$ OEC. Assuming most of this particulate was sodium sulphate, the sulfur content of this reduced emission was likely in the range of 0.7 to 0.8 pounds per hour. This matches well with the 1 to 2 pound per hour $\mathrm{SO}_{2}$ emissions increase observed, the sulfur portion of which would be 0.5 to 1.0 pounds per hour.

TABLE $\mathrm{X}$

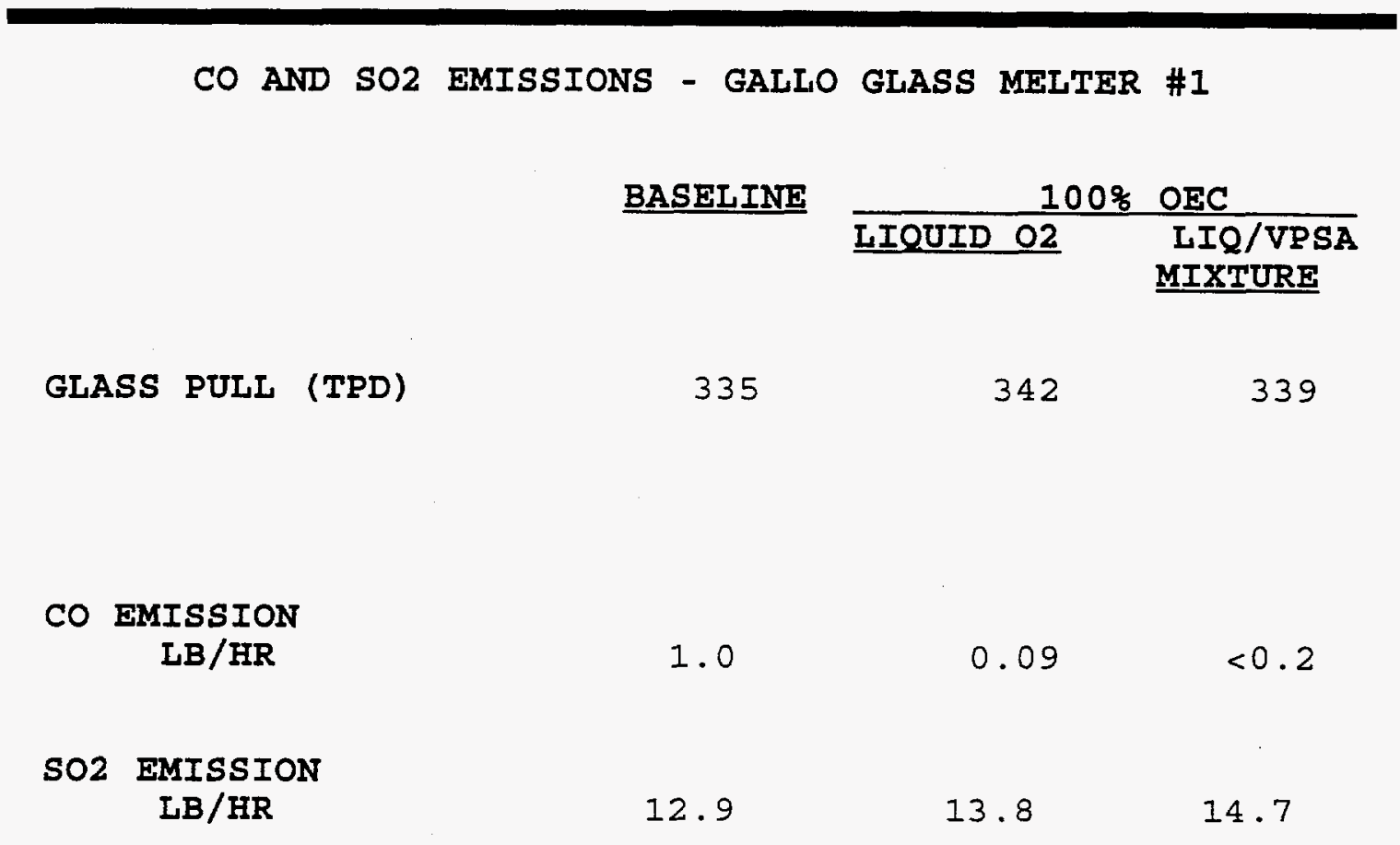


A reduction in sulfur retention by the glass would also contribute to increased $\mathrm{SO}_{2}$ emissions, by the necessary data to evaluate whether such a change occurred was not collected as part of this project.

\subsection{Burner Performance}

The oxy-fuel burners supplied by Corning for melter \#1 at Gallo operated the first two years of the oxy-fuel melting campaign without maintenance or any signs of deterioration to the burners or burner blocks. Based on these observations, the burners are expected to last the entire melting campaign without any major maintenance requirement.

\subsection{VPSA Oxygen Supply System}

A key objective of Phase II was to demonstrate the capabilities of a large scale PSA system, and in particular, to show that the power requirements and costs were as projected in Phase I. Specific goals were:

1. Verify that an advanced PSA system can reliably supply oxygen at a low energy consumption rate of less than $350 \mathrm{kwh} /$ ton of equivalent pure oxygen produced.

2. Demonstrate that large PSA systems will result in significantly lower power draw and product cost as a result of their attractive economies of scale.

The objective was to demonstrate the above on a plant that required a minimum of 20 tons per day of oxygen, and install and run the plant after the furnace had operated on liquid oxygen for a few months test period.

\subsubsection{Process Description and Plant Design}

The basis of Praxair's advanced PSA technology and what makes it leading state of the art is inherent in two aspects of its design: 
1. The adsorbent used is highly efficient with over twice the separating capability of other PSA oxygen adsorbents on the market. It was developed specifically for air separation.

2. The Vacuum/Pressure Swing Adsorption (VPSA) cycle employed makes optimum use of the advanced adsorbent to lower power draw and product cost.

The adsorbent and cycle directly result in low power draw. Additionally, the high efficiency of the adsorbent allows plants that are much smaller with fewer vessels and valves than today's typical PSA/VSA systems. This also allows a high degree of prepackaging which reduces installation time and costs. Overall, the combination allows for highly efficient operation while minimizing installation and operating complexity.

The oxygen enriched air production system demonstrated in Phase I of this project by Praxair was scaled up from 1 ton per day to over 50 tons per day and a pair of units were built and installed at Gallo. The first major task was to design this scaled up system. This included process design, equipment selection, control systems design, computerization, and overall system optimization.

Figure 19 shows a schematic of a VPSA system. The major equipment includes the feed air blower, vacuum pump, vessels with sieve, motors and motor control center, valve skid, and product compressor (when required). During process sequencing, the two adsorption vessels operate $180^{\circ}$ out of phase. While one vessel is on a pressure adsorption step to produce high purity oxygen, the remaining vessel undergoes regeneration to remove previously adsorbed materials from the adsorbent. 


\section{OxyGEN ${ }^{T M}$ VPSA System}

ज

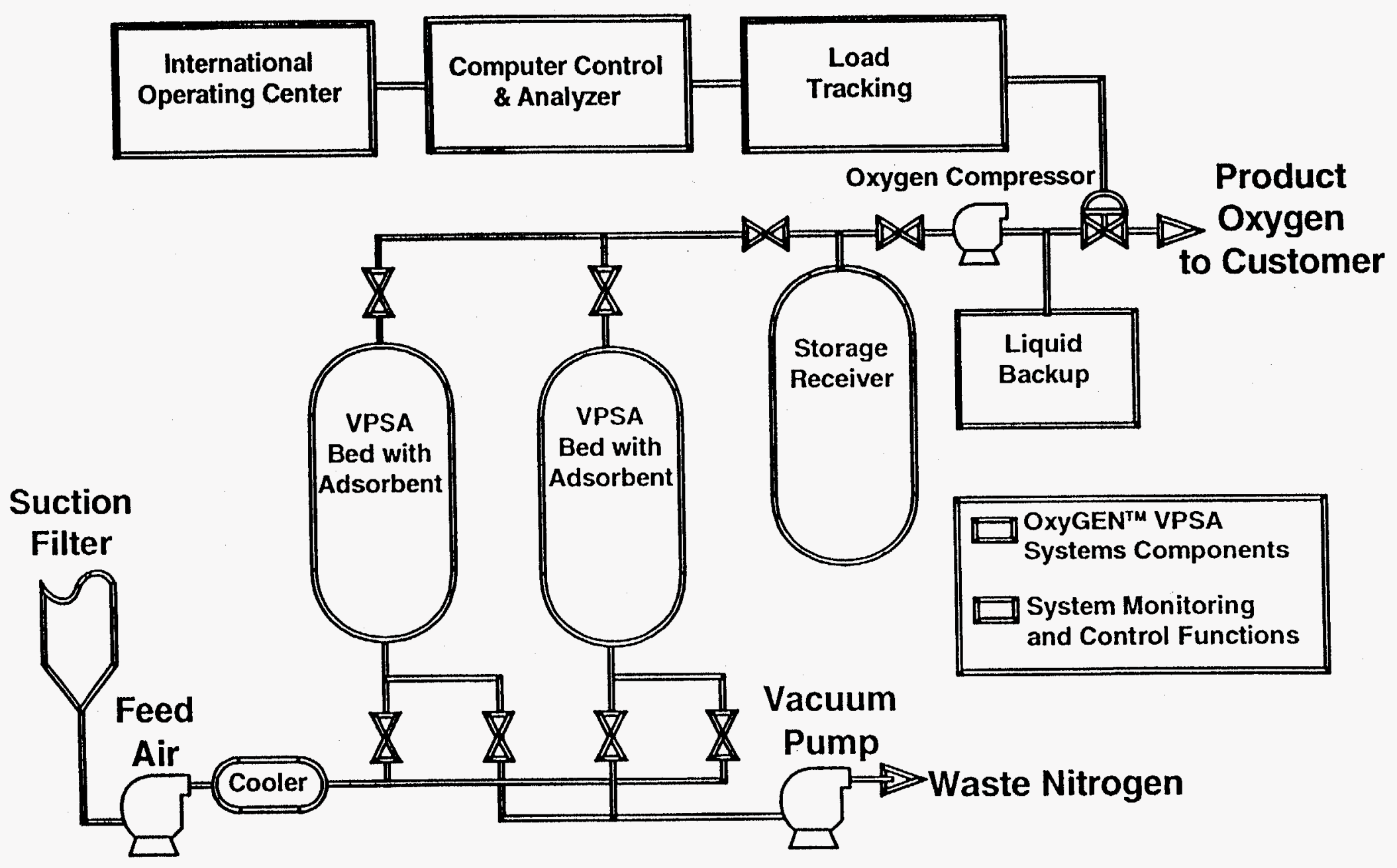


The adsorption step takes place at elevated pressures with feed air supplied by the feed blower. During adsorption nitrogen, water, and carbon dioxide are preferably adsorbed, while the majority of oxygen and argon pass through the vessel along with a small quantity of nitrogen. This oxygen product gas undergoes only a small pressure loss during the step, thereby entering the product surge tank at pressures near the adsorption pressure.

Regeneration occurs at reduced pressures, with this pressure reduction resulting in previously adsorbed nitrogen, water, and carbon dioxide being stripped from the adsorbent material. Utilization of a vacuum pump results in enhanced regeneration and therefore, utilization of the adsorbent, resulting in maximum process performance. Discharge of the vacuum pump is directly to the surroundings.

Duration of the adsorption/regeneration steps is monitored by a process controller, with the desired step time inputted to the controller. Following the termination of a step, the controller adjusts the process valves, such that the vessel previously on adsorption now undergoes regeneration, and the second vessel undergoes adsorption.

The oxygen product is provided automatically on demand to the customer from the product purge tank. It is delivered directly to the customer use point if low pressure is required ( $<5$ psig) or through a product oxygen compressor if higher pressure is required.*

The design and selection of all plant components must factor in initial costs as well as on-going operating costs, particularly energy costs. The feed blower and vacuum pump, for example, have a number of commercial options to meet the flow and pressure

* The oxygen supplied to the Gallo plant was at a pressure of 20 to $25 \mathrm{psig}$, so a compressor was required. 
requirements of the process. Options include centrifugal and reciprocating type machines as well as Roots type blowers. Considering the dynamic nature of the VPSA cycle, positive displacement machines offer significantly improved efficiency over centrifugal machines. When comparing positive displacement machines, Roots type blowers are lower cost, easier to install, and require less maintenance over the long term. For vacuum service the Roots type blower can be water sealed which results in about $20 \%$ lower energy requirement than "dry" operation. The major disadvantage of the blowers is that they require more "noise treatment" than the other options. Overall the optimum choice is the Roots type blowers.

The rest of the equipment must also be designed with consideration for the trade-off between initial cost and power cost. For example, vessels, piping and valves are optimized considering the impact of pressure drop on system efficiency.

The control system is designed for unattended operation with the capability to remotely monitor and control the plant. Another key component for reliable operation is the design of the automatic valves. This dynamic process requires control valves that can withstand high cyclic service (over 1 million cycles per year). Complete valve assemblies solenoids, actuators, and butterfly valves are selected on that basis.

The overall optimization of the Gallo VPSA system included the final selection of the process, equipment, and controls to ensure the lowest cost product considering the customer's availability of utilities and the final product requirements (i.e. pressure). This optimization included consideration for operating costs (i.e. power) as well as initial cost of the equipment and installation. 


\subsubsection{Installation and Start Up}

The installation phase of the project included plant packaging and detail construction design as well as the actual installation. Each 55 ton per day VPSA plant was prepackaged in five skids to minimize the field construction time and cost. As shown in Figure 20 the packages were broken down as follows: feed blower skid, process skid, vacuum blower skid, auxiliary skid, and the electrical skid. The packages were designed with detailed piping, tubing and wiring done to minimize those activities in the field.

Other detail design activity was completed in the control systems area such as wiring schematics, panel designs, and process and instrumentation drawings. The construction package then was completed including civil, mechanical, and electrical drawings and specifications. At the end of the detail design stage "Design Safety Checklists" are completed to ensure that the design met all applicable safety standards.

The construction package was released for bidding purposes and a qualified contractor was selected to assemble and install the VPSA System at Gallo. Praxair provided on-site construction assistance throughout the mechanical and electrical installation. During this time, a number of quality assurance and safety checks were made as the plant was being built per Praxair's quality work process. At the completion of the construction phase the plant was functionally checked out to ensure all systems would perform as intended. Because the plant was highly prepackaged, the time to install the two plants was reduced significantly from plants that were not prepackaged. 

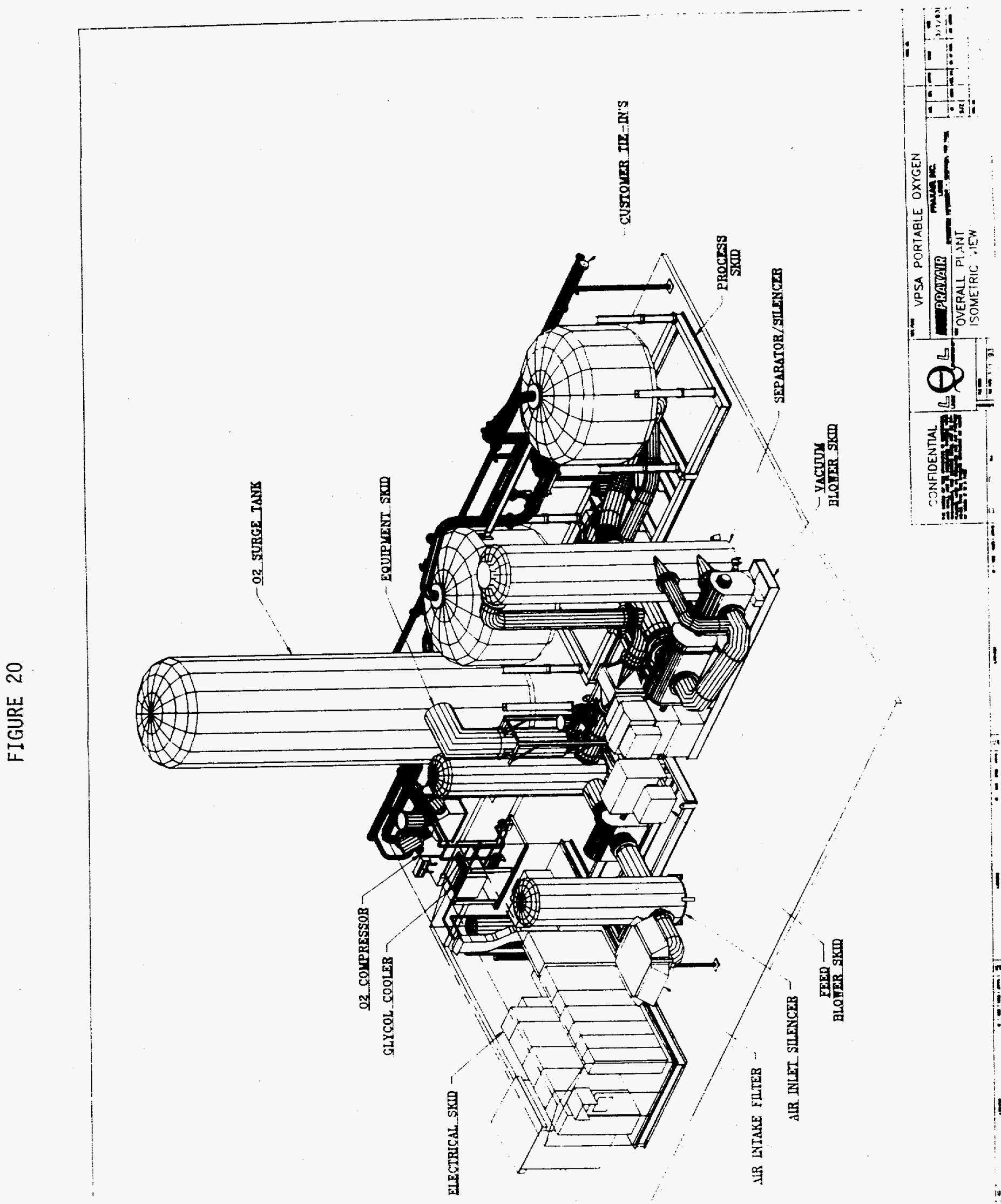
After completion of the functional systems checks, including run-in of the feed blower and vacuum pump, the VPSA process skid was started and cycle adjustments made to optimize performance. Mechanically and VPSA process wise, the plant start-up went smoothly, however, a problem encountered at this time was the noise from the plant. Although it was anticipated that the plant would be "noisy",it is an unattended facility, and given its location within the Gallo plant boundaries, it was not expected to be a problem for people at the plant, in the community or for Praxair personnel. The noise characteristics were, however, a problem for some members of the Modesto community. Praxair worked with Gallo to develop and agree upon noise treatment required to satisfy the neighboring community. After the noise treatment was completed, the plant was put on-stream around the clock to provide oxygen for the Gallo furnaces.

The plants operate automatically with the capability to remotely monitor performance. The plant computer can provide instantaneous information on flows, purity, temperatures, pressures, etc., or historical information such as hourly or daily averages. This information is also very valuable for troubleshooting to pinpoint problems after they happen (i.e. the historical data) or for anticipating potential problems (i.e. instantaneous information).

\subsubsection{VPSA Plant Performance.}

After the VPSA plant had been operated for a few weeks, a detailed performance test was conducted to measure product oxygen flow, purity, and total system power draw for one of the 55 ton per day plants. Table XI lists of the instrumentation used to collect the data. Two test runs were made and are summarized in Table XII. The single plant 


\section{YPSA PERFORMANCE TEST INSTRUMENTATION}

\section{COMPONENT}

1. Servomex Oxygen Analyzer

2. Orifice Plates

3. Rosemount Pressure Transmitter

4. Rosemount Differential Pressure Transmitter

5. Omega Thermocoupies

6. Dranatz Power Demand Analyzer

7. Potential Transformer

8. Current Transformer

9. Plant Control Computer

\section{DESCAIPTION}

Model: OA 272

Range: $0-100 \% \mathrm{O}_{2}$

Daniel Flow Tube/

Orifice

Model: 1151 \&

Model: 2044

Model: 1151 \&

Model: 2088

Models: CASS-18

Model: 808 with Isolated CT Terminations

GE-643X92

GE-750410G353

Analog Devices-input cards Octagon Systems Corp. -

Basic Programming

- Flow Computer

- Data Recorder
EXPECTED

ACCURACY

$0.5 \%$

$2 \%$

$0.5 \%$

$0.5 \%$

$1 \%$

$2 \%$

$.3 \%$

$.6 \%$

$.5 \%$

\section{CALBRATION}

By Praxair Technology Center
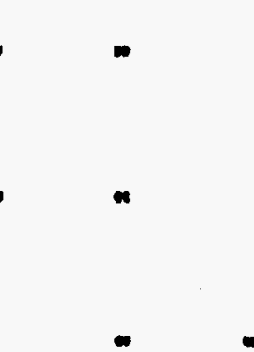

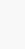

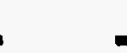

At Factory

At Factory

At Factory

By Praxair Technology Center 


\section{TABLE XII. VPSA PERFORMANCE TEST SUMMARY}

TEST \#1

TOTAL GAS FLOW (NCFH)

PRODUCT PURITY (\% O2)

TOTAL OXY FLOW (TPD)

TOTAL POWER DRAW $(\mathrm{kW})$

ENERGY (kWh/TON O2)
64160

90.24

57.55

776

323
TEST \#2

61370

90.32

55.1

739

322 
produced 55 to 58 tons per day of contained oxygen at 90 to $91 \%$ purity and at an electrical power demand of 320 to $325 \mathrm{kwh} /$ ton of oxygen. It is important to note that the addition of silencers on the plant to solve the noise problem added 10 to $15 \mathrm{kwh} / \mathrm{ton}$. The silencers add pressure drop in the system which equates to more work by the feed blower and vacuum pump to overcome this added drop. Without the silencers the power draw would be approximately $310 \mathrm{kwh} / \mathrm{ton}$. Subsequent plants have been designed to minimize the effect of noise attenuation on power draw based on the knowledge gained on this project.

Due to the success of the use of oxygen in combustion, the market for VPSA systems for this application has grown rapidly. Since the DOE/Gallo project was started, a number of other VPSA/combustion projects have been successfully completed, allowing the impact of various operating variable of power consumption to be assessed. Electrical power draw for these plants has varied from $250 \mathrm{kwh} /$ ton to $320 \mathrm{kwh} /$ ton depending on the oxygen supply pressure and the noise attenuation required. The higher the oxygen pressure requirement, the higher the power draw, and resultant oxygen cost (see Figure 21). The oxygen pressure requirement at the inlet to Gallo's distribution is 20 to 25 psig. If lower pressure can be used (i.e. 5 psig), then the power draw would be 30 to $40 \mathrm{kwh} /$ ton lower. The lowest power requirement achieved (i.e. $250 \mathrm{kwh} /$ ton) reflects a 5 psig system with the latest technology advances. The number is continuing to fall as new adsorbents and cycles are developed.

In the Phase I report, the economics of larger scale VPSA system was projected to be as depicted in Figure 22. It was recognized that the cost of oxygen $(\$ /$ ton) would decrease significantly as the plant size was increased above 1 ton per day. Specifically, it was projected that costs would go from about $\$ 100 /$ ton to less than $\$ 50 /$ ton. At the low specific 


\section{Effect Of Product Pressure On Product Cost}

VPSA Systems

$\infty$ Relative Product Cost

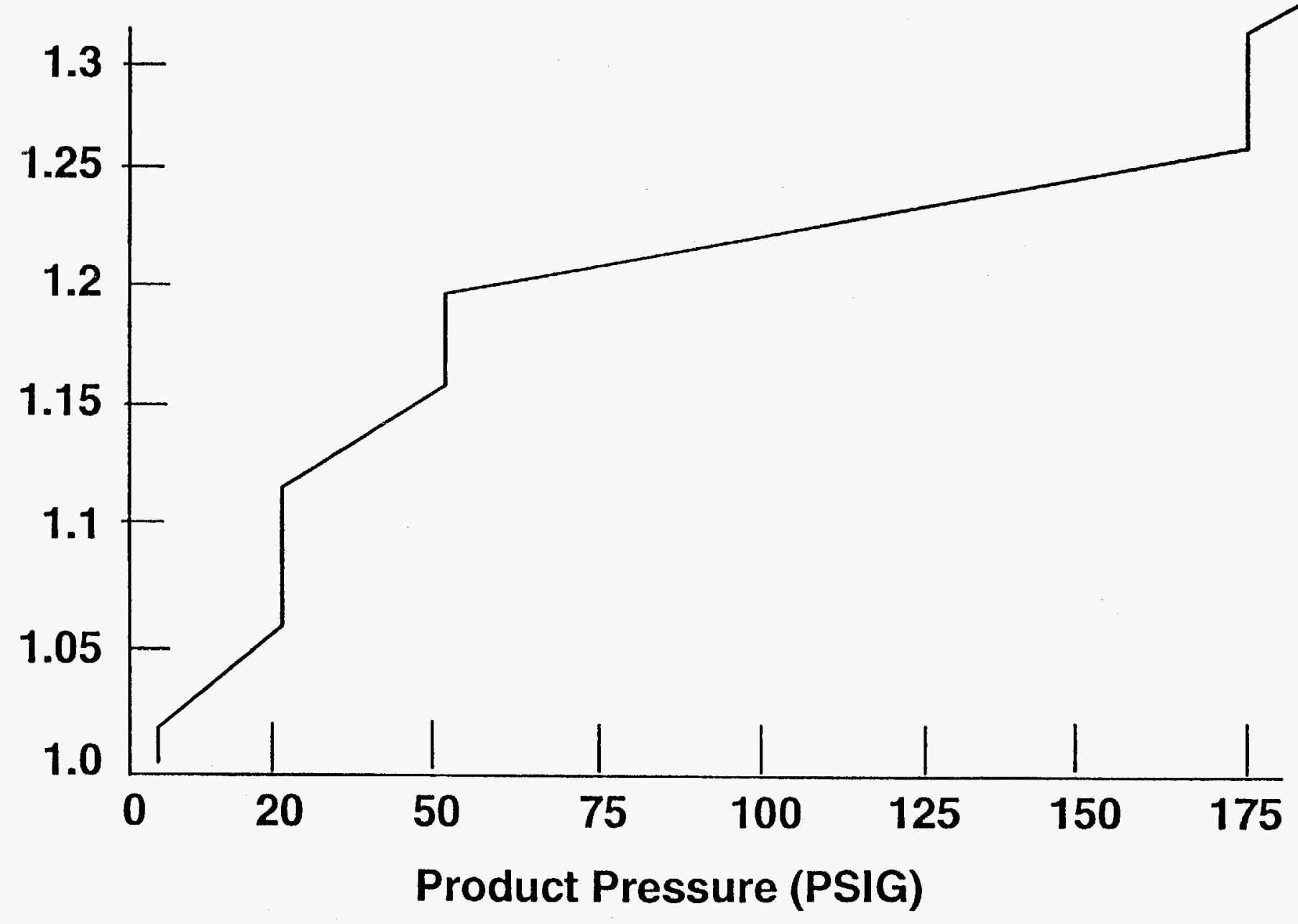




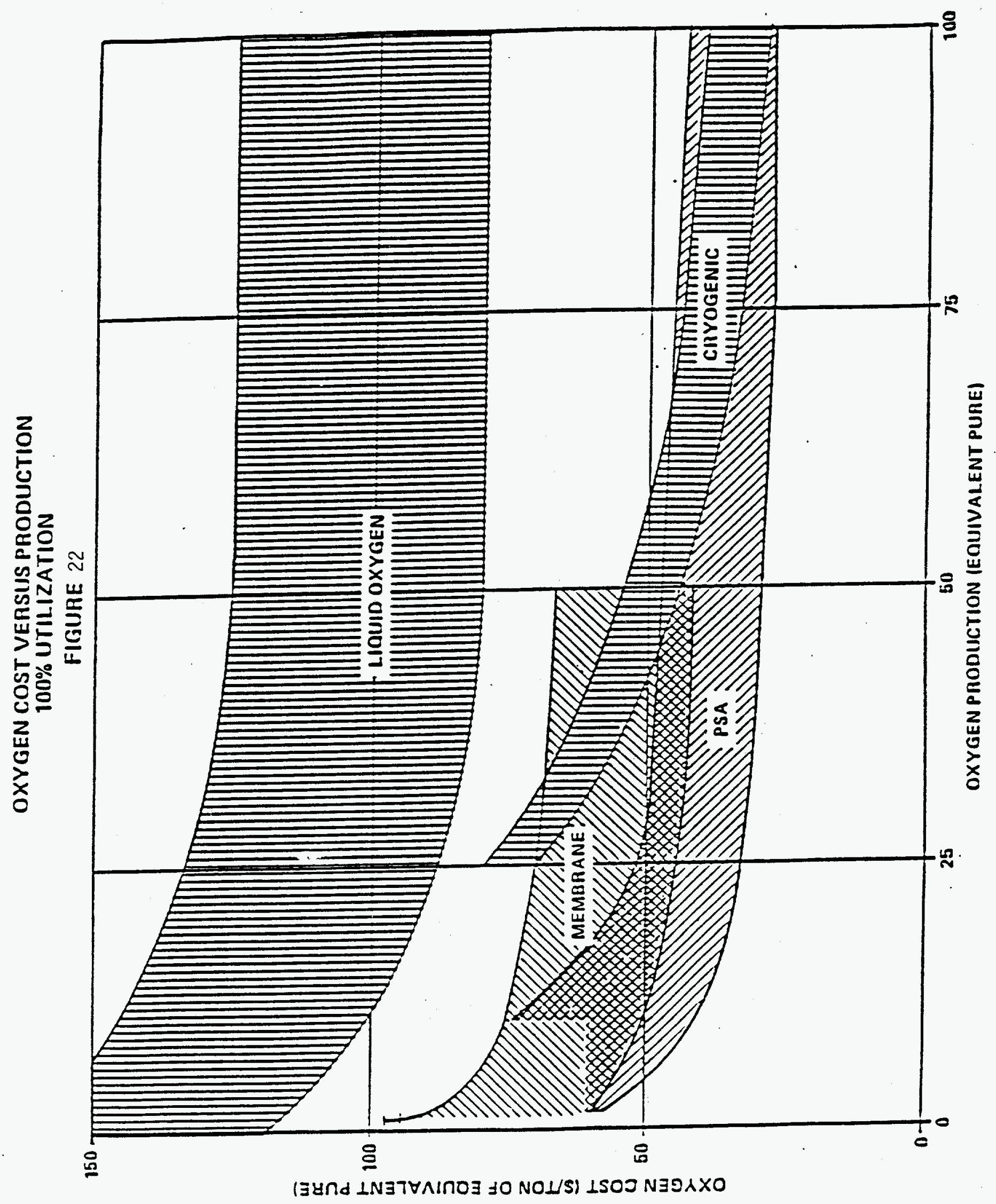


power requirements described above, VPSA oxygen can typically be supplied today at a cost of $\$ 30$ to $\$ 35 /$ ton, which is at the bottom edge of the original projections per Figure 22 . Typically, about $40 \%$ of the cost is for power. As seen from the results, scale-up of the VPSA oxygen system has resulted in a low cost method to produce oxygen at the customer's site.

\subsection{ENERGY IMPLICATIONS AND ECONOMICS OF REGENERATIVE MELTER CONVERSION TO $100 \%$ O.E.C.}

\subsection{Energy Implications}

The energy performance comparisons conducted at Carr-Lowrey and Gallo indicate that the energy consumption of a regenerative glass melter can be reduced by conversion from regenerative firing to $100 \%$ OEC. However, the production of oxygen for $100 \%$ OEC melting requires electrical input, which in turn requires consumption of fuel at an electric power plant. Therefore, a broader, "back to the power plant" analysis must be performed to determine the overall energy impact of regenerative melter conversions to $100 \%$ OEC.

Whether or not overall energy consumption is reduced by a particular glass melter conversion will depend on numerous factors. First of all, the energy requirements for baseline regenerative operation can vary greatly depending on factors such as the heat recovery effectiveness of the regenerators, glass pull per unit hearth area, oxidant:fuel ratio settings and accuracy of ratio control, and the amount of electric boost utilized. Some of these factors, as well as others such as oxygen plant energy efficiency and oxygen supply pressure, will also affect the overall energy requirement for oxy-fuel melting.

Conversion to $100 \%$ OEC potentially allows different melting strategies to be 
employed that can affect overall energy consumption. For example, electric boost is used in regenerative melters to achieve increased pull without increasing refractory temperature, or to maintain a given pull at lower firing rate and glass surface temperature in order to comply with air emissions regulations. Auxiliary oxy-fuel burners have been used in regenerative glass melting to achieve significant pull increases without increasing electric boost or crown temperatures (13). This was done by taking advantage of increased flexibility in locating and orienting oxy-fuel burners to optimize heat release patterns and accelerate batch melting. Although not demonstrated in this project, it should be possible to incorporate these same firing strategies into $100 \%$ OEC operation, lessening the need for electric boost. Additionally, the reduced $\mathrm{NO}_{\mathrm{x}}$ and particulate emissions rates achieved with $100 \%$ OEC operation lessen the need for electric boost to achieve compliance with environmental regulations.

With these considerations in mind, Table XIII presents an analysis of the overall energy requirements of a generic 300 TPD container glass melting operation, comparing several cases of regenerative and oxy-fuel operation. Two base cases are presented: a regenerative melter operating with electric boost of $0.5 \mathrm{MMbtu} / \mathrm{ton}$, and fuel input of 3.7 MMbtu/ton (case 1), and an unboosted regenerative melter with a specific fuel consumption of $4.45 \mathrm{MMbtu} / \mathrm{ton}$ (case 2). Contrasted to these are 2 oxy-fuel melting cases: a melter with electric boost of $0.4 \mathrm{MMbtu} / \mathrm{ton}$, and fuel input of $3.35 \mathrm{MMbtu} / \mathrm{ton}$ (case 3), and an unboosted melter operating at $3.95 \mathrm{MMbtu} / \mathrm{ton}$ (case 4). The percentage melter energy savings achieved with $100 \%$ OEC reflected in these various cases is in line with the savings observed at Gallo and Carr-Lowrey. 
TABLE XIII. GLOBAL ENERGY ANALYSIS

300 TPD CONTAINER GLASS OPERATION

\begin{tabular}{|c|c|c|c|c|c|}
\hline & CASE 1 & CASE 2 & CASE 3 & CASE 4 & CASE 5 \\
\hline OXIDANT: & AIR & AIR & OXYGEN & OXYGEN & $\begin{array}{l}\text { OXYGEN } \\
\text { (WITH BATCH/ } \\
\text { CULLET PREHT }\end{array}$ \\
\hline ELECTRIC BOOST? & YES & No & YES & NO & NO \\
\hline GLASS PULL (TPD): & 300 & 300 & 300 & 300 & 300 \\
\hline $\begin{array}{l}\text { NOX EMISSIONS } \\
\text { (LB/TON GLASS) }\end{array}$ & $3-6$ & $4-6$ & $0.6-1$ & $0.6-1$ & $0.5-0.8$ \\
\hline
\end{tabular}

MELTER ENERGY:

(MMBTU/TON)

$\begin{array}{llllll}\text { FUEL } & 3.70 & 4.45 & 3.35 & 3.95 & 3.20 \\ \text { ELECTRIC } & 0.50 & 0.00 & 0.40 & 0.00 & 0.00\end{array}$

OXYGEN (TPD)

$0 \quad 0$

83.8

98.8

80.0

"GLOBAL" ENERGY ANALYSIS

ELECTRICITY (kWh/DAY)

MELTER

OXYGEN PROD'N

$\begin{array}{rrrrr}43950 & 0 & 35160 & 0 & 0 \\ 0 & 0 & 22194 & 26169 & 21200 \\ 43950 & 0 & 57353 & 26169 & 21200\end{array}$

TOTAL ELEC.

43950

448

585

267

216

FUEL FOR ELECTI
PRODUCTION (*)

(MMBTU/D)

o

267

1110

1335

1005

1185

960

TOTAL FUEL CONSUMPTION

(MMBTU/DAY)

1558

1335

1590

1452

1176

RELATIVE FUEL

REQUIREMENT:

BASE

$86 \%$

$102 \%$

$93 \%$

$75 \%$

* Assumes 10,200 Btu power plant fuel input per kWh of electric output. 
It is important to note that cases 1 through 4 in Table XIII compare air-fuel cases in which a large portion of exhaust gas energy is recovered to preheat combustion air, to oxy-fuel cases with no heat recovery from the melter exhaust gases. Over $1 / 3$ of the fuel energy input to an oxy-fuel melter is carried away by exhaust gases. About three-fourths of this is sensible heat that typically leaves the melter at a temperature of 2650 to $2750^{\circ} \mathrm{F}$. Case 5 in Table XIII represents a hypothetical oxy-fuel firing case where a portion of this exhaust gas energy is used to preheat batch and cullet to $700^{\circ} \mathrm{F}$ before charging them to the melter. While batch/cullet preheating can also be applied to regenerative melters, it is not as economically attractive, since fuel savings alone are achieved. Batch/cullet preheating applied to an oxy-fuel fired melting results in oxygen savings roughly equal in dollar value to the value of the fuel savings.

Comparison of cases 1 through 4 in Table XIII shows that, if electric boost usage is unchanged following conversion to oxy-fuel operation, the fuel savings in the melter will typically be insufficient to balance increased power plant fuel input for oxygen production. However, an electric boost reduction of about $0.1 \mathrm{MMbtu}$ per ton of glass results in a roughly "break even" energy comparison between regenerative and $100 \%$ OEC operation, and deeper boost reductions result in a clear overall energy advantage for $100 \%$ OEC. Batch and cullet preheating combined with oxy-fuel firing results in a 12 to 25 percent reduction in overall energy requirement relative to air-fuel firing.

\subsection{Economics of Melter Conversion}

The comparative economics of converting to $100 \%$ OEC versus other options varies with the specific circumstances and timing of a proposed conversion, and must be evaluated 
on a case by case basis. Still, a generic analysis sheds light on the relative importance of various factors affecting the economics of $100 \%$ OEC.

An economic analysis of regenerative air-fuel fired glass furnaces and oxy-fuel fired furnaces was conducted for a generic $300 \mathrm{TPD}$ container melter. The analysis takes as a starting point an existing melter approaching the end of its campaign, and evaluates various rebuild, retrofit, and replacement options. The following cases were analyzed, using specific energy consumption values from the previous section where applicable:

1. Rebuild melter for regenerative air-fuel firing, without stack gas treatment for emissions abatement, and with electric boost. Minimum achievable $\mathrm{NO}_{\mathrm{x}}$ emissions is 3 to 4 pounds per ton, and emissions are typically higher. This could result in noncompliance with regulations in some jurisdictions before the end of the melting campaign.

2. Rebuild melter for $100 \%$ OEC operation, without $\mathrm{NO}_{\mathrm{x}}$ emissions abatement, and with 20 percent electric boost reduction. $\mathrm{NO}_{\mathrm{x}}$ emissions of 0.6 to $1 \mathrm{lb}$ per ton achievable, depending on burner design and application.

3. Rebuild melter for $100 \%$ OEC operation, with electric boost eliminated. $\mathrm{NO}_{\mathrm{x}}$ emissions of 1 pound or less per ton of glass are achievable.

4. Rebuild melter for regenerative air-fuel firing, with added investment for Selective Catalytic $\mathrm{DENO}_{\mathrm{x}}$. This option is analyzed, even though there are serious technical obstacles to SCR's applicability to glass furnaces. Various reports have indicated that, at a minimum, an electrostatic precipitator is required upstream of the deNO $\mathrm{x}_{\mathrm{x}}$ system, and that even with this precaution the SCR catalyst is gradually "poisoned" by volatiles in the melter exhaust 
gases, reducing its effectiveness (14). If this problem can be solved, $\mathrm{NO}_{\mathrm{x}}$ emissions below $1 \mathrm{lb}$ per ton should be achievable.

5. Replace the existing melter with a new electric melter. This would essentially eliminate $\mathrm{NO}_{\mathrm{x}}$ emissions.

Table XIV shows the capital outlays required for each case, for the initial and subsequent rebuilds respectively. These costs are based on estimates provided to Praxair by glass furnace engineering companies for the glass tank itself, and on Praxair's own estimates of oxy-fuel equipment costs. The cost of an initial conversion to $100 \%$ OEC operation is about $\$ 1.3 \mathrm{MM}$ less than rebuilding for conventional firing due to elimination of regenerators. This cost difference increases to $\$ 5.5 \mathrm{MM}$ if investment if a deNO $\mathrm{x}_{\mathrm{x}}$ system is required to meet $\mathrm{NO}_{\mathrm{x}}$ emissions requirements with air-fuel firing.

The cycle times for furnace and regenerator rebuilds are also listed in Table XIV. For the regenerative melter, the melter and regenerator rebuild cycles are assumed to be 7 and 14 years, respectively. The rebuilding cycle of the oxy-fuel furnace is assumed to be the same as the air furnace. A 3 year rebuild cycle is assumed for the electric melter.

Since capital and operating costs vary substantially over time for the different cases evaluated, Net Present Value (NPV) analyses were conducted from year 0 to year 20 to compare relative economics. Details of the NPV calculations at a discount rate of $15 \%$ are presented in Table XV.

At year 0 the initial rebuild or furnace replacement cost is charged. A rebuild period of 30 days is assumed, and entered in year 1 . Annual utility costs" are calculated based on 365 days minus the rebuild period. Annual maintenance and insurance costs are included, and assumed to equal $3 \%$ of the initial capital investment. The amount of the initial capital 
TABLE XIV. REBUILD COSTS - 300 TPD CONTAINER GLASS FURNACES

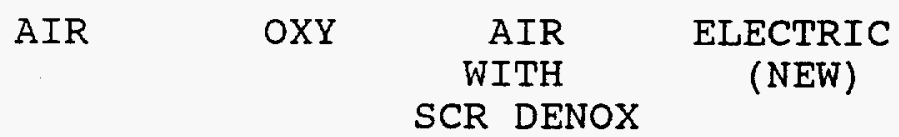

INITIAL REBUILD

SUSPENDED CROWN

MELTER / REFINER

PORTS

REGENERATOR

STRUCTURAL STEEL

CHARGER/INJECTOR

BURNER/COMBUSTOR

FLUE / STACK

ELEC \& CONTROL

COOLING

ENGINEERING

WATER \& AIR

E.P. \& SCRUBBER

DE-NOX SYSTEM

CATALYST

735

350

1,350

50

30

30

40

45

20

120

5

SCR DENOX

TOTAL $(\$ 1,000)$

SUBSEQUENT REBUILDS

SUS. CROWN

MELTER / REFINER

PORTS

REGEN (EVERY OTHER REBUILD)

STRUCTURAL STEEL

CHARGER/INJECTOR

BURNER/COMBUSTOR

FLUE / STACK

ELEC \& CONTROL

COOLING

ENGINEERING

WATER \& AIR

E.P. \& SCRUBBER

DE-NOX SYSTEM

CATALYST

TOTAL $(\$ 1,000)$

FURNACE REBUILD CYCLE (YR)

REGEN REBUILD CYCLE (YR)
$2,775 \quad 1,465$

6,975

4,050
140

2,000

1350

50

30

30

40

45

20

120

5

2250

1750

200
300

60

80

40

900

180

300

50 
NPV COST ANUYSIS 300 TPD CONTAIIER GLASS NELITERS

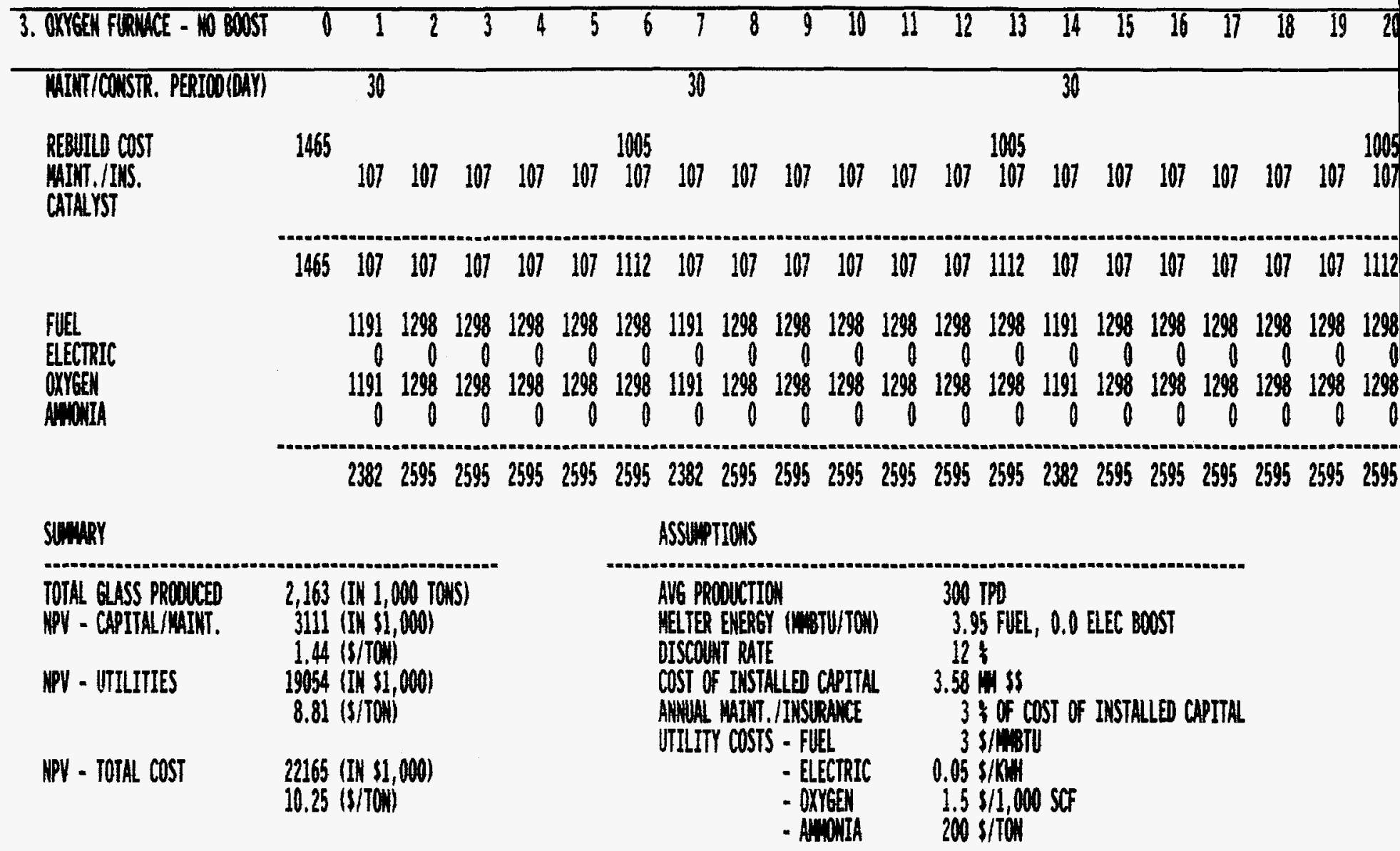

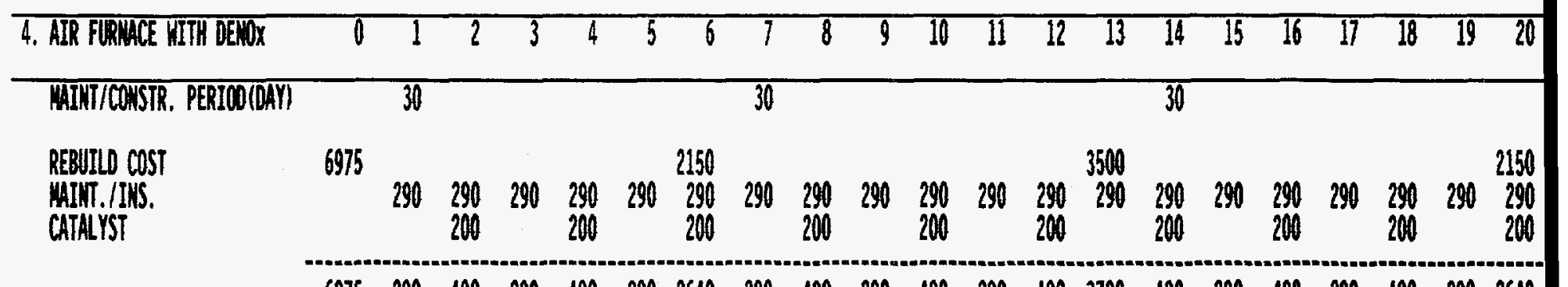

FUEL

ELECTRIC

OXYGEN

Amouith

$\begin{array}{lllllllllllllllllllll}6975 & 290 & 490 & 290 & 490 & 290 & 2640 & 290 & 490 & 290 & 490 & 290 & 490 & 3790 & 490 & 290 & 490 & 290 & 490 & 290 & 2640\end{array}$ 11161215121512151215121511161215121512151215121512151116121512151215121512151215 $\begin{array}{llllllllllllllllllll}736 & 802 & 802 & 802 & 802 & 802 & 736 & 802 & 802 & 802 & 802 & 802 & 802 & 736 & 802 & 802 & 802 & 802 & 802 & 802\end{array}$ $\begin{array}{llllllllllllllllllll}54 & 59 & 59 & 59 & 59 & 59 & 54 & 59 & 59 & 59 & 59 & 59 & 59 & 54 & 59 & 59 & 59 & 59 & 59 & 59\end{array}$

19062077207720772077207719062077207720772077207720771906207720772077207720772077

\section{SLIMARY}

TOTAL GLASS PROOCEED

NPV - CAPITAL/MAIT.

NPV - UTLLTIES

NPY - TOTAL COST
2.163 (IN 1,000 TONS)

11856 (I) 51,000$)$

$5.53(\mathrm{~s} / \mathrm{TON})$

15247 (IN S1, 000)

$7.05(5 / 70 N)$

27203 (IN 11,000$)$

$12.58(\mathrm{~s} / \mathrm{TOH})$

ASSHFTIIOAS

ANG PRowiction

MELTER ENERGY (METU/TON)

DISCOWIT RATE

COST OF INSTALED CAPTTAL

ANHAL MAIT./IKSLRAMCE

UTILITY COSTS - FUEL

- EIECTRIC

- OXYGEY

- Anvina
300 TPO

3.7 FUEL, 0.5 ELEC BOOST

124

9.65 iss

3 \& Of COST OF INSTALLE CAPITAL

3 s/mBTU

0.05 s/Rill

$1.5 \$ 11,000 \mathrm{SCF}$

$200 \mathrm{~s} / 7 \mathrm{~W}$ 


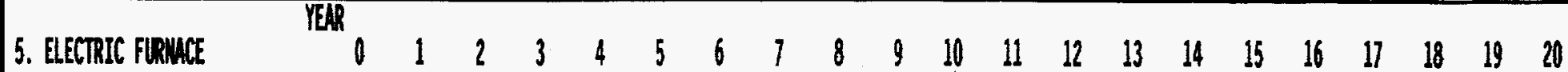

MITI/CONSTR. PERIOO(DAY)

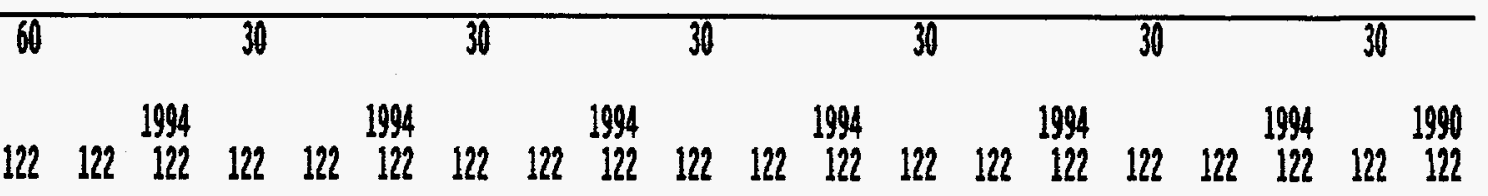

MINT.IIKS.

CATALST

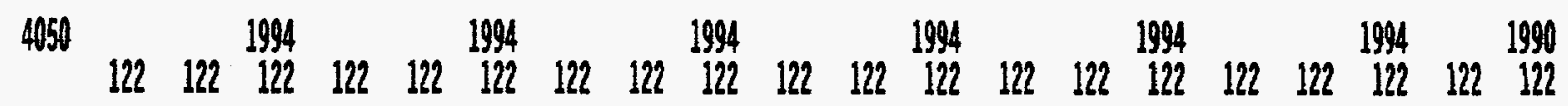

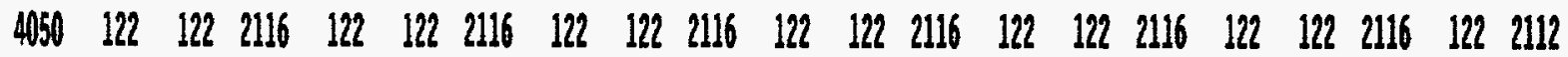

FUEL

ELECTRIC

OXYGEN

Awowith

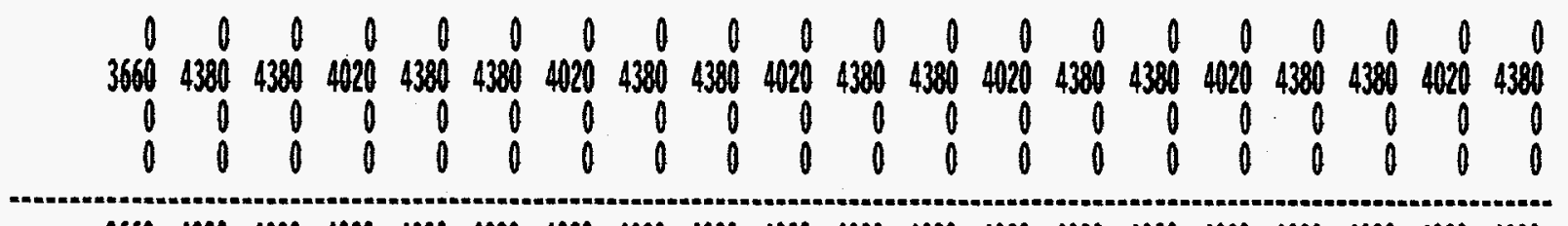

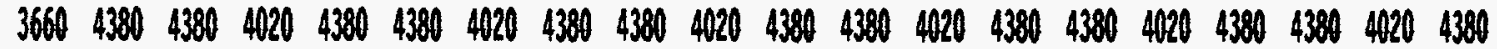

\section{Sumary}

ASSUPTITONS

TOTAL GLSSS PROCCED

NPV - CAPITAL/AIMT.

NPY - VITLITIES

NPY - TOTAL COST
2,118 (IN 1,000 TONS)

9448 (II) 31,000 )

4.46 (s/70N)

31383 (II \$1, 000)

14.82 (\$/TOW)

40831 (IN $\$ 1,000)$

$19.28(s / 70 \mathrm{~N})$
AVG PRDOUCTIION

MELTER ENERTY

ANUL MINT.IIISSDAACE

DISCOWHT RATE

UTILITY COSTS - FUEL

- ELECTRIC

- OXYGEN

- Amín
300 TPO

$800 \mathrm{Kh} / \mathrm{HON}$

3 i OF COST OF INSTALED CAPTTAL

$12 \%$

$3 \mathrm{~S} / \mathrm{MBT}$ TV

$0.05 \mathrm{~s} / \mathrm{KH}$

$1.5 \mathrm{~S} / 1,000 \mathrm{SCF}$

200 S/TOH 
investment for each case is listed in the assumptions section of each table, and is based on estimates from furnace engineering companies. These estimates reflect the total costs of installed capital, and exceed the rebuild costs listed in Table XIV.

The furnaces are rebuilt every seven years (three years for the electric melter) and regenerators are rebuilt every fourteen years. Overall cost outlays are projected in this way for 20 years and, assuming a discount rate of $12 \%$, the future costs are discounted and summed. The overall glass production and the costs as net present values are summarized. NPV costs per ton of glass are also calculated.

Results of the analysis are summarized in Figure 23. The following conclusions can be drawn from this economics study:

1. Substantial savings in furnace rebuild and fuel costs are achieved with oxy-fuel firing. However, the overall utility costs of oxy-fuel firing are higher than those of a regenerative furnace due to the additional cost of oxygen.

2. The NPV of the capital and operating costs of converting an existing regenerative melter to oxy-fuel firing is 10 to 20 percent greater than that of rebuilding the regenerative furnace without a deNO $\mathrm{x}_{\mathrm{x}}$ system. However, the oxy-fuel furnace typically reduces $\mathrm{NO}_{\mathrm{x}}$ emissions by $90 \%$ relative to regenerative operation.

3. The economics of retrofitting for oxy-fuel firing is about 10 to 20 percent better than that of rebuilding for regenerative firing with a catalytic deNO system designed for similar levels of $\mathrm{NO}_{\mathrm{x}}$ emissions.

4. Due to high operating cost of electric melting, replacing a regenerative melter with an electric melter is the most expensive option evaluated. 


\section{ECONOMICS - 300 TPD CONTAINER MELTER NPV ANALYSIS; 12\% DISCOUNT RATE; 20 YRS}

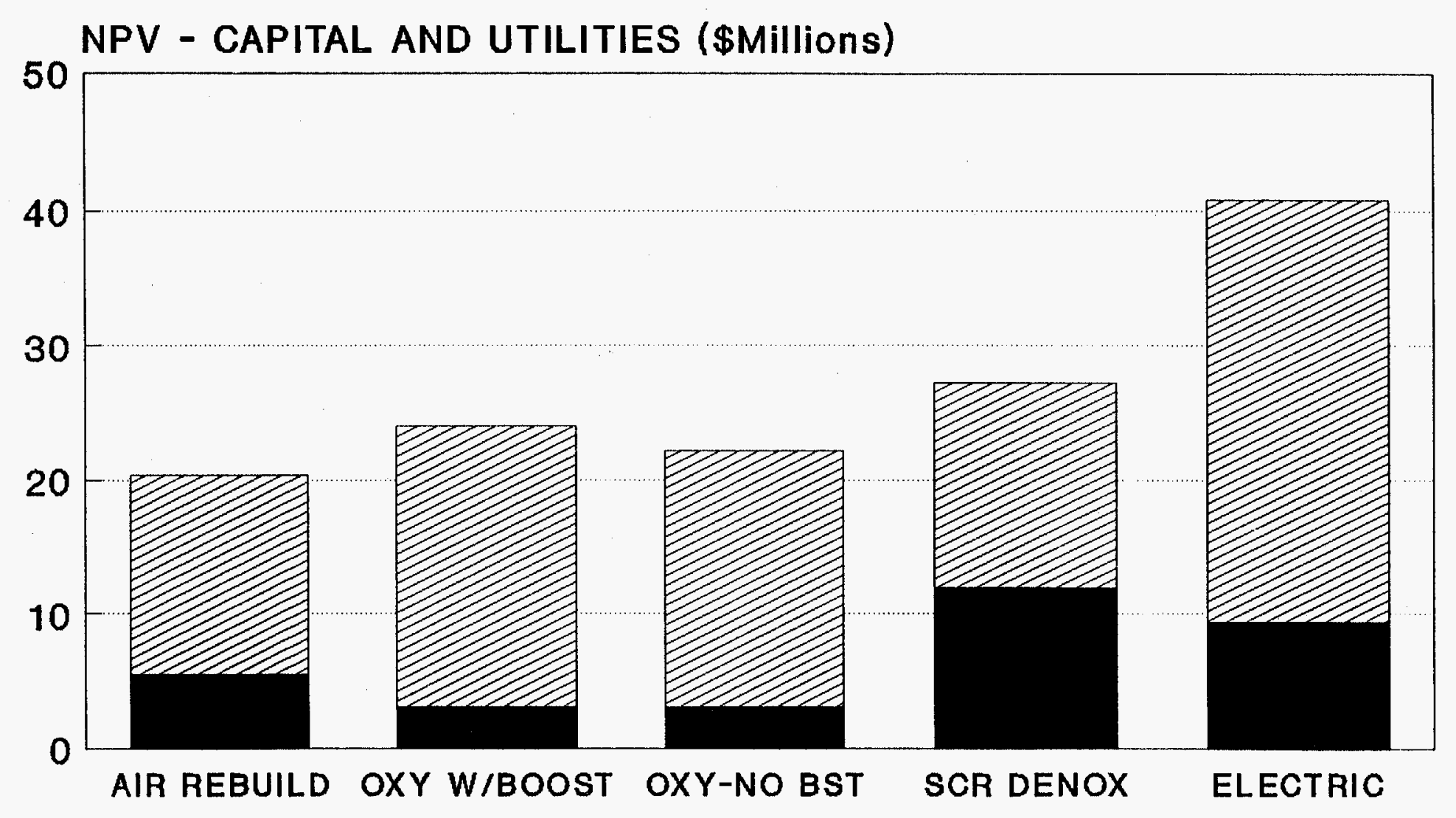

CAPITAL COST UTILITIES COST

FIGURE 23 


\subsection{COMBUSTION SPACE MODELLING}

\section{FURNACE THERMAL ANALYSIS AND VERIFICATION}

A furnace heat transfer model was employed during this project, first to model and verify results from pilot scale experimental furnaces, then to analyze flame characteristics and burner placement for glass furnaces, and finally to conduct full glass furnace performance modelling and verification.

The furnace model used was originally developed for boiler applications. In the first study it was modified for glass furnace conditions. In Phase I of this project, model predictions were verified against pilot scale test data taken from experimental furnaces. Good agreements were obtained and the results were reported elsewhere $(3,15)$.

A second study was conducted prior to field tests to analyze the effects of oxy-fuel burner flame characteristics and placement on furnace thermal conditions. A furnace end section which includes the bridge wall and a pair of regenerator ports was modelled in detail for a base air case and several oxy-fuel firing cases. The firing rates of two oxy-fuel burners that matched the heat flux distribution of the base air case were determined. The effects of the height and angle of the oxy-fuel burners on the temperature and heat flux distributions were predicted to evaluate the optimum burner placement of the oxy-fuel burners.

The main conclusions of the simulations were that; (1) in spite of the small flame diameters, the high momentum low flame temperature oxy-fuel burners can create temperature and heat flux distributions equivalent to those of the base air case with a wide flame and (2) both lower burner elevation and angling of the oxy-fuel burners toward the 
glass surface tend to increase heat transfer to glass surface and reduce the peak refractory temperatures. A detailed technical paper describing the model assumptions and results was presented previously and attached in Appendix A (16). The results of this study also provided the basis to develop general design considerations for oxy-fuel fired glass furnaces and presented in a glass industry conference (17).

In the third study the model was applied to the furnace at Gallo Glass. Furnace wall temperatures were measured by an optical pyrometer after the conversion to oxy-fuel firing. Model predictions and comparison with measured temperatures will be published in a separate paper. 


\subsection{REFERENCES}

1. H. Kobayashi, "Oxygen Enriched Combustion System Performance Study, Phase I Interim/Final Report, Volume I - Technical and Economic Analysis, "U.S. Department of Energy, March, 1987.

2. H. Kobayashi, "Oxygen Enriched Combustion System Performance Study, Phase I Final Report, Volume II - Market Assessment", U.S. Department of Energy, September, 1988.

3. Y. Kwan et. al., "Oxygen Enriched Combustion System Performance Study, Phase I Final Report, Volume III - Burner Tests and Combustion Modeling, "U.S. Department of Energy, September, 1988.

4. D. A. LaGree, "Oxygen Enriched Air Production System," U. S. Department of Energy, November, 1988.

5. J. T. Brown, "100\% Oxygen-Fuel Combustion for Glass Furnaces", pp.202-217 in the Proceedings of the 51st Conference on Glass Problems, edited by Charles H. Drummond. American Ceramic Society, Westerville, Ohio (1991)

6. D. E. Shamp, D. H. Davis, "Application of $100 \%$ Oxygen Firing at Parkersburg, West Virginia",pp.218-239 in the Proceedings of the 51st Conference on Glass Problems, edited by Charles H. Drummond. American Ceramic Society, Westerville, Ohio (1991)

7. D. Moore, J. T. Brown, "Conversion of a Large Container Furnace from Regenerative Firing to Direct Oxy-Fuel Combustion. These Proceedings.

8. M. Cable, C. Rasul, J. Savage, "Laboratory Investigation of Foaming and Reboil in SodaLime-Silica Melts", Glass Technology, Vol. 9, No. 2, April 1988.

9. W. Trier, Glass Furnaces, Design Construction and Operation, pp 81-82, Society of Glass 'Technology, Sheffield, England, 1987.

10. R. J. Ryder, E. C. Taylor, K. B. Tanner, "Pollutant Emissions From Glass Container Furnaces", pp. 199-205 Glass Technology, Vol. 21, No.4, August, 1980.

11. H. Kobayashi, R. Beerkens, P. Ercole, R. Barbiero, "Emissions of Particulates and NOx From Oxy-Fuel Fired Glass Furnaces", Proceedings of the Second Conference of the European Society of Glass Science and Technology, June, 1993.

12. R.G.C. Beerkens, TNO, The Netherlands, Proprietary reports to Praxair, Inc. Nov. 1992.

13. G. Tuson, H. Kobayashi, E. Lauwers, "Industrial Experience With Oxy-Fuel Fired Glass Melters", presented at Glassman Europe, April, 1993. 
14. G. Moilanen, B. Van Kalsbeek, "NOx Control Options for Glass Furnaces", Proceedings of 51st Conference on Glass Problems, American Ceramic Society, 1991.

15. W. Richter, R. Payne, "Modelling Study of Burner and Furnace Performance For Oxygen Enriched Combustion Systems", AFRC Spring Meeting, May 10-11, 1988.

16. W. Richter, H. Kobayashi, AFRC 1990 Fall International Symposium, San Francisco, CA, October 8-10, 1990.

17. H. Kobayashi, W. Richter, "Design Considerations and Modelling of the Glass Melter Combustion Space for Oxy-Fuel Firing", Proceedings of XVI International Congress on Glass, Sociedad Espanola De Ceramica Y Vidro, 1992. 

APPENDIX A 

COMBUSTION SPACE MODELLING OF OXY-FUEL FIRED GLASS MELTER

\author{
Wolfgang Richter \\ Consultant \\ Irvine, California 92714
}
Union Carbide Industrial Gases Inc., Linde Division
Tarrytown, New York 10561

( 1990 Union Carbide Industrial Gases Technology Corporation

Paper presented at American Flame Reserach Committee 1990 Fall International Symposium on $\mathrm{NO}_{x}$ Control, Waste Incineration and oxygen Enriched Combustion, San Francisco, CA, October 8-10, 1990. 

COMBUSTION SPACE MODELLING OF OXY-FUEL FIRED GLASS MELTER

\author{
Wolfgang Richter \\ Consultant \\ Irvine, California 92714 \\ Hisashi Kobayashi \\ Union Carbide Industrial Gases, Inc., Linde Division \\ Tarrytown, New York 10561
}

\begin{abstract}
A three-dimensional heat transfer code based on the zonal method was applied to evaluate the oxygen-fuel firing of a crossfired regenerative glass melter. A furnace end section which includes the bridge wall and a pair of the regenerator ports was modelled in detail for a base air case and several oxy-fuel firing cases. The firing rates of two oxy-fuel burners that matched the heat flux distribution of the base air case were determined. The effects of the height and angle of the oxy-fuel burners on the temperature and heat flux distributions were predicted to evaluate the optimum burner placement of the oxyfuel burners. The main conclusions of the simulation are that; (1) in spite of the small flame diameters, the high momentum low flame temperature oxy-fuel burners can create temperature and heat flux distributions equivalent to those of the base air case with a wide flame and (2) both lower burner elevation and angling of the oxy-fuel burners toward the glass surface tend to increase heat transfer to glass surface and reduce the peak refractory temperatures.
\end{abstract}

\title{
INTRODUCTION
}

Oxygen-fuel firing of glass melters is gaining increasing industry acceptance as a viable way to reduce NOx, particulates and other toxic emissions and to improve energy efficiency. Small specialty glass tanks have been converted to oxygen firing and operating commercially for several years (Ref. 1). A 110 TPD unit melter was converted to oxygen firing about a year ago (Ref. 2). Union Carbide Industrial Gases (UCIG), Inc. has recently conducied successful oxy-fuel firing programs in large tanks for glass bottles and fibers. Since the combustion and heat transfer conditions with oxy-fuel firing can be substantially different from those with the conventional air firing, retrofitting of existing air fired furnaces with oxy-fuel burners requires a careful selection of the type and number of oxy-fuel burners and their proper placement on the glass tank walls. At present these burner decisions are made based on (1) experiences in other industrial furnaces, (2) experimental data on flame characteristics of small scale burners in test furnaces and (3) theoretical heat transfer considerations. very conservative approaches are generally taken in converting existing furnaces 
and designing new furnaces for oxy-fuel firing to avoid costly commercial mistakes.

The optimum furnace design with oxy-fuel firing is likely to be different from the existing furnaces designs for air firing due to a sharp reduction in the flue gas volume and to the heat transfer rate increase possible with oxy-fuel firing. Numerical modelling of the combustion space of glass furnaces offers potential to optimize the furnace design and burner placement for oxy-fuel firing. Although numerical simulation has been used for many years to understand the mechanism of glass melting and for commercial design of glass furnaces, simplified heat transfer models were often used for the combustion space as the focus of modelling was the analysis of glass flow patterns (Ref. 3). In particular, most of these simplified combustion space heat transfer models, do not account for the effects of flame position and characteristics on glass bath heat transfer.

on the other side, advances in numerical methods and computer speed and capacities, have led to the development of complex models, which directly couple comprehensive 3-D finitedifference combustion space analysis, with 3-D melter analysis (Refs. 4,5). However, these latter models, while attractive in the straightforwardness of their approach, require still an enormous effort in time to set up and to validate, and in computational and financial resources to run.

Therefore, the current analysis was based on a approach which is complex enough to allow to study the impact of local flame radiation on heat transfer to the glass, but which avoids the complexity of the comprehensive models by using simplified boundary conditions at the glass surface and by decoupling the combustion space gas flow analysis, as well.

\section{APPROACH}

The current approach uses a 3-D heat transfer and combustion zone model, which allows accurate assessment of local radiative heat transfer between gas heat sources, furnace gas volume, refractory walls and heat sinks. Furnace flow and flame heat release pattern are semi-empirically prescribed. However, flame heat release patterns are based on measurements in pilot-scale furnaces and actual flame observations. Thermal boundary conditions at the glass surface are simplified either by assigning effective temperatures and emissivities, or by use of a simple heat conduction model into the glass bath. Use of these simplified boundary conditions is justified by the fact that one of the goals of the current study is to identify 02-Burner configurations which generate similar net heat flux distributions as does conventional air firing. 
A further simplification was introduced by considering only a section of a cross-fired glass furnace. In the current project only the end-section of such a furnace was modelled. This allowed to use computational grids small enough that the computer code of the model could be executed on PC's. The model developed for above approach is described in detail in the following sections.

\section{3-D Zone Model}

As already mentioned, the present study is based on a 3-D heat transfer and combustion zone model (Ref. 6). This model has successfully been applied in the past for thermal performances studies of a variety of boiler, industrial and pilot-scale furnaces (Ref. 7) including furnaces almost completely insulated by refractory walls like a glass furnace. The model is especially suitable for the latter furnaces, since emphasis is laid on accurate treatment of multi-directional radiative exchange, which is by far the dominant mode of heat transfer in these high temperature furnaces.

In zone-type models such as the current one, the combustion space is sub-divided by a net of well-stirred volume zones, and by a net of corresponding boundary zones. Average zone temperatures are obtained of total energy balances set up for each zone. The heat balance for a volume zone is formulated by Eq. (1) :

$$
Q_{r}+Q_{B}+Q_{d}-Q_{c h}=0,
$$

where $Q_{r}$ and $Q_{g}$ are the net heat fluxes over the zone boundaries by radiation and advection, respectively. $Q_{d}$, which is small in high temperature furnaces, represents the convective transport through a wall boundary layer from a near wall volume zone to a adjacent surface zone. $Q_{c h}$, finally is the net heat release in the volume zone due to flame reactions obtained from species balances solved in addition to the volume zone heat balances.

Contrary to the more expensive finite-difference combustor models, the advective mass flow rates necessary to calculate the terms $Q_{8}$ in $\mathrm{Eq}$. (1) are not obtained from a simultaneous solution of momentum balances, but are rather input into the zone model, thus allowing to spend available computational resources for a more accurate simulation of radiative exchange.

The multi-directional transport of radiative energy between all wall and surface zones (i.e. term $Q_{r}$ in Eq. (1)) is calculated with the semistochastic method (Ref. 6). This method which is derived from Monte-Carlo calculation techniques is illustrated in Fig. $1 . Q_{x}$ is expressed by Eq. (2) : 
$Q_{r}=4 \mathrm{~V} \Sigma_{n=1}^{4} \quad a_{n} K_{n} \quad \sigma T_{g}^{4}-\Sigma_{n=1}^{4} \Sigma_{\text {beam }} Q_{\text {beam, a }}$

Eq. $(\dot{B})$ implies that the radiative properties of the combustion products are approximated with a so-called 'Weighted-Grey-Gas Approach' (Ref. 8) with $n=4$ grey ranges. $a_{n}$ is the weighing factor and $\mathrm{K}_{\mathrm{n}}$ is the grey absorption co-efficient assigned to the $n$th range.

The radiation model works as follows. The emissive power of all grey ranges ( 1 st term of Eq. (2)) of a volume zone (surface zones are treated in analogy) is distributed among a finite number of beams. The beams are emitted over the whole view angle and traced through the arrangement of volume zones until they impinge on wall. The beam gradually loose energy through absorption. The amount of energy $Q_{\text {beam, a }}$ absorbed from a beam by a volume zone is expressed by :

$$
Q_{\text {beam, a }}=Q_{\text {beam, in }}\left[1-\exp \left(-K_{n} d s\right)\right]
$$

$Q_{\text {beam in }}$ is the energy flux of a beam incident on the volume zone and d's is the path length of the beam cut out by this zone. The energy amounts $Q_{\text {beam }}$ absorbed from all beams passing a zone are accumulated. The radiative sub-balance according to Eq. (2) is calculated for each iteration cycle necessary to solve the total energy balance (1).

since in the current study wall surfaces are treated as grey, diffuse radiators and reflectors, reflected energy amounts from beams incident on a wall are accumulated at the corresponding surface zones, and added to surface emission in the next iteration step. Combined wall emission and reflection is then treated in analogy of volume emission described above, however taking the cosine law into account.

The current semistochastic method is distinguished from pure Monte-carlo methods by the fact, that some events in the history of a beam are deterministically influenced rather than based solely on random numbers (see Ref. 6).

The zone model considers, besides radiation from wall zones, radiation from gaseous species $\mathrm{CO} 2$ and $\mathrm{H} 2 \mathrm{O}$ and from soot particles. Zonal concentration of these species are calculated from the combustion model described further below. Weighing factors and specific absorption coefficients of the gaseous species utilized for the 'Weighted-Grey-Gases-Approach' are taken from Ref. 8. The specific absorption coefficients for soot are prescribed according to an approach suggested in Ref. 9. 


\section{Furnace Flow Field}

Besides the radiation terms, the total energy balance of each volume zone includes contributions from convective transport and from heat release due the flame reactions. As mentioned above, the advective transport of sensible heat is based on predetermined zonal mass flux distributions. There are several means to obtain such distributions ranging from simple engineering guesses to sophisticated 3-D fluid dynamics calculations. In the present study, suitable furnace flow distributions were determined from a mixed-type approach, combining enclosed jet theory, educated guesses and computer routines for continuity considerations and for direct graphical display of mass flux density vectors.

The jet theory was in particular applied to estimate the flow for the $\mathrm{O}_{2}$ firing configuration. It was assumed that the forward flows of the high momentum $\mathrm{O}_{2}$-jets which fired from opposite furnace sides in a staggered manner, were not interacting. The flow fields associated with each burner were constructed as follows.

The multi-jet outlet of an $\mathrm{O}_{2}$ burner was replaced by an equivalent nozzle diameter taking flame expansion into account. Forward flow profiles and local entrainment rates.were calculated with the assumption that the jet entrains fluid halfway the distance between jet origin and impingement of the jet envelope at surrounding walls. The backflow necessary to support the entrainment rates was empirically distributed over the furnace with help of profile factors.

In a final step, the flow fields derived for the individual burners were arithmetically superimposed. Also superimposed are pairs of turbulent mass flux vectors with prescribed strength, in order to simulate large scale turbulent exchange over zone boundaries. The simple approach described above is currently validated by 3-D fluid dynamics modeling. Entrainment rates of the $\mathrm{O}_{2}$-flames were also validated with results of comprehensive 2-D modeling previously carried out for pilot-scale $\mathrm{O}_{2}$-burner trials (Ref. 10).

\section{Combustion Model}

The calculation of zonal heat release is based on the furnace flow obtained from above model and on an empirical function, which accounts for the mixing controlled progress of burn-out. In this model, the gaseous fuel is represented by fuel lumps, which 
follow the turbulent flow. The lumps are tracked within the zone arrangement. The lifetime of individual lumps is statistically calculated with help of weighted random numbers in such a way that the unburnt matter of a large assembly gas fuel lumps of same origin is an exponential function of residence time $t$ :

$Q_{u n b} / Q_{u n b, 0}=\exp \left[-\left(1 / c_{b}\right)\left(t / t_{b}\right)^{m}\right]$

$Q_{\text {unb,o }}$ is the sum of chemical heat of all gaseous fuel lumps originating from the same burner inlet zone, and $Q_{\text {unb }}$ is the corresponding amount after time $t$. Accumulation of chemical heat from all fuel lumps reacted in a volume zone yields the chemical source term $Q_{c h}$ needed for the total energy balance (Eq. 1). By using the value 0.1448 for the constant $c_{b}, t_{b}$ can be identified as the time needed to achieve (at least on average) burn-out down to 99.98 .

In the current study, the heat release distribution in the air flames was calculated using $t_{b}=0.75 \mathrm{~s}$ and $\mathrm{m}=2$. The value for $t_{b}$ was chosen so, that $99.9 \%$ burn-out was achieved just at the flue gas port. Thus the observed flame length was matched.

The time constant tb for the $\mathrm{O}_{2}$ flames was chosen so that the length of the $\mathrm{O}_{2}$ flames observed in pilot scale experiments was matched. Fig. 2 shows measured axial values of unburnt fuel and of $\mathrm{O}_{2}$-concentration dependent on distance from the $\mathrm{O}_{2}$ burner normalized with an equivalent nozzle diameter $d_{e q}$. The distance $\mathrm{z} / \mathrm{d}_{\mathrm{eg}}=121.2$ represents the width of the furnace investigated in the current study. Also plotted into Fig. 2 are burn-out distributions based on Eq. 4 and used in the model. The curves denoted by $A 5$ represent an $\mathrm{O}_{2}$ flame with a load 3.71 higher than the flame represented by curves $A 6$ (see also below). Both sets of curves were obtained for $m=3$. For flame $A 5, t_{b}=0.045 \mathrm{~s}$ was utilized and for the lower load flame, $t_{b}=0.167 \mathrm{~s}$, i.e. the ratio for $t_{b}$ of both flames was assumed to be proportional to their load ratio.

The heat release model described above is coupled with species transport equations which allow to calculate zonal concentrations of major combustion products and $\mathrm{O}_{2}$ needed to compute specific heats. The zonal concentrations of $\mathrm{CO}_{2}$ and $\mathrm{H}_{2} \mathrm{O}$ are also used to calculate zonal absorption coefficients $K_{n}$ as required by $E q$. (2). The current radiation model requires additionaliy estimation of flame soot concentrations. Whereas the $\mathrm{O}_{2}$ flames are soot free, luminous radiation plays a certain role in air flames. The natural gas/air flames considered in this study were very sooty. In order to calculate soot absorption coefficients in these flames, it was assumed that flame soot is present in a zone in proportion to unburnt fuel calculated with above 
combustion model-for the same zone. An empirical value was used for the constant of proportionality.

\section{Thermal Boundary Conditions}

Prescription of thermal boundary conditions for the combustion space must distinguish between the refractory surfaces above glass melt, the port openings as well as the glass bath itself. All three sections require either calculation or prescription of effective temperatures and effective emissivities of the radiating boundaries.

\section{Heat Losses through Refractory Walls}

Local surface temperatures of the refractories exposed to the combustion space were calculated with the zone model and with a 1-D model for heat conduction through the refractory walls using effective values for the ratio $\mathrm{k} / \mathrm{s}$ of conductance to refractory thickness and estimations for outside refractory temperatures.

\section{Calculation of Port Heat Losses}

Net radiation through the port openings constitutes a major heat loss of the combustion space. In case of $\mathrm{O}_{2}$-combustion, the ports were also considered to be open, since the experimental set-up for $\mathrm{O}_{2}$-conversion of the furnace considered in this study was planned for all ports to be left open. The analysis of port radiation was separately carried out by applying the zone model for a representative section of a port and the upper regenerator.

The port analysis yielded ultimately port view factors, which differed between the cycles for air combustion and also for $\mathrm{O}_{2}$-combustion. The view factors $\mathrm{F}_{\mathrm{f}-\mathrm{B}}>\mathrm{rg}$ are defined by Eq. (5) ., which relate the net heat flux $\varepsilon_{p}$ through the combustion space port opening with area $A_{p}$ to the incident radiation $q_{p}$, in from the combustion space and to an effective black regenerator temperature $T_{r g, e f f}:$

$$
Q_{p}=F_{f->r g} A_{p}\left(q_{p, i n}-\sigma T_{r g, e f f}^{4}\right)
$$

Boundary conditions at Glass surface

In prescribing thermal boundary conditions at the melter surface, it was assumed that the glass of the end-section was batch-free. Two different types of thermal boundary conditions were then studied. 
In a first set of calculations, a uniform effective temperature $\mathbf{T}_{\mathrm{gl}}=2600^{\circ} \mathrm{F}(1700 \mathrm{~K})$ and an effective emissivity of $\epsilon_{g l}=0.88$ were used for the whole glass surface. The value used for $\epsilon_{g l}$ corresponds to the greys hemispherical emissivity of a transparent glass sheet with infinite optical thickness and a refractive index of 1.7 (Ref. 11).

The second set of calculations was carried out by calculating effective temperatures of the glass surface with help of a simple heat conduction model into the glass. It is assumed that temperatures of the glass are uniform $\left(2410^{\circ} \mathrm{F}=1600 \mathrm{~K}\right)$ in a horizontal plane located at a certain vertical distance into the bath. A uniform effective ratio of conductance to thickness of the glass layer was then determined so, that the area-weighted effective glass surface temperature was $1700 \mathrm{~K}$ (2600F). The surface emissivity used in this approach was again $\epsilon_{g l}=0.88$.

It is believed, that use of a uniform value for glass surface temperatures simulates closer conditions for a transparent glass, where as the second way to calculate boundary conditions, is more representative for a darker glass. Both approaches are certainly very approximate. However, it has to be pointed out, that predictions of relative performance changes for the air and $\mathrm{O}_{2}$-system can still be accurate provided similar incident heat flux distributions at the glass bath can be achieved in the $\mathrm{O}_{2}$-system by appropriate burner selection, placement and operation.

\section{INPUT DESCRIPTION AND CASE DEFINITIONS}

\section{Furnace Description}

The glass furnace investigated in this study is designed for a pull rate of 350 TPD. The furnace is cross-fired and is currently operated with natural gas using regeneratively heated air as oxidizer. A horizontal cross-section of the furnace is shown in Fig. 3. The furnace is $27.2 \mathrm{ft}(8.28 \mathrm{~m})$ wide and $49.6 \mathrm{ft}$ $(15.11 \mathrm{~m})$ long. The distance between glass surface and crown is $8.7 \mathrm{ft}(2.64 \mathrm{~m})$. Each of the five ports of each furnace side is equipped with two pipe burners with 2.3" nozzle diameters. The burners point from each port side at an angle of 47 degrees relative to the port axis and produce five long flames which extend over the whole furnace width. The time between a switch of the burners of one side to the opposite side is $30 \mathrm{~min}$.

\section{oxy-fuel Burner}

The Linde "A" Burner, patented by Union Carbide Industrial Gases, Inc., was chosen for the oxy-fuel firing cases. The burner offers high momentum low flame temperature characteristics 
suitable for glass furnaces (Ref. 12). The arrangement of the burners are shown in Fig. 4 .

\section{Model Geometry for End-Section}

For reasons described in an earlier section, it was decided to conduct the 3-D modeling study of the combustion space for only one section of the furnace, namely the end-section. The space covered by the model, which is indicated in Fig. 3, extends from the center-plane between the fourth and the fifth ports to the bridge-wall. Thus, the model assumes that heat transfer in the combustion space is symmetrical with respect to the vertical center-plane. In the graphical display of the results following later, this symmetry feature will be utilized by extending the plots of the furnace variables up to the center-plane of the fourth port.

The 3-D zone arrangement used in the heat transfer model of the end-section is displayed in Fig. 4. The zone arrangement utilized basically consists of a $9 * 6 * 7$ rectangular volume $z$ ones with some of the near roof zones distorted or omitted in order to simulate the curvature of the furnace roof.

\section{Thermal Boundary Conditions for End-section}

The thermal boundary conditions considered for the endsection are summarized in Table 1.

A uniform value of 0.5 was assumed for the emissivity of all refractory surfaces. The effective ratios of conductance to wall thickness $(k / s)$ eff as well as the outside surface temperatures for various furnace wall sections were deducted from an heat loss analysis carried out for air operation by a furnace manufacturer. In particular, the ratios $(\mathrm{k} / \mathrm{s})$ eff were determined so that the current zone model will predict the same overall heat losses, if the flame side surface temperatures coincide with those used in the heat loss analysis mentioned above.

Table 1 also lists the view factors and effective regenerator temperatures used in Eq. (5) to calculate the port losses for aix and $\mathrm{O}_{2}$ combustion, respectively. The mean values for $T_{\text {rg,eff }}$ used in the air case are also supported by measurements of gas and refractory temperatures in the upper regenerator carried out over the whole firing cycle.

The boundary conditions at the glass surface were prescribed as discussed in the general description of the approach. In particular, two sets of calculations were carried out. The first set of calculations was carried out assuming a uniform effective 
glass surface temperature of $2600^{\circ} \mathrm{F}(1700 \mathrm{~K})$. In the second set of calculations, a constant temperature of $2420^{\circ} \mathrm{F}(1600 \mathrm{~K})$ was assumed to occur someway into the glass bath. A uniform effective ratio of conductance to thickness of $\mathrm{k} / \mathrm{s}=0.612 \mathrm{~kW} /$ $\mathrm{m}^{2} \mathrm{~K}$ was used in order to calculate heat transfer through the upper glass bath layer. This value was determined so, that the area weighted glass surface temperatures averaged $2600^{\circ} \mathrm{F}$ (1700 $\mathrm{K}$ ) for the baseline $\mathrm{O}_{2}$ firing configuration. In both set of calculations, an effective glass surface emissivity of 0.88 was utilized.

\section{Maior operating Conditions and Case Definitions}

Major operating conditions of the end-section considered for air and $\mathrm{O}_{2}$-Firing are listed in Table 2 . The gross fuel heat input of $12.16 \mathrm{MMBtU} / \mathrm{hr}(3563 \mathrm{~kW})$ utilized for air firing is related to the gas burners of one port. The fuel heat input cited for $\mathrm{O}_{2}$ firing relates to half of the fuel input for $\mathrm{O}_{2}$ burner $\mathrm{A} 5$ plus the heat input for $\mathrm{O}_{2}$ burner $\mathrm{A6}$ (see Fig. 4). The air preheat of $2330^{\circ} \mathrm{F}(1550 \mathrm{~K})$ utilized for conventional air firing corresponds to average measured values for the burner load considered. Similarly, the $\mathrm{O}_{2}$ concentrations of 2.2 Vol. $\frac{8}{6}$, dry corresponds to average $\mathrm{O}_{2}$ concentrations measured during the flue gas cycle in the upper regenerator.

All cases studied in this paper are defined in Table 3 . The 3-D modeling effort comprises tive major cases. However, four of these cases are also presented for a variation, in which the glass surface temperatures are calculated from a simple model rather than prescribed to be constant. The cases with constant glass surface temperatures are numbered 1.0 through 5.0 , and the cases with variable surface temperatures 1.1 through 5.1 .

Case 1 is the case conducted for conventional air combustion and serves, in the context of this study, as bench mark for performance comparisons with predictions of Cases 2 through 5 for the $\mathrm{O}_{2}$-firing system. The firing arrangement for case 1 is shown in Fig. 4 .

Case 2 through 5 were performed for a latitudinal arrangement of two oxygen burners as shown in Fig. 4. The burners are numbered $A 5$ and $A 6$. A5 fires along the centerline between the two last ports of the glass furnace (Ports 4 and 5 ). A6 fires in opposite direction with burner axis located in the plane which divides the breast wall section between last port and the bridge wall in half.

Case 2 with equal burner load A5/AG was performed to optimize the $\mathrm{O}_{2}$ configuration. All other oxygen cases were performed for burner load ratio A5/A6 of 3.71. Case 3 is defined 
as baseline with burner directed horizontally and mounted 2 ft $(0.610 \mathrm{~m})$ above the glass bath. Case 4 with horizontal burners $1.3 \mathrm{ft}(0.396 \mathrm{~m})$ above glass surface was conducted to study the impact of burner elevation. In Case 5 finally, the $\mathrm{O}_{2}$ burners mounted at $2 \mathrm{ft}$ were angled downwards towards the center-line of the furnace.

\section{RESULTS AND DISCUSSION}

\section{Air Case and Model Verification}

Results obtained for conventional air firing (Case 1) of the end-section are displayed in Figs. 5 through 8 . Fig. 5 shows the relative mass flux distribution utilized in horizontal and vertical cross-sections of the furnace. The flow is characterized by a weak outer recirculation field surrounding the forward flow emerging from the firing port. The recirculation eddy extends over the whole furnace depth. Its strength was prescribed to be 1.0 times, the inlet mass flow. However, previous experience with the zone model has shown that, in weak recirculating flows like in the current air case, the actual recirculation strength has only a weak effect on thermal performance provided bulk flow features are approximately simulated.

Fig. 6 shows the distributions of gas temperatures (F) predicted for air firing in a horizontal and in a vertical furnace cross-section through the flame as well as in a vertical cross-section located halfway between Port 5 and the bridge wall. The predicted flame extends over the whole furnace depth up to the flue gas port. This agrees with observations made in the actual furnace. It was observed that sooty flame tips extended intermittently into the opposite port. The mean gas exit temperature predicted is $2851^{\circ} \mathrm{F}(1840 \mathrm{~K})$. This is in good agreement with optical pyrometer measurements, which yielded averaged gas temperatures near the flue gas port of ca. $2857^{\circ} \mathrm{F}$ $(1843 \mathrm{~K})$ as seen from the regenerator observation ports.

Fig. 7 shows the distribution of refractory temperatures (F) predicted for all walls of the furnace end-section for air firing. In this graph, as well as in all following graphs for air combustion, the display of the variables (i.e. the refractory temperatures in this case) is symmetrized with respect to the furnace axis. This approximately accounts for the complete firing cycle. Maximum refractory temperatures of $2684^{\circ} \mathrm{F}$ predicted for the furnace roof fall into the range of measured mean crown temperatures, which varied from $2650^{\circ} \mathrm{F}$ for the section of Port 1 to $2850^{\circ} \mathrm{F}$ for the end-section (Port 5). The maximum roof refractory temperature of the non-symmetric prediction was $2694^{\circ} \mathrm{F}(1752 \mathrm{~K})$. In comparing the model predictions with the 
behavior of the actual furnace, one has to consider that the actual fuel distribution between the port burners was not uniform. Furthermore, the actual furnace volume is larger than that the virtual volume of twice the end-section considered in the current model set-up.

Some gradients of predicted refractory temperatures are due to the fact that the refractory material and outer insulation differed from section to section. This effect is especially obvious for the uninsulated tuckstones located just over the glass surface. Relatively low surface temperatures are predicted for these stones.

Fig. 8 a shows the symmetrized net heat flux distribution predicted at the glass surface for air combustion and assuming uniform effective temperatures of the glass surface of $2600^{\circ} \mathrm{F}$ $(1700 \mathrm{~K})$. The shape and the inhomogeneity of these heat flux profiles indicate a considerable influence of direct flame radiation on overall heat transfer to the glass. The heat fluxes to the glass vary from maximal $98 \mathrm{~kW} / \mathrm{m}^{2}$ below the flame to less than $40 \mathrm{~kW} / \mathrm{m}^{2}$ adjacent to the bridge wall.

$\underline{O}_{2}$-Burner Load Optimization and $\mathrm{O}_{2}$ Base Case

In the first step carried out to optimize the $\mathrm{O}_{2}$-firing configuration, the thermal load of the $A 5$ and $A 6 O_{2}$ burners of the end-section (see Fig. 4) was considered to be equal (Case 2). The resulting net heat flux distribution to the glass surface is shown in Fig. 8b. Iike in the air case, the $\mathrm{O}_{2}$-flames generate a radiation image on the glass surface. Maximum heat fluxes of $114 \mathrm{~kW} / \mathrm{m}^{2}$ predicted for flame A5 was slightly higher than those predicted for air combustion.

However, by comparing Fig. $8 \mathrm{~b}$ with Fig. $8 \mathrm{a}$, it is obvious, that the glass surface section near the bridgewall receives too much heat in the $\mathrm{O}_{2}$ case. If two glass surface sections are defined so that section 1 is the glass area between the centerlines of Ports 4 and 5 and section 2 is the remaining area up to the bridge wall, then the heat flux ratio between sections 1 and 2 is 1.54 for air Case 1 compared to only 1.03 for $\mathrm{O}_{2}$ Case 2 . Furthermore in the $\mathrm{O}_{2}$ case, maximum refractory temperatures of the bridge wall exceeded the ones predicted for air case 1 by $67^{\circ} \mathrm{F}(37 \mathrm{~K})$.

In order to lower the bridge wall temperatures and in order to achieve a heat flux ratio between sections 1 and 2 which is more similar to that predicted for air combustion, the load ratio $\mathrm{A} 5 / \mathrm{A} 6$ was increased from 1 in case 2 to 3.71 in case 3 . This resulted in an increase of the heat flux ratio between sections 1 and Sections 2 from 1.03 to 1.31. It also led to a local heat 
flux distribution at the glass surface, which is more similar to that predicted for air Case 1 (Compare Fig. 9b with Fig. 9a), and lowered maximum bridgewall temperatures from $2725^{\circ} \mathrm{F}(1769 \mathrm{~K})$ to $2696^{\circ} \mathrm{F}(1753 \mathrm{~K})$. The $\mathrm{O}_{2}$ case with load ratio $\mathrm{A} 5 / \mathrm{A} 6=3.71$ was consequently defined as baseline $\mathrm{O}_{2}$ Case 3 .

Further results for the baseline $\mathrm{O}_{2}$ Case 3 are depicted in Figs. 10 through 12. Fig. 10 shows the relative mass flux distribution of the baseline $\mathrm{O}_{2}$ case determined for the horizontal and two vertical cross-sections through the axes of Burners $A 5$ and $A 6$. Note, that the mass flux density vectors shown in this figure were plotted in a scale ten times smaller than in corresponding Fig. 5 for the air case.

Derivation of the flow patterns displayed in Fig. 10 is based on enclosed jet theory and flow superposition as described earlier. In particular, a recirculation strength of 15 times the inlet jet mass was utilized for both $\mathrm{O}_{2}$ jets. Fig. 10 shows that the jets do not significantly influence each other, however, due to its much higher absolute mass flow, jet A5 determines the flow direction in recirculation regions. These features were confirmed in 3-D fluid dynamics calculations carried out independently for the burner configuration of case 3 .

Gas temperature distributions (F) predicted for the $\mathrm{O}_{2}$ baseline Case 3 in horizontal and vertical burner planes are depicted in Fig. 11. Due to the high recirculation rates, maximum flame temperatures of $3432^{\circ} \mathrm{F}(2162 \mathrm{~K})$ are only slightly higher than those predicted for air combustion $\left(3364^{\circ} \mathrm{F}=2124 \mathrm{~K}\right)$. These gas temperature maxima are found in Flame $A 5$ which is hotter than Flame A6 due to its much higher load.

Fig. 12 shows the refractory temperatures predicted for $\mathrm{O}_{2}$ Case 3 at all walls of the furnace end-section. Maximum refractory temperatures of the roof are with $2732^{\circ} \mathrm{F}(1773 \mathrm{~K}) \mathrm{ca}$. $48 \mathrm{R}(27 \mathrm{~K})$ higher than those predicted for air combustion (Fig. 6). There is a clear correlation between the location of the maximum refractory temperatures and the adjacent gas flow. Maximum refractory temperatures are encountered there, where the gas flow vectors, especially in the flame tail, are directed towards the walls. In $\mathrm{O}_{2}$ Case 3, these areas are the breastwall region opposite to the $A 5$ burner and the roof section adjacent to this breastwall area. This behavior is less noticeable for Burner $A 6$ due to the shorter high temperature flame zone.

A similar correlation can be found between near wall flow direction and maximum heat fluxes, although the heat flux peaks are influenced as well by bulk radiation effects. Fig. 8 b shows, that, compared to $\mathrm{O}_{2}$ Case 2 with burner load ratio $A 5 / \mathrm{A} 6=1$ (Fig.7b), maximum heat fluxes to the glass shifted nearer to the 
opposite breastwall of Burner $A 5$ and are found in the region, where the flame envelope touches the glass surface. The weaker relative heat flux maximum associated with Flame $A 6$ is located more towards the center of the furnace due to the shortness of the high temperature zone of this flame.

\section{Impact of $\mathrm{O}_{2}$-Burner Elevation and Burner Angling}

It is clear from the previous statements, that burner positioning and angling must have some influence on maximum refractory temperatures, on net heat flux distribution to the glass and on overall heat transfer efficiency. In order to investigate these influences, $\mathrm{O}_{2}$ Cases 4 and 5 were conducted.

In Case 4, both the $A 5$ and the $A 6$ burners remained horizontally directed, but were lowered from 2 ft above glass surface to only $1.3 \mathrm{ft}$ over glass surface. The impact of burner elevation on net heat flux distribution is shown in Fig. 12, which compares the results obtained for Case 4 with the heat fluxes predicted for the baseline $\mathrm{O}_{2}$ Case 3. By lowering the burners from $2 \mathrm{ft}$ to $1.3 \mathrm{ft}$, peak heat fluxes at the glass increased from $115 \mathrm{~kW} / \mathrm{m}^{2}$ to $122 \mathrm{~kW} / \mathrm{m}^{2}$. This increase is accompanied by a decrease of peak roof refractory temperatures by $15 \mathrm{R}(8 \mathrm{~K})$.

A still more dramatic effect on heat flux distribution to the glass is obtained when the $\mathrm{O}_{2}$-burners are angled towards the glass surface in direction of the furnace center-line (Case 5). The relative mass flux distribution utilized in this case is shown in Fig. 13. Fig. 14 shows the gas temperature distributions predicted for the angled $\mathrm{O}_{2}$ flames. Compared to the horizontal $\mathrm{O}_{2}$ flames of the baseline case (Fig. 10), maximum flame temperatures decreased by $\mathrm{ca}$. 150 (F). This is an indication for an improved heat transfer to glass surface. The net heat flux distribution at the glass surface produced by the angled flames is depicted in Fig. 15b. compared to the baseline Case 3 (Fig. 15a), maximum heat flux densities increased from 115 $\mathrm{kW} / \mathrm{m}^{2}$ to $131 \mathrm{~kW} / \mathrm{m}^{2}$ and, as can be expected, the location of the heat flux maximum of each flame shifted more towards its corresponding burner wall. The increase of peak heat fluxes is accompanied by an overall increase of heat transfer efficiencies (see section on overall performance).

The angling of the $\mathrm{O}_{2}$-burners also causes a considerable redistribution of refractory temperatures as shown in Fig. 16. Compared to the distribution for the baseline $\mathrm{O}_{2}$ Case 3 (Fig. 11), maximum roof refractory temperatures are lowered by $20 \mathrm{R}$ (11 K) and the location of roof peak fluxes has shifted towards Burner A5. However, the stronger flow along the glass after 
impingement of jet A5 on the glass surface causes an increase of maximum breast wall temperatures by $40 \mathrm{R}(22 \mathrm{~K})$ compared to the baseline $\mathrm{O}_{2}$ case.

Effect of Variable Glass surface Temperatures

The preceding results, which were obtained using a uniform effective surface temperature of the glass, showed relative large in homegenities in the distribution of net heat fluxes at the glass surface. Largest and smallest net heat fluxes of $95 \mathrm{~kW} / \mathrm{m}^{2}$ and $35 \mathrm{~kW} / \mathrm{m}^{2}$, respectively, were for instance predicted for air combustion (Case 1), and of $110 \mathrm{~kW} / \mathrm{m}^{2}$ and $40 \mathrm{~kW} / \mathrm{m}^{2}$ for the baseline $\mathrm{O}_{2}$ case (Case 3 ). For the $\mathrm{O}_{2}$-cases in particular, the local heat flux distributions at the glass surfaces were to a certain extent mirror images of the gas temperature distribution within the $\mathrm{O}_{2}$-flames.

Considerably flatter net heat flux distributions are predicted, when the glass near the surface responds to the imprint of the net heat flux distributions through change of its temperature. This effect is modelled by the simple model for variable glass surface temperatures. Results obtained from this model are shown in Fig. $18 \mathrm{a}$ for air combustion and in Fig. $18 \mathrm{~b}$ for the baseline $\mathrm{O}_{2}$ burner configuration. In case of air combustion and variable glass temperatures (Case 1.1), largest and lowest heat fluxes are only $83 \mathrm{kw} / \mathrm{m}^{2}$ and $47 \mathrm{kw} / \mathrm{m}^{2}$, respectively. Similarly, for the baseline $o_{2}$ Case with variable glass surface temperatures (Case 3.1), highest and lowest heat fluxes amount to $80 \mathrm{~kW} / \mathrm{m}^{2}$ and $50 \mathrm{~kW} / \mathrm{m}^{2}$, respectively.

Resulting distributions of calculated effective surface temperatures for air Case 1.1 and baseline $o_{2}$ case 3.1 are compared in Figs. $19 \mathrm{a}$ and 19b., respectively. Peak glass temperatures $T_{\mathbf{8}, g l, m a x}$ for air combustion reach $2663^{\circ} \mathrm{F}(1735 \mathrm{~K}$ ) and the differences between this peak and the lowest temperatures predicted is $\mathrm{dT}_{\mathrm{g}, \mathrm{gl}}=105 \mathrm{R}(59 \mathrm{~K})$. For $\mathrm{O}_{2}$ combustion, these numbers are $T_{8, g l, \max }=2656^{\circ} \mathrm{F}(1731 \mathrm{~K})$ and $d T_{8, g l}=90 \mathrm{R}(50 \mathrm{~K})$, respectively.

As it can be expected, in all cases investigated with variable glass surface temperatures, maximum refractory temperatures increased by about $10 \mathrm{~K}$ (20F) compared to corresponding cases assuming a uniform effective glass surface temperature. The higher peak refractory temperatures are offset by lower refractory temperatures in furnace corners, especially in the $\mathrm{O}_{2}$ cases which exhibit a somewhat more inhomogeneous refractory temperature distribution. This can be seen in Figs. 20 and 21 which display the refractory temperature distribution predicted for the air Case 1.1 and for the $\mathrm{O}_{2}$ case 3.1 , respectively. 


\section{OVERALI PERFORMANCE COMPARISON AND CONCLUSIONS}

Overall heat transfer performance data predicted for all cases is listed in Table 4. Note, that the fuel heat input cited in this table, is calculated with the lower calorific value. Table 1 confirms the known fact, that overall heat transfer efficiency of the $\mathrm{O}_{2}$-firing system is improved compared to conventional air combustion. For the $\mathrm{O}_{2}$-firing systems studied, this increase is achieved without significant increase in maximum flame temperatures and maximum refractory temperatures. Although the air flames are wider than the $\sigma_{2}$ jet flames, the discrepancy in size of the $\mathrm{O}_{2}$ flames is offset by much higher mixing and recirculation rates induced by the $\mathrm{O}_{2}$-burners.

It is also obvious from Table 4, that positioning and angling of the $\mathrm{O}_{2}$-burners can influence overall performance to a certain degree. Lowering the burners (Case 3) slightly increases heat transfer efficiency to the glass surface. A somewhat stronger improvement is achieved when the burners are angled towards the glass surface. In this case, heat transfer efficiency is increased by 0.5 percentage points compared to the baseline $\mathrm{O}_{2}$ case with horizontal burner orientation.

The study also showed, that there is certainly an impact of the glass surface thermal properties on heat transfer in the combustion space itself. A darker glass will likely tend to smooth out local inhomogenties of net heat fluxes to the glass by increase of glass surface or near surface temperatures, thus reducing the effect of the firing system or of the burner placement on heat flux distribution.

Although some of the absolute predictions made in the present study may be inaccurate due to simplifications of the current approach, there is little doubt that the general trends concluded from this study are realistic. This is due to the dominance of radiation on overall heat transfer in the high temperature glass furnace, and radiative exchange is treated very accurately by the current model.

\section{ACKNOWLEDGEMENT}

This work was jointly funded by the U. S. Department of Energy and Union Carbide Industrial Gases, Inc. under contract No. DE-FC07-88ID12833. The authors would like to express appreciation to Mr. J. Keller of EG\&G and Mr. R. N. Chappell of the U. S. Department of Energy for their support and advice. 


\section{REFERENCES}

[1] J. Brown, et. al., "oxygen-Fuel Fired Glass Furnace," Amer. Ceramic Society, Glass Division, Pacific Coast Regional Meeting, Nov. 1-3, 1987.

[2] Shamp, D.E. and Davis, D. "Application of 1008 Oxygen Firing at Parkersberg, W.V." H.A. Nelson Memorial Glass Seminar, Louisville, KY, April 11, 1990.

[3] Nolet, D. A., and R. A. Murnane. Development of Modeling Techniques for Glass Furnaces. 1st International Conference on Advances in the Fusion of Glass. Alfred University, New York, June 14-17, 1988, pp. 13.1 - 13.21

[4] Ungan, A. and Viskanta, R., "state-of-the-Art Numerical Simulation of Glass Melting Furnaces," Ceramic Eng. Sci. ProC., $9[3-4]$, pp. 203-220 (1988).

[5] Carvavalho, M. G., P oliveira and V. Semiao. A ThreeDimensional Modelling of an Industrial Glass Furnace. $J$. Inst. Energy, 1988, 448, pp. 143-156.

[6] Richter, W., and M. P. Heap. A Semistochstic Method for the Prediction of Radiative Heat Transfer in Combustion Chambers. Western States Section, The Combustion Institute, 1981 Spring Meeting, Paper 81-17, 1981.

[7] Richter, W. , Scale-Up and Advanced Performance Analysis of Boiler Combustion Chambers. 1985 ASME winter Annual Meeting, Paper 85-WA/HT-80, 1985.

[8] Smith, T. F., and Z. F. Shen. Evaluation of Coefficients for the Weighted Sum of Gray Gases Model. 20th Joint ASME/AICHE National Heat Transfer Conference, Paper 81-ht55,1981 .

[9] Johnson, T. R., and J. M. Beer. The Zone Method Analysis of Radiant Heat Transfer: A Model for Luminous Radiation. $J$. Inst. Fuel, Vol $46,1973, \mathrm{p} 388$.

[10] Richter, W., and R. Payne. Modeling Study of Burner and Furnace Performance for oxygen Enriched Combustion Systems. AFRC 1988 Spring Meeting, May.10-11, 1988, Toronto, Canada.

[11] Gardon, R. A review of Radiant Heat Transfer in Glass. J. of the American Ceramic Society. Vol. 44., No. 7, July 1961 
[12] Anderson, J.E., "A Low No $x$ Low Temperature Oxygen Fuel Burner," 1986 . Symposium on Industrial Combustion Technologies, Chicago, IL, Apr. 29-30, 1986. 


\section{List of Tables}

Table 1: Input Parameters for Boundary Conditions at Refractory Walls, Ports and Glass Surface

Table 2: Major operating Conditions Considered for Air and $\mathrm{O}_{2}-$ Firing

Table 3: Case Definitions

Table 4: Overall Performance Comparisons

\section{List of Figures}

Figure 1: Beam Tracking in Semistochastic Radiation Model

Figure 2: Modeling of Heat Release Distribution in 'A' Burner $\mathrm{O}_{2}$-Flames

$\bar{F}$ igure 3: Cross-section of 350 tons/day Glass Furnace, Location of oxygen Burners and Definition of End-section Considered in Model

Figure 4: Zone Arrangement Used in 3-D Heat Transfer Model of End-Section

Figure 5: Relative Distribution of Mass Flux Density Vectors Used in Heat Transfer Model for Conventional Air operation (Case 1)

Figure 6: Distribution of Gas Temperatures (F) Predicted for Conventional Air Operation (Case 1)

Figure 7: Distribution of Refractory Surface Temperatures (F) for Conventional Air operation and Uniform Glass Surface Temperatures (Case 1)

Figure 8: Net Heat Flux Densities $\left(\mathrm{kw} / \mathrm{m}^{2}\right)$ at Glass Surface for Conventional Air operation (Case 1) and Comparison with $\mathrm{O}_{2}$-Firing Configuration for Burner Load Ratio A5 $/$ A $=1$ (Case 2)

Figure 9: Net Heat Flux Densities $\left(\mathrm{kW} / \mathrm{m}^{2}\right)$ at Glass Surface for Conventional Air Operation (Case 1) and Comparison with $\mathrm{O}_{2}$-Firing Configuration for Burner Load Ratio A5 $/ \mathrm{A} 6=3.71$ (Case 3 ) 
Figure 10: Relative Distribution of Mass Flux Density Vectors Used in Heat Transfer Model for Baseline $\mathrm{O}_{2}$-Burner Configuration (Case 3)

Figure 11: Distribution of Gas Temperatures (F) Predicted for Baseline $\mathrm{O}_{2}$-Burner Configuration (Case 3 )

Figure 12: Distribution of Refractory Surface Temperatures (F) for Baseline $\mathrm{O}_{2}$-Burner Configuration and Uniform Glass Surface Temperatures (Case 3)

Figure 13: Impact of Burner Elevation on Net Heat Flux Densities $\left(\mathrm{kW} / \mathrm{m}^{2}\right)$ at Glass Surface for $\mathrm{O}_{2}$-Firing (Case 3 vs. Case 4)

Figure 14: Relative Distribution of Mass Flux Density Vectors Used in Heat Transfer Model for Study of Impact of $\mathrm{O}_{2}$ Burner Inclination (Case 5)

Figure 15: Distribution of Gas Temperatures (F) Predicted for Configuration with Inclined $\mathrm{O}_{2}$-Burners (Case 5)

Figure 16: Impact of $\mathrm{O}_{2}$-Burner Inclination on Net Heat Flux Densities $\left(\mathrm{kW} / \mathrm{m}^{2}\right)$ at Glass Surface for Uniform Glass surface Temperatures (Case 3 vs. Case 5)

Figure 17: Distribution of Refractory Surface Temperatures (F) Predicted for Configuration with Inclined $\mathrm{O}_{2}$-Burners (Case 5)

Figure 18: Comparison of Net Heat Flux Densities $\left(\mathrm{kW} / \mathrm{m}^{2}\right)$ at Glass surface between $\mathrm{Air}$ and $\mathrm{O}_{2}$ Firing Predicted Nonuniform Glass Surface Temperatures (Case 1.1 vs. Case 3.1)

Figure 19: Effective Glass Surface Temperatures (F) Calculated from Simple Model for Non-uniform Glass Temperatures and Comparison between $\mathrm{Air}$ and $\mathrm{O}_{2}$ Firing (Case 1.1 vs. Case 3.1)

Figure 20: Distribution of Refractory Surface Temperatures (F) Predicted for Conventional Air Firing and Non-uniform Glass Surface Temperatures (Case 1.1)

Figure 21: Distribution of Refractory Surface Temperatures (F) predicted for Baseline $\mathrm{O}_{2}$-Burner configuration and Non-uniform Glass surface Temperatures (Case 3.1) 
TABLE 1 : INPUT PARAMETERS FOR BOUNDARY CONDITIONS AT REFRACTORY WALLS, PORTS AND GLASS SURFACE

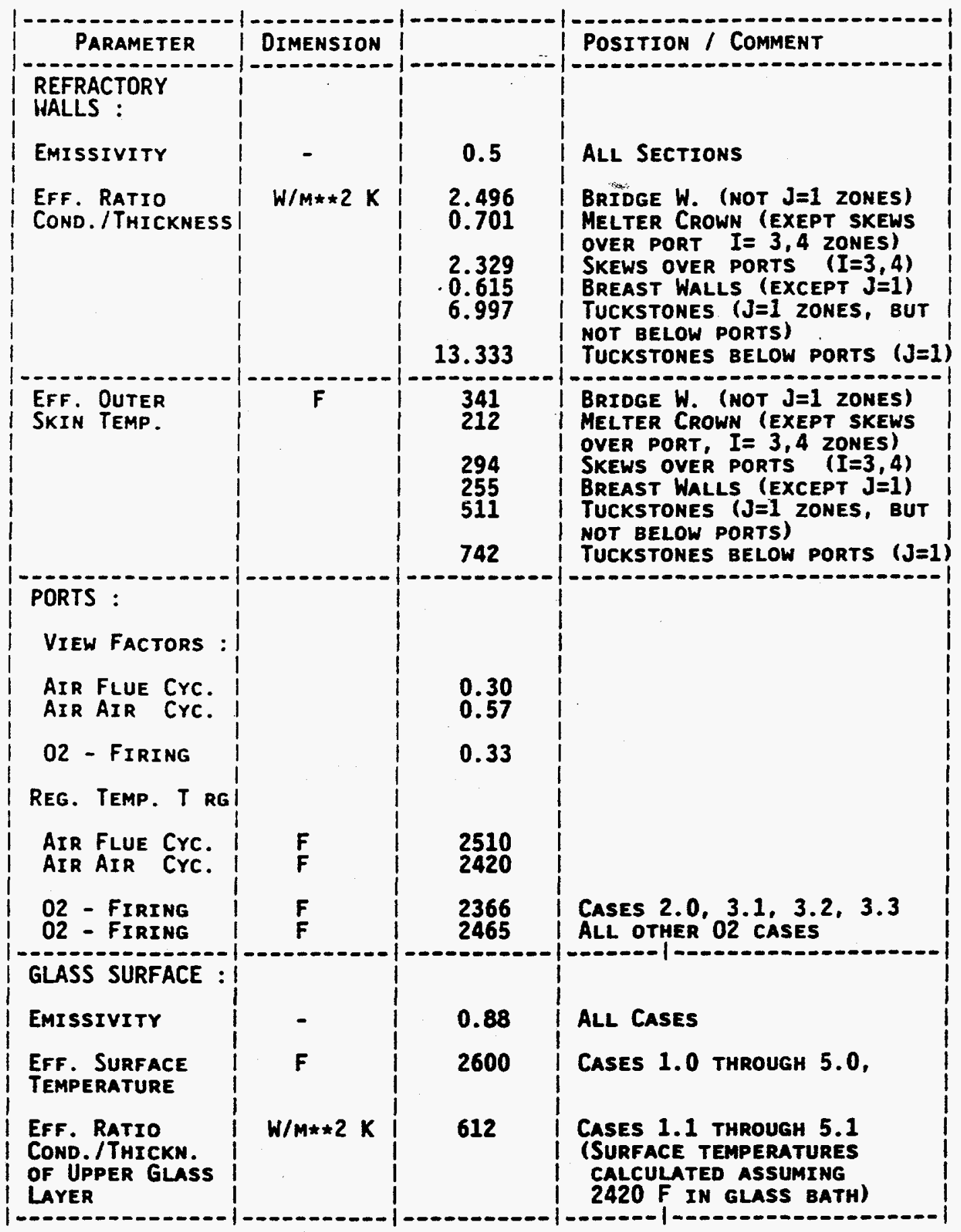


TABLE $2:$ MAJOR OPERATING CONDITIONS FOR SECTION CONSIDERED FOR AIR AND 02-FIRING

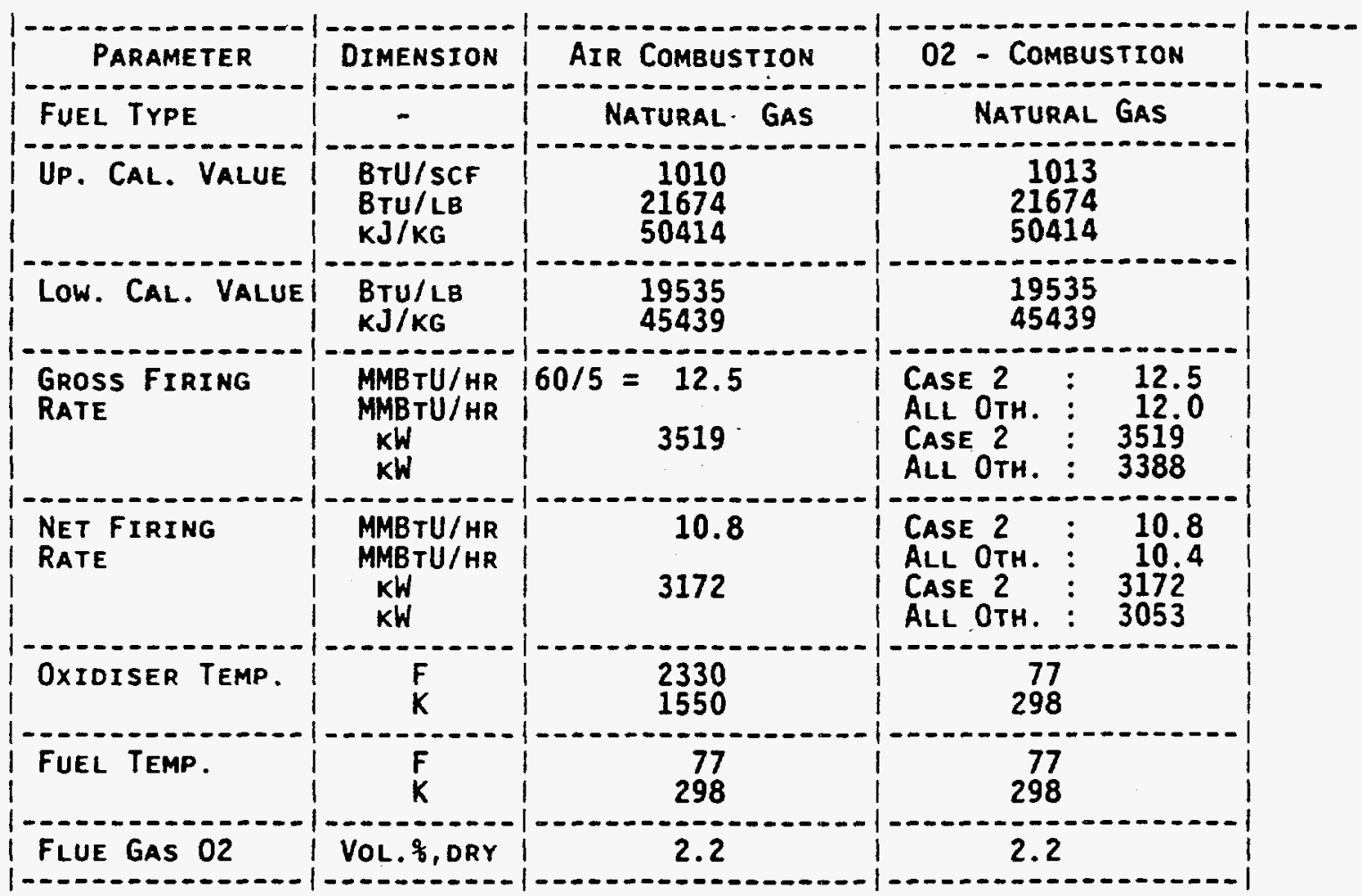

TABLE 3 : CASE DEFINITIONS

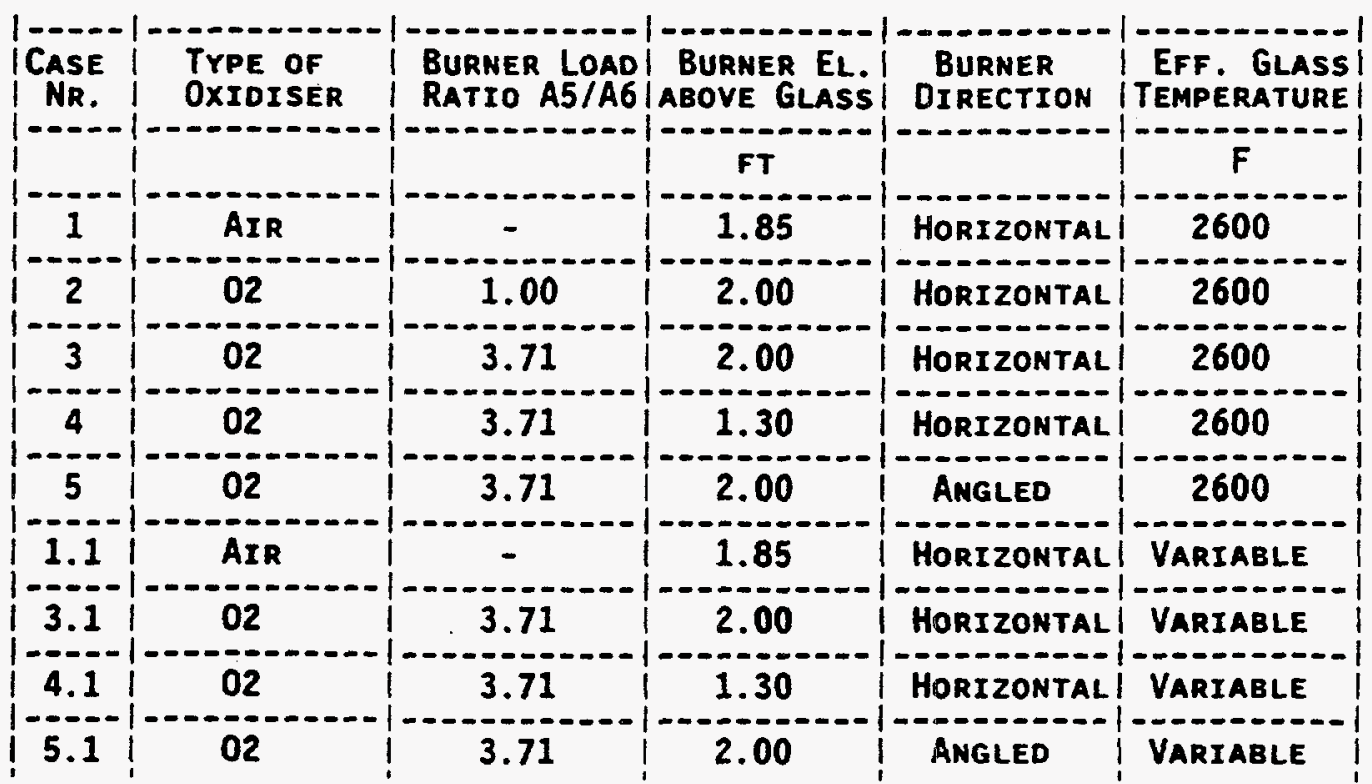


TABLE 4: OUERRLL PERPORHACE COMPRRSONS FOR ENO SECTIOH

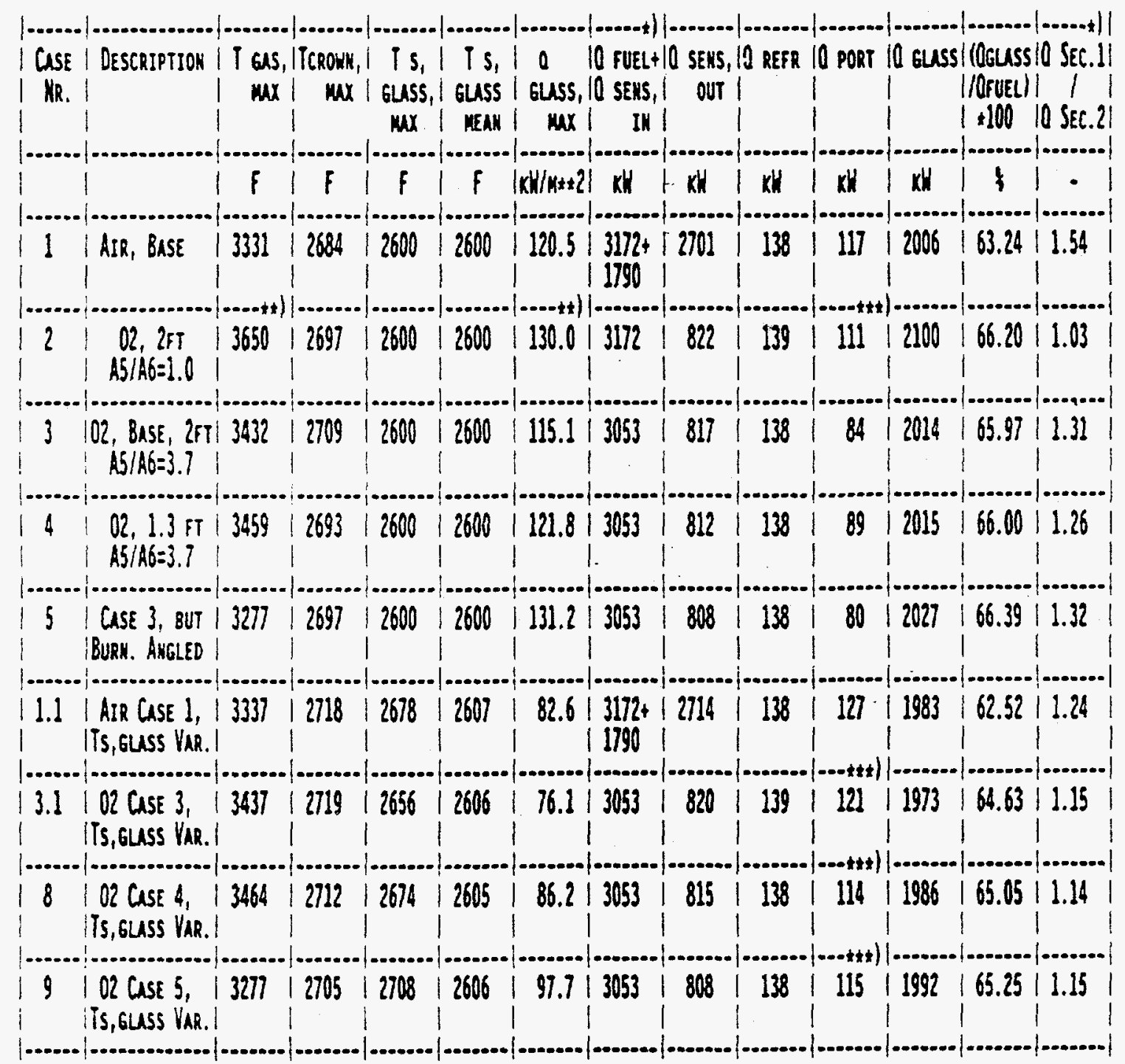

1) Heat fluxes calculated until snmetay plane through axis of Burner a5, but heat flux section ratio calcouted AS DEFIMED IK TERT.

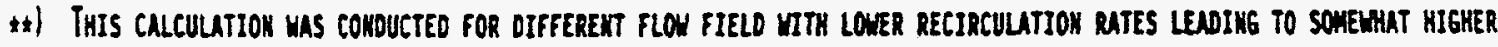
GAS TEPPERTTURES ANO MUXIMUM hEAT FLUXES.

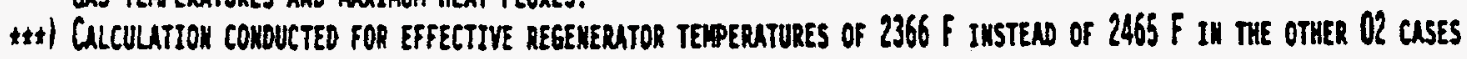




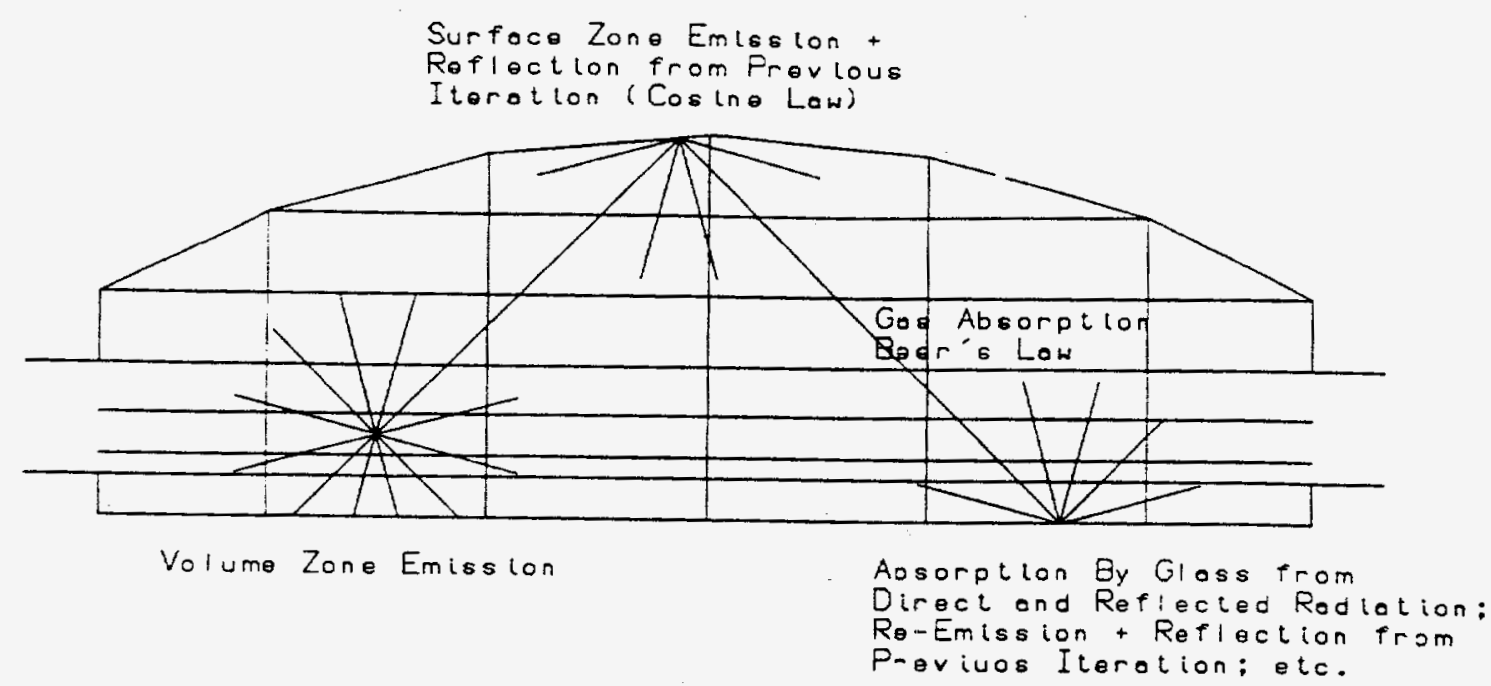

Figure 1 : Beom Trock tng in Somistochostic Rodiotion Model

(a) Unburnt Fuel on Ax is

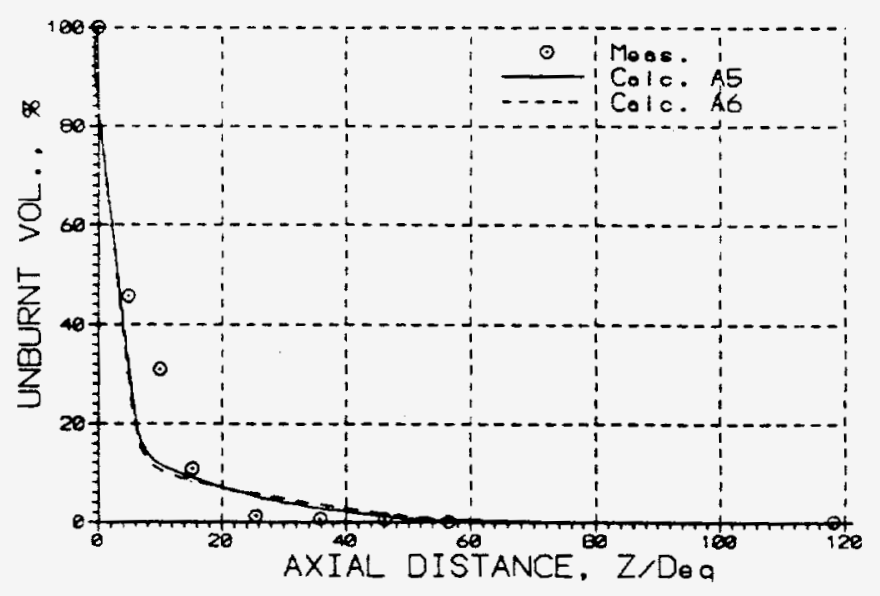

(b) O2-Concentration on Ax is

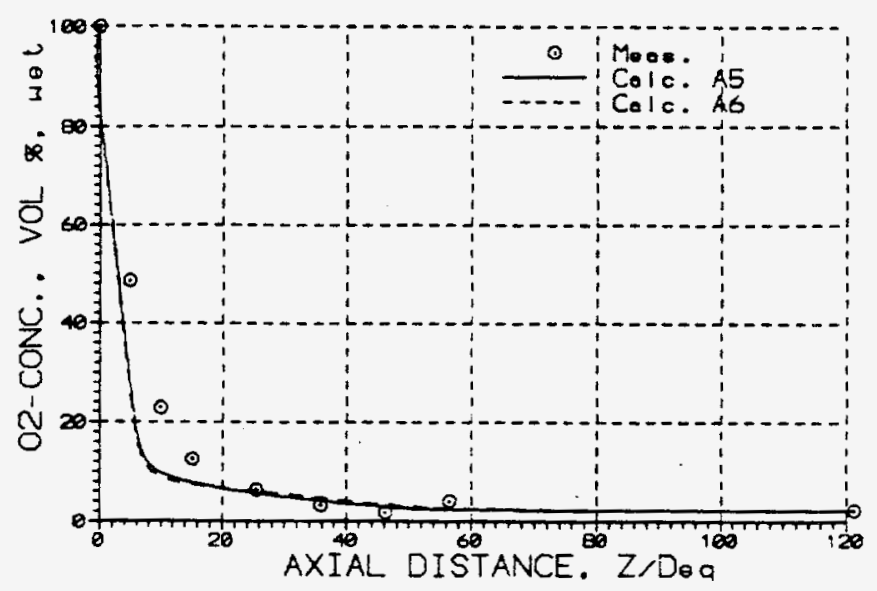

Figure 2 : Modelling of theot Releose Disiribution in 'A' Burnar O2-Flomes 


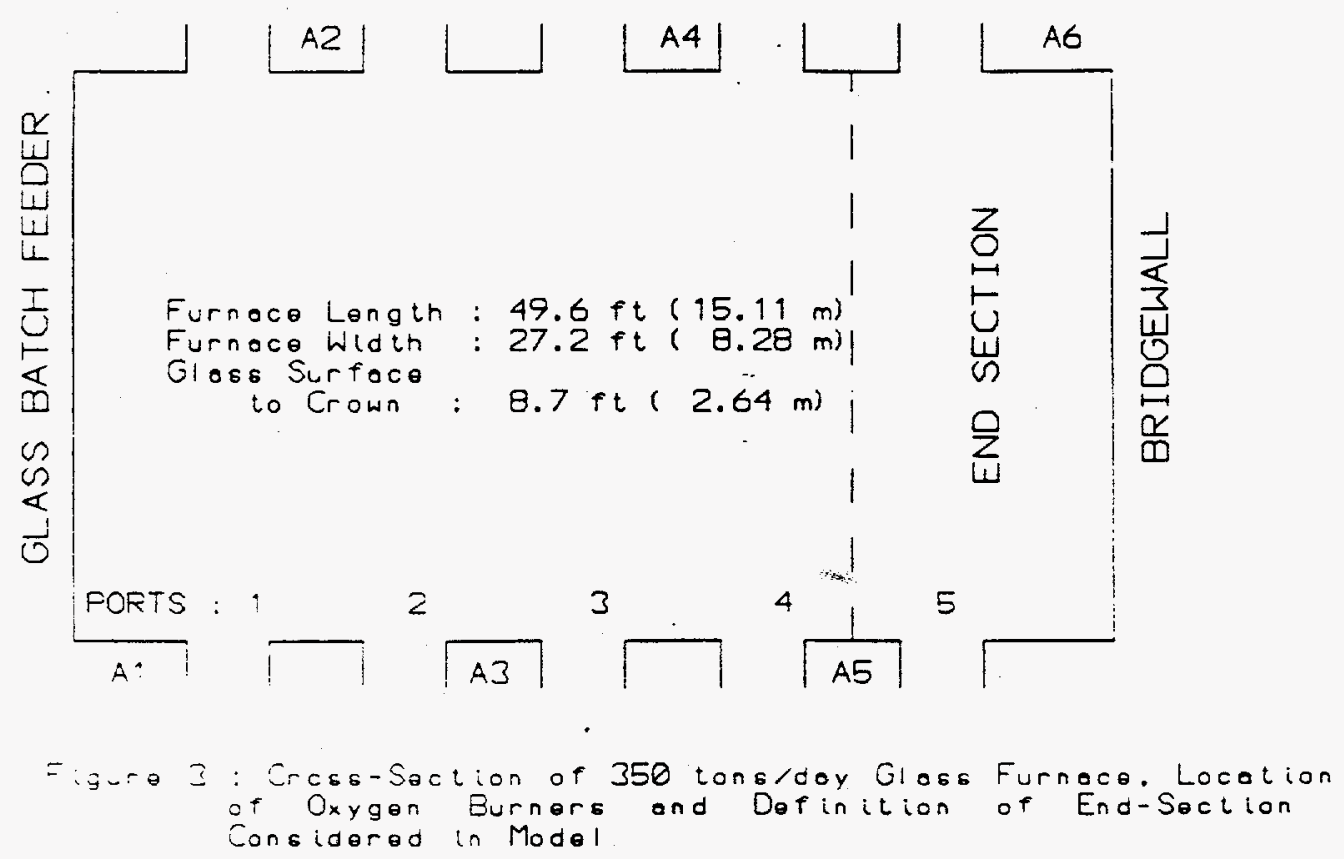

(a) Hortzontel Cross-Section

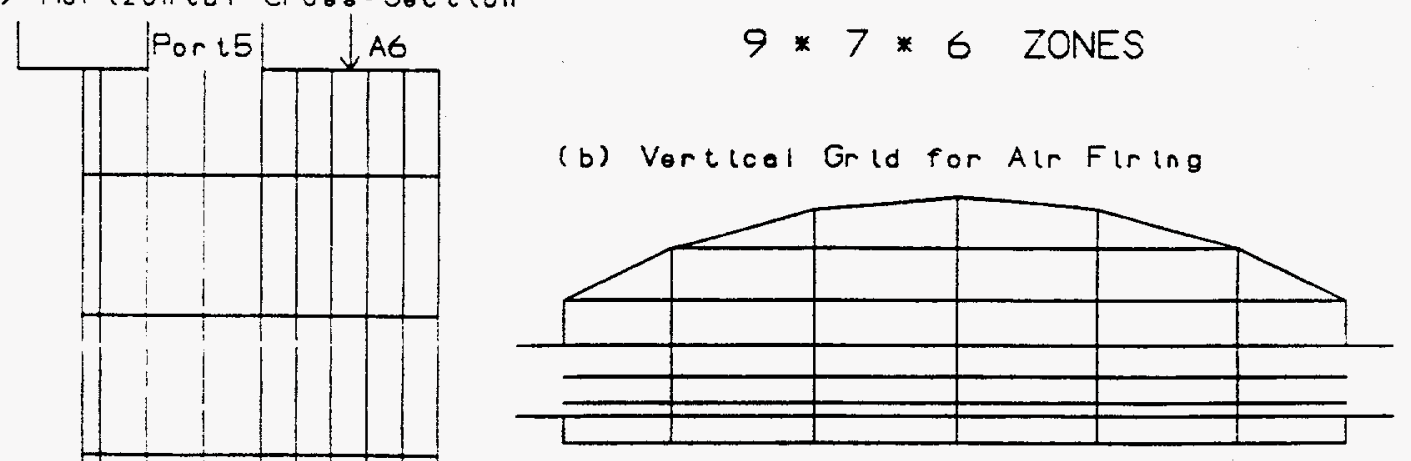

(c) Vorticel Grid for 02-Configurotion
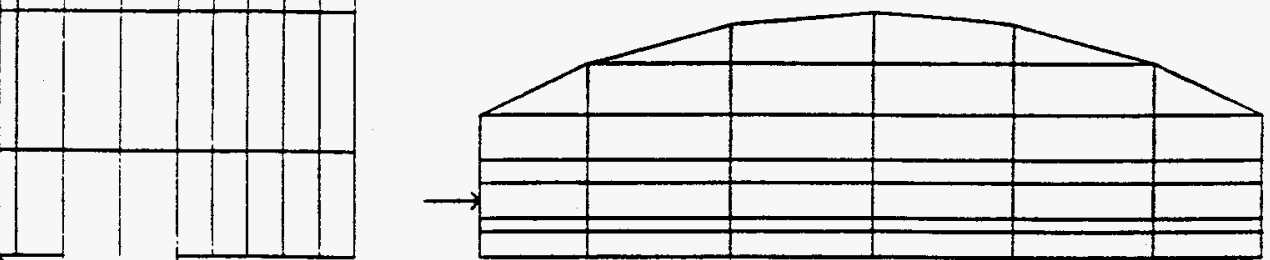

A5 Por 15

Figure 4 : Zone Arrongement Used in 3-D Hoot Trancfor Model of End Soction 


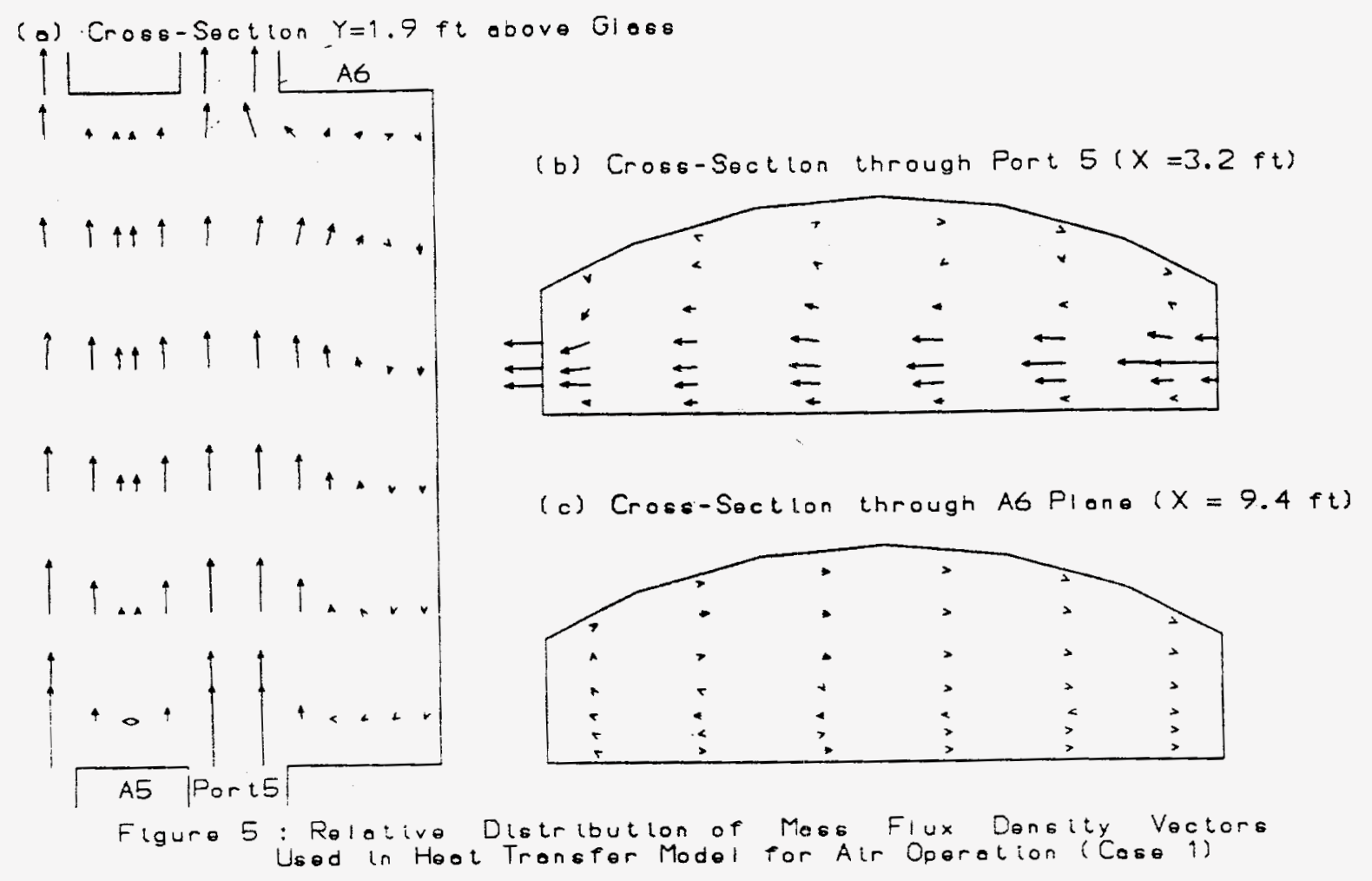

(o) Crose-Section $Y=1.9$ ft obove Gloos

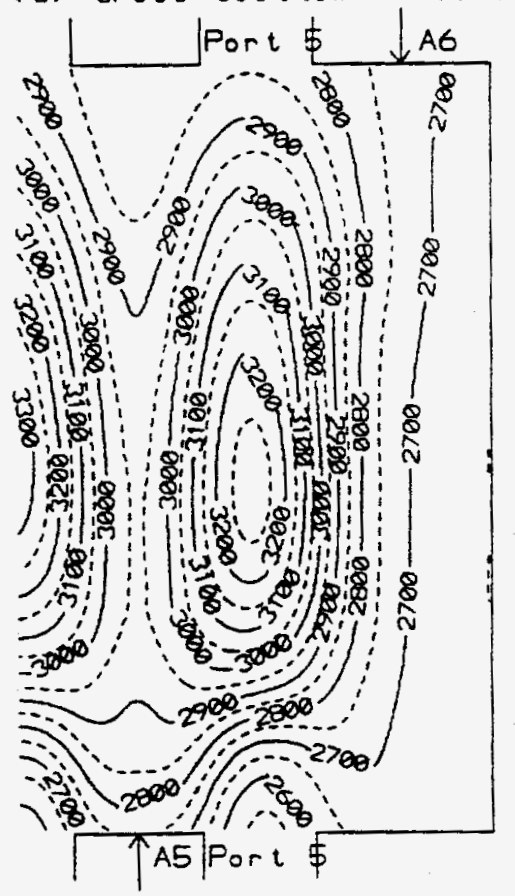

(b) Crose-Section throwgh Port $5(x=3.2 \mathrm{ft})$

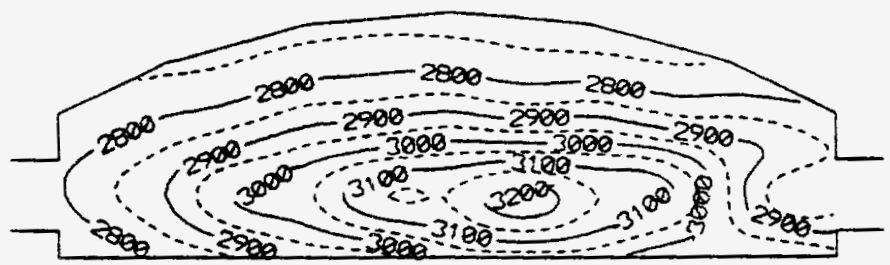

(c) Cross-Section through AG Plane $(X=9.4 \mathrm{ft})$

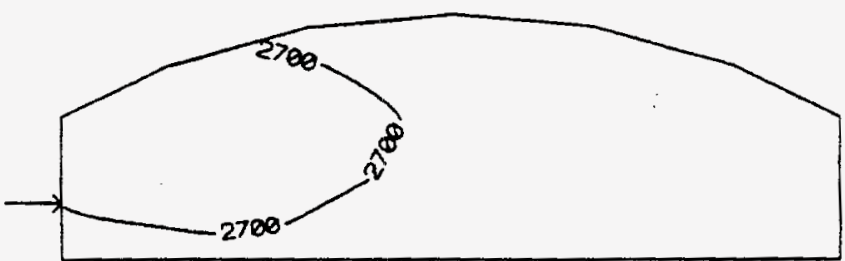

Figure 6 : Distributlon of Gos Tomporaturos (F) Prodictod for
Conventional Alr Oporation (Cose i) 

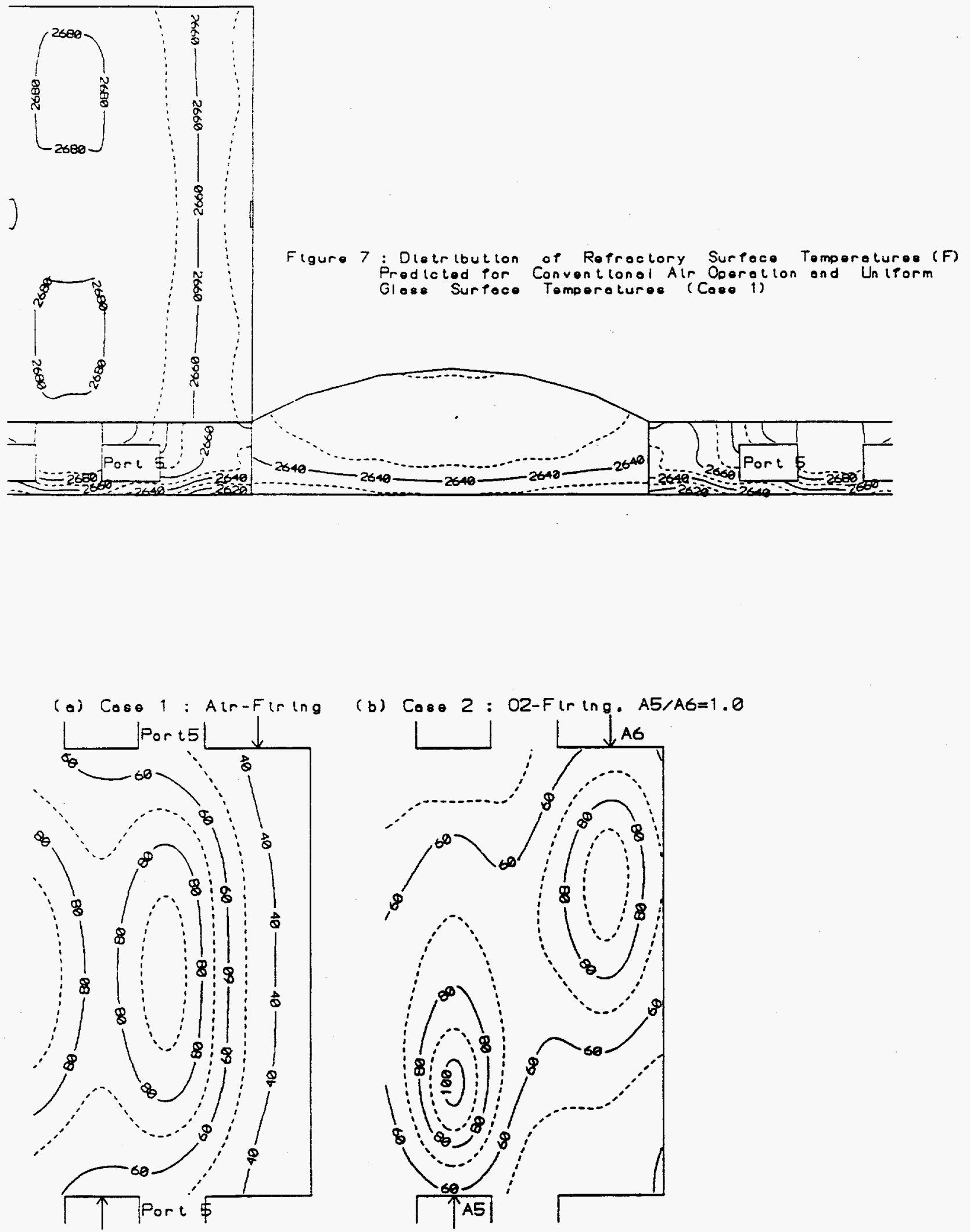

(b) $\operatorname{Cos} \theta 2: 02-F \ln \operatorname{lng} . A 5 / A G=1.0$

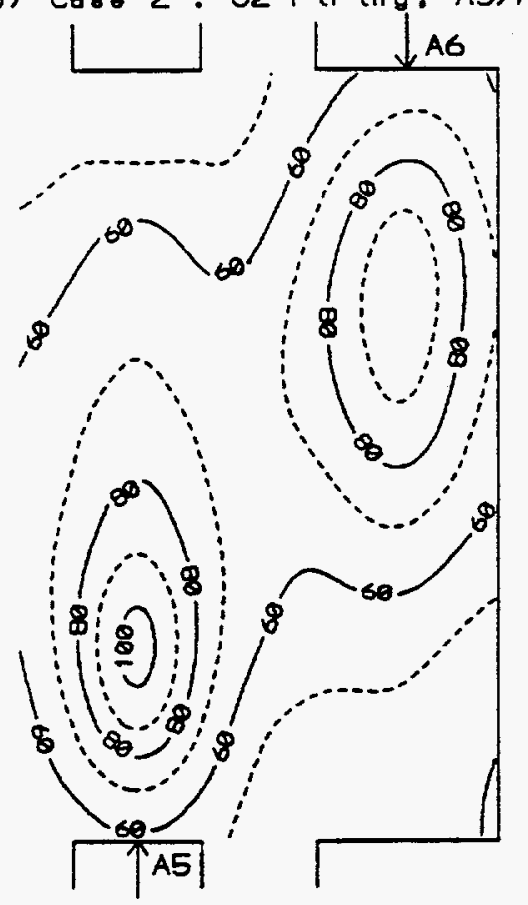

Figura 8 : Nol Hoet Flux Deneltlos ( $\left.1 W / m^{m}=2\right)$ ot Glose Surfoce for Convontlonol Atr Oporation (Cose 1) and Comporison with O2Fir ing Conf iguration for Burnor Load Ratlo $A 5 / A G=1$ (Cosir 2 ) 

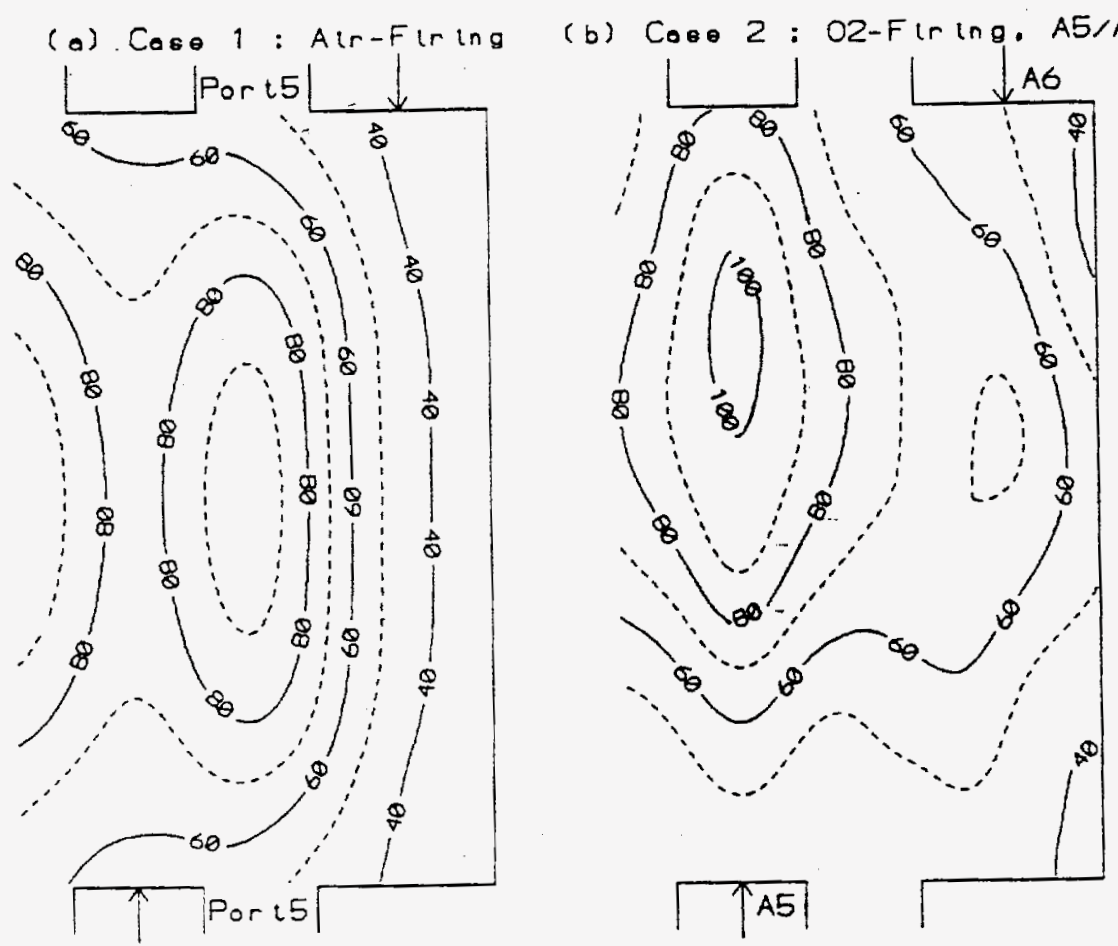

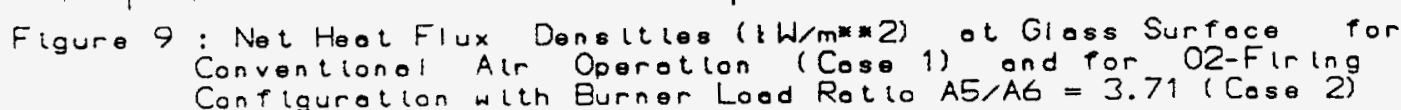

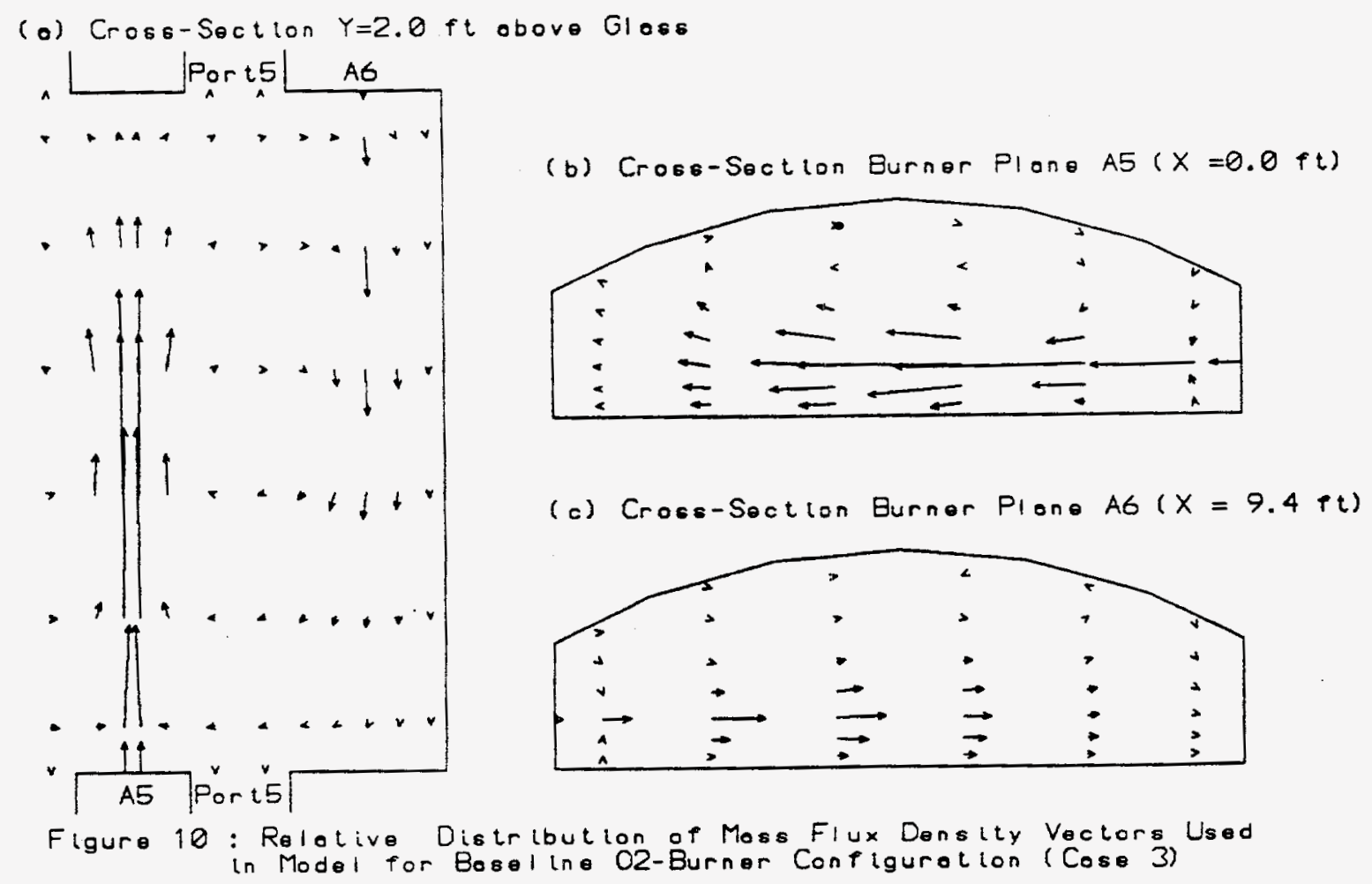



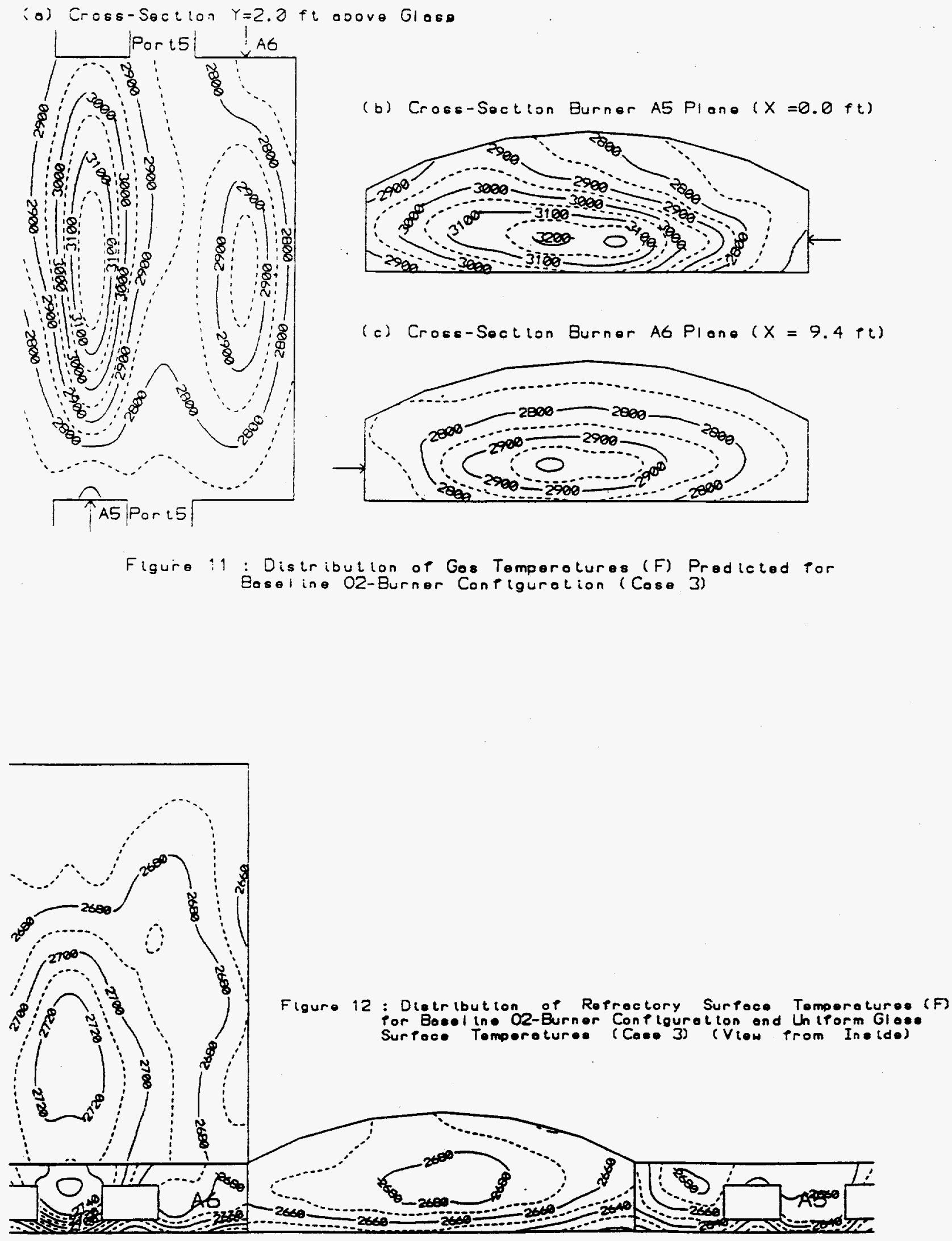


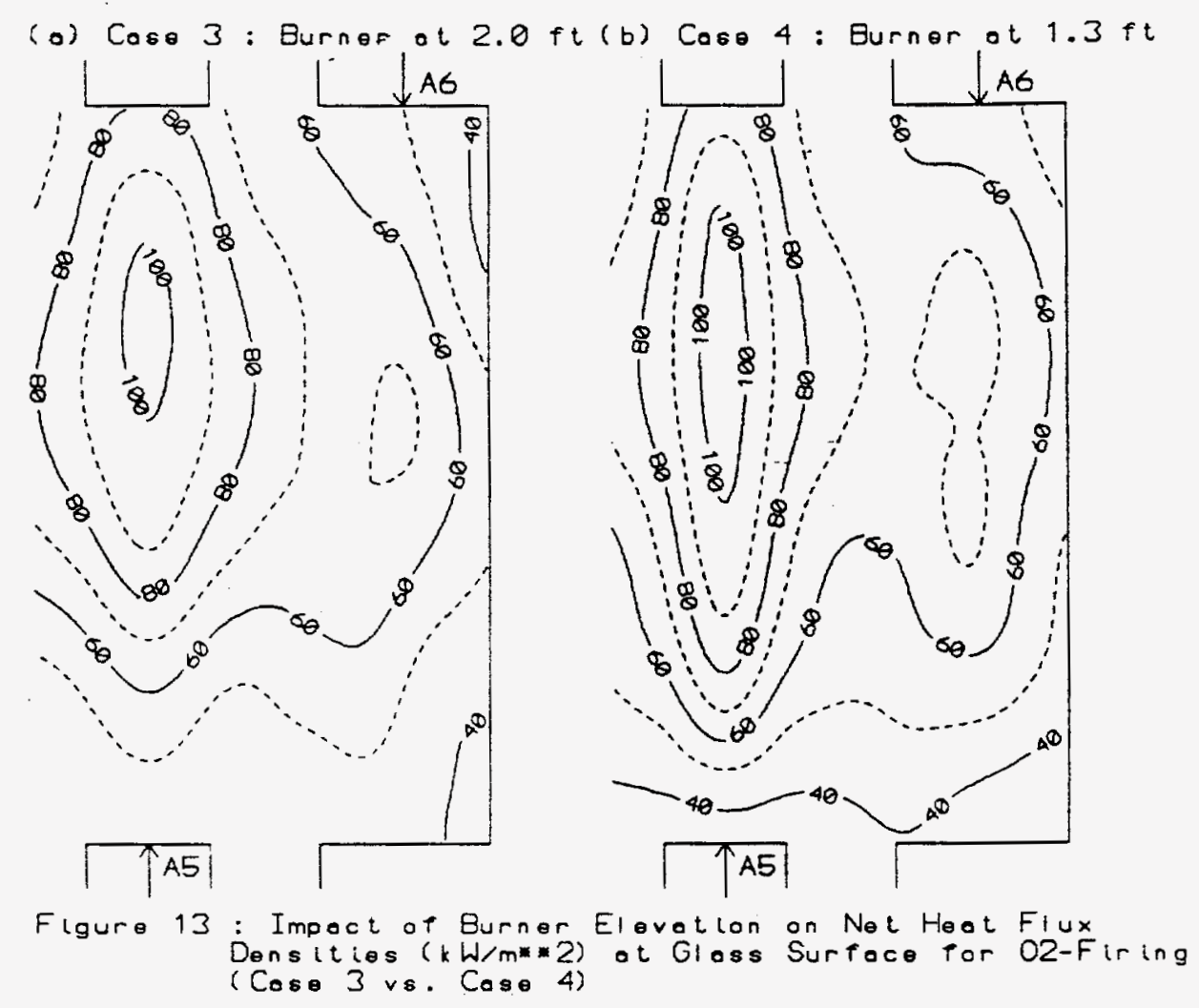

(a) Crose-Section $Y=2.0$ ft obove Glase

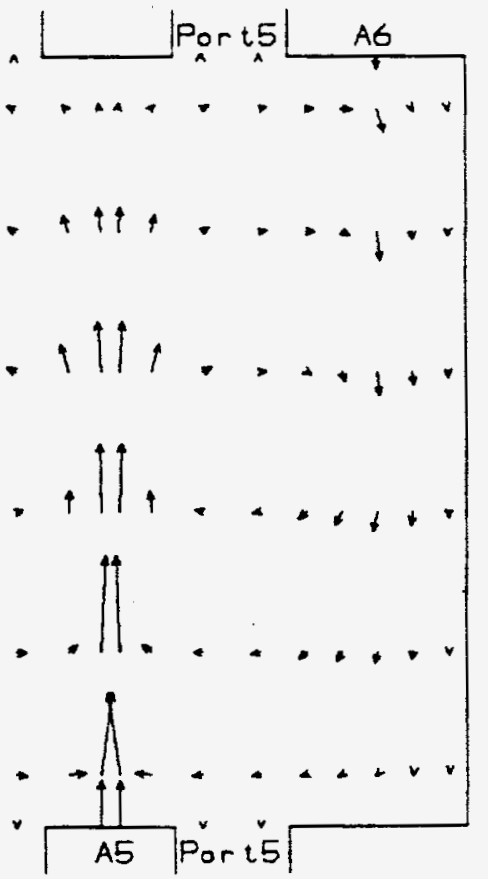

(b) Cross-Soction Burner Plone $A 5(X=0.0 \mathrm{ft})$

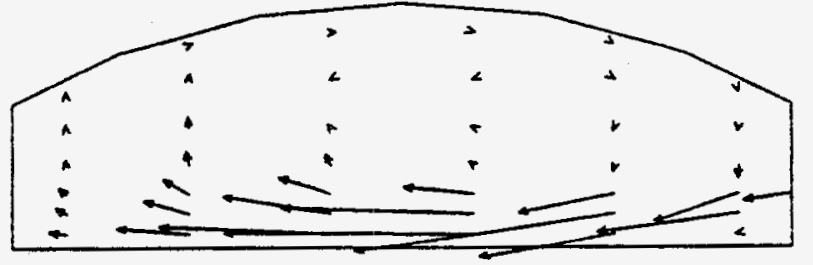

(c) Cross-Section Burner Plone AG $(X=9.4+t)$

Figure 14 : Relative Distrtbutionof Mose Fiux Denstty Vectors Used
in Study of Impoct of O2-Eurner Inclination (Cose 5 ) 


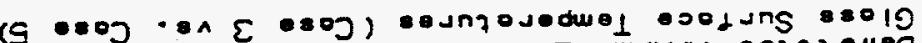

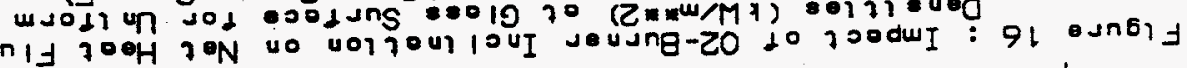
$\times n I J 700 \mathrm{H}$. $\mathrm{N}$ u

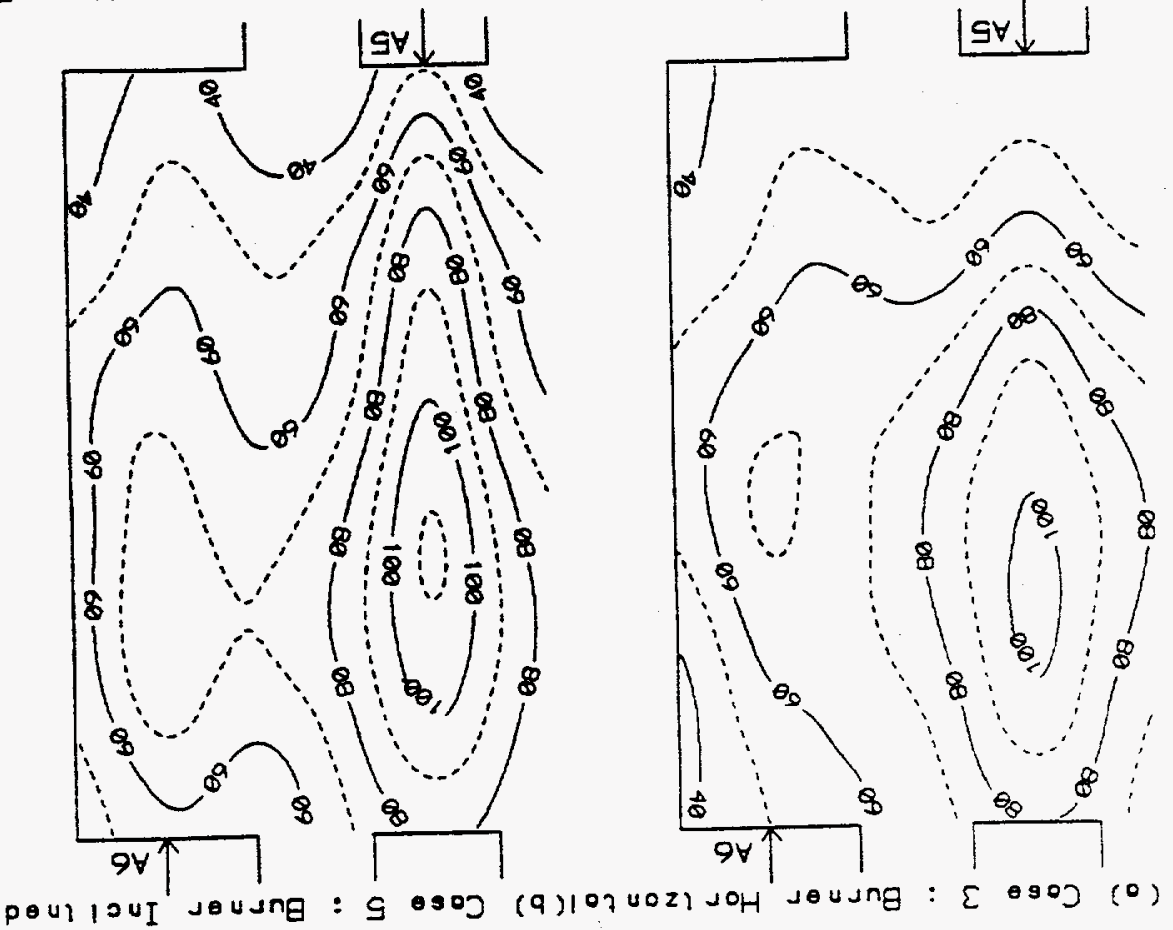

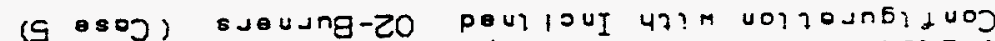

doj pejolpedd (J) sounjojedwel sog do volinq?

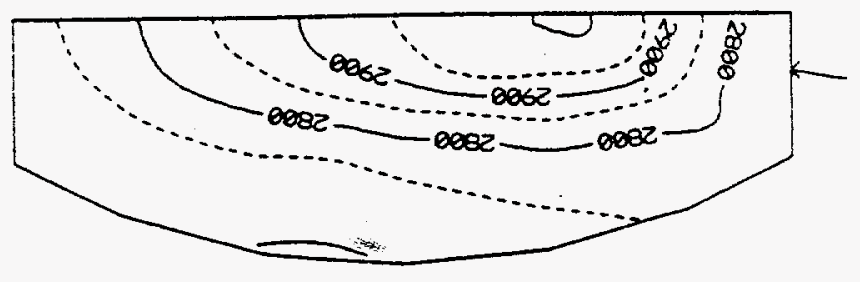

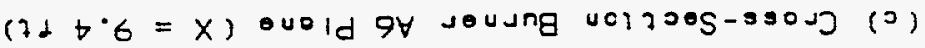

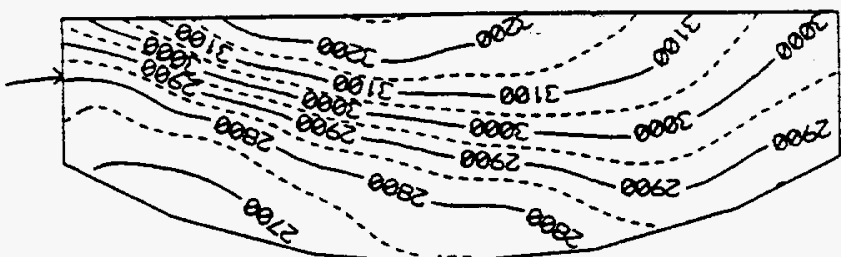

$\left(z+0^{\circ} \theta=x\right)$ ourld $9 \forall$ jeusng ve)

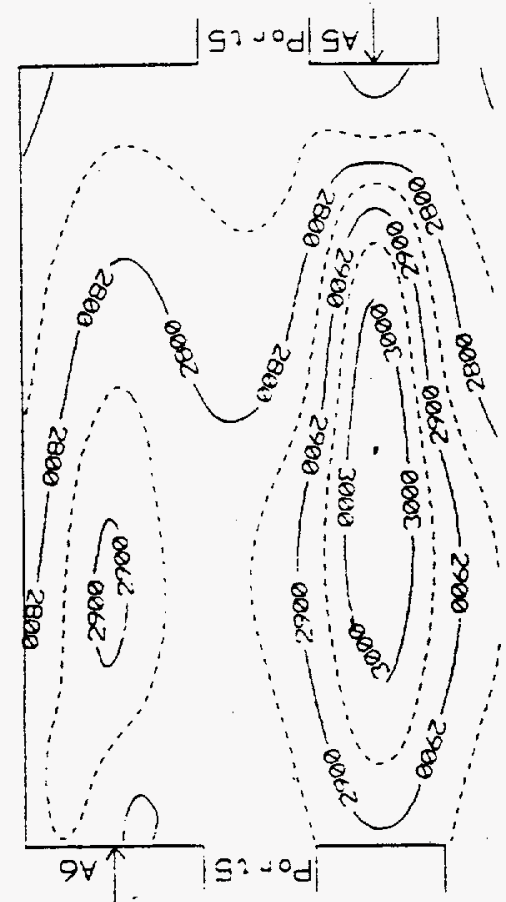

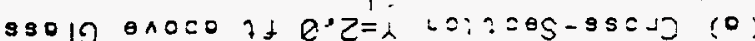



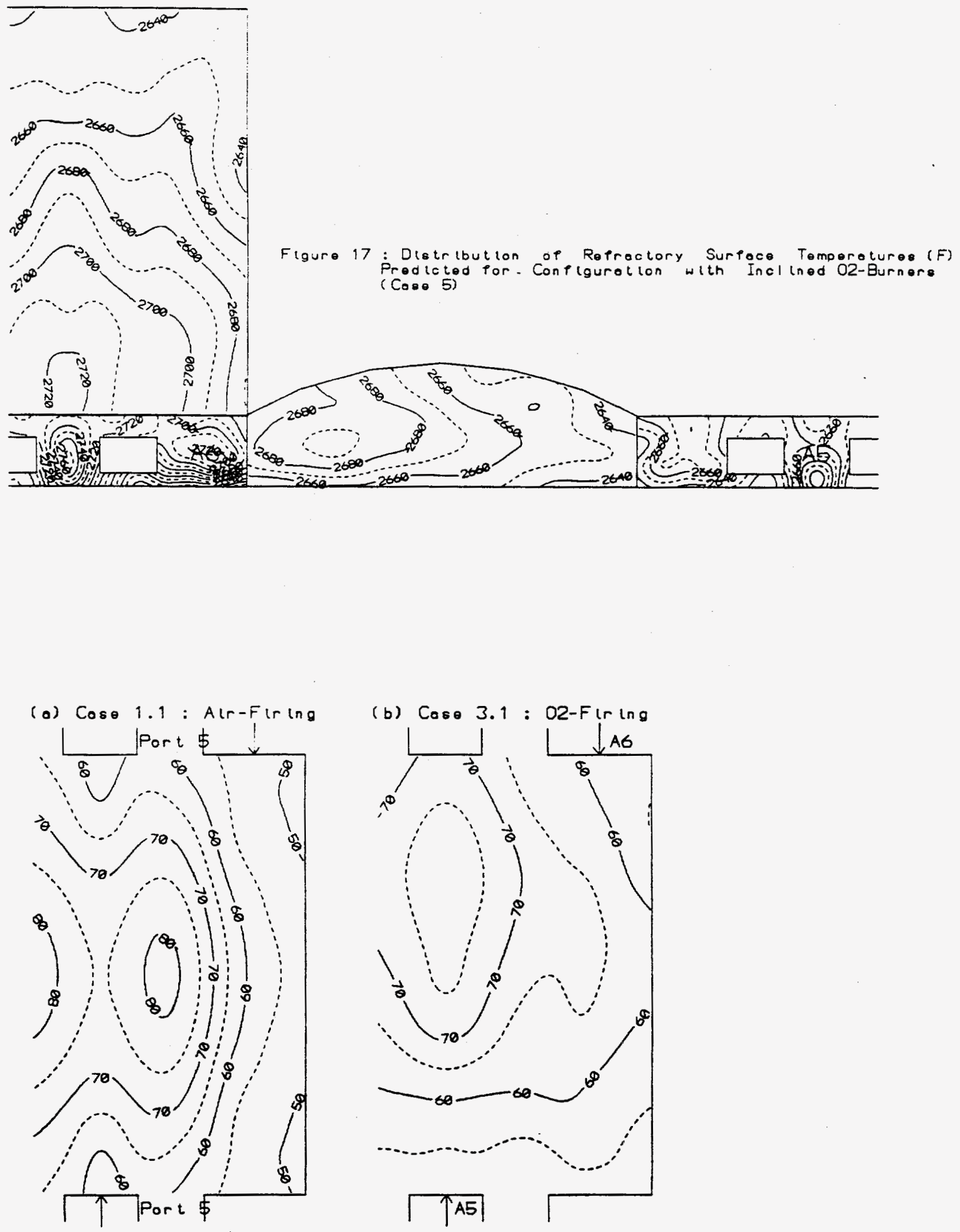

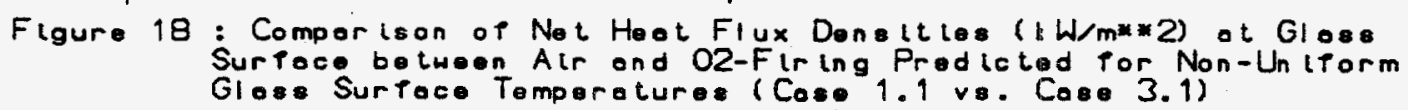



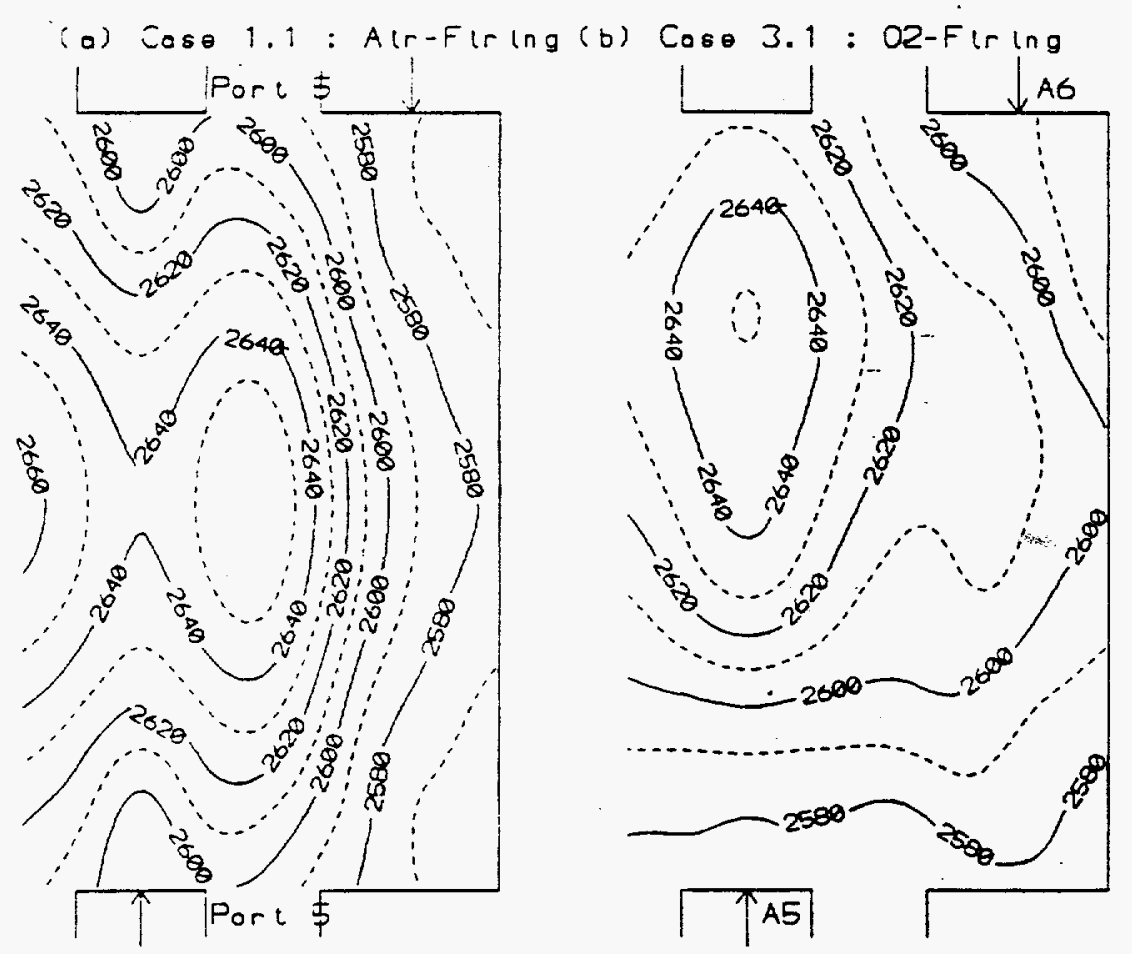

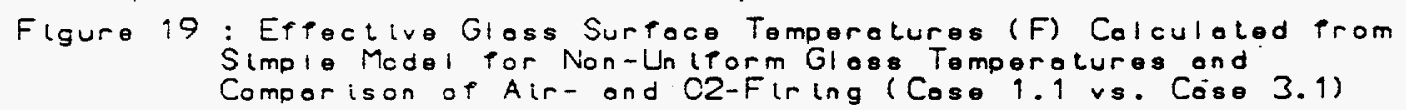

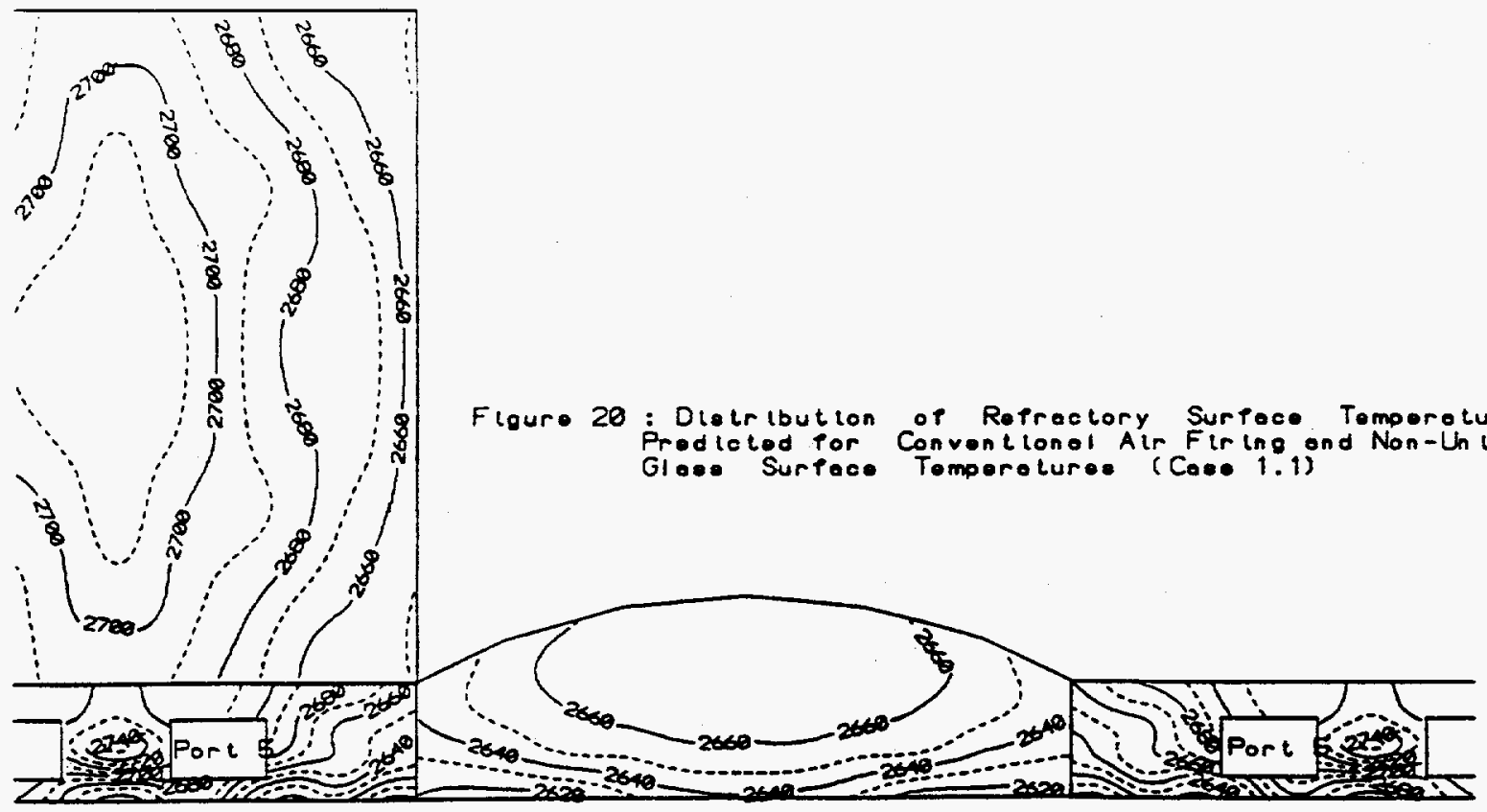




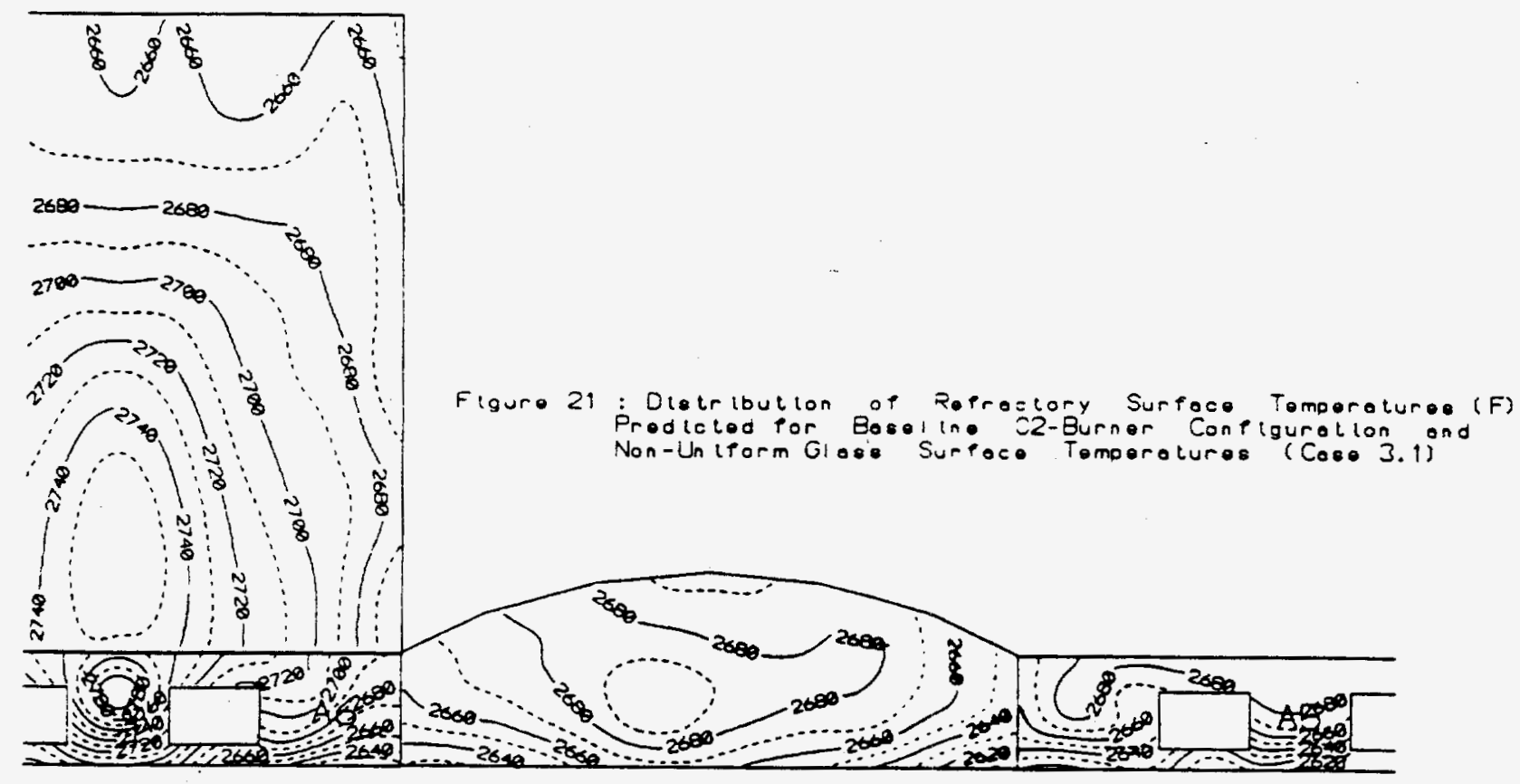

